University of Tennessee Health Science Center UTHSC Digital Commons

\title{
A Secular Increase in the Tempos of Tooth Formation: 1980-2010
}

Kevan Michael O'Neill

University of Tennessee Health Science Center

Follow this and additional works at: https://dc.uthsc.edu/dissertations

Part of the Orthodontics and Orthodontology Commons

\section{Recommended Citation}

O'Neill, Kevan Michael , "A Secular Increase in the Tempos of Tooth Formation: 1980-2010" (2012). Theses and Dissertations (ETD). Paper 194. http://dx.doi.org/10.21007/etd.cghs.2012.0229.

This Thesis is brought to you for free and open access by the College of Graduate Health Sciences at UTHSC Digital Commons. It has been accepted for inclusion in Theses and Dissertations (ETD) by an authorized administrator of UTHSC Digital Commons. For more information, please contact jwelch30@uthsc.edu. 


\title{
A Secular Increase in the Tempos of Tooth Formation: 1980-2010
}

\begin{abstract}
Introduction: Improved environments in the U.S. have resulted in taller, larger, and heavier children and adults compared to past generations. Studies of other skeletal-dental dimensions have shown increases across generations, and our perception is that teeth now are forming faster. The purpose of this study is to test for a secular trend towards faster tempos of tooth mineralization in a sample of U.S. white adolescents over the past quarter century (1980-85 to 2005-10).

Materials: Two cohorts of 200 children each were identified, each with an age range of 10-to- 15 years, one group from 1980-85 and the more recent group from 2005-10. Children all were phenotypically normal American whites from the same dental clinic. Stages of tooth mineralization were scored for the lower 8 permanent tooth types using the 8-grade Demirjian system (Demirjian A, Goldstein H, Tanner JM. A new system of dental age assessment. Hum Biol 1973;45:211-27). Proportional hazards analysis was used to test for cohort differences while controlling for sexual dimorphism in tooth formation tempos.
\end{abstract}

Results: In the age interval studied, 10 tooth-stage combinations could be analyzed statistically. Median ages of the stages were characteristically younger in the recent (2005-10) cohort, and 5 of these 10 comparisons achieved statistical significance $(P<0.05)$. The difference between the cohorts is larger in girls than in boys. Faster tempos of development are on the order of $1 / 2$ year.

Conclusion: Faster growth tempos mean that age-sensitive procedures-such a serial extraction or harnessing adolescent growth-occur at younger ages and that published standards for tooth formation and emergence probably now are biased. Faster maturation also suggests that children of the same chronological age are biologically more mature than in the past. It remains to be seen how widespread these secular quickenings are, both geographically and across segments of the population.

\section{Document Type}

Thesis

Degree Name

Master of Dental Science (MDS)

\section{Program}

Orthodontics

\section{Research Advisor}

Edward F. Harris, PhD

\section{Keywords}

Demirjian system, dental age, root formation, secular trend, tooth eruption, tooth mineralization

\section{Subject Categories}

Dentistry | Medicine and Health Sciences | Orthodontics and Orthodontology 


\title{
A SECULAR INCREASE IN THE TEMPOS OF TOOTH FORMATION:
}

1980-2010

\author{
A Thesis \\ Presented for \\ The Graduate Studies Council \\ The University of Tennessee \\ Health Science Center
}

\begin{abstract}
In Partial Fulfillment
Of the Requirements for the Degree

Master of Dental Science

From The University of Tennessee
\end{abstract}

By

Kevan Michael O'Neill, D.D.S.

May 2012 
Copyright ( 2012 by Kevan Michael O'Neill.

All rights reserved. 


\section{ACKNOWLEDGEMENTS}

Without the guidance and support by my research director, Dr. Edward F. Harris, this project would not have been possible. His encouragement and friendship has made this research project a wonderful learning experience. I will forever be grateful to him as I look back on my years at the University of Tennessee.

Thank you to my research committee and their dedication to this effort: Dr. William Parris, Dr. Quinton Robinson, and Dr. Richard Williams.

To my family: Mom, Dad, Brendan, Shannon and Mr. Gus Gus for their unending love and support.

To my co-residents, as we worked together sifting our way through residency.

To Katayun, my love and inspiration. 


\begin{abstract}
Introduction: Improved environments in the U.S. have resulted in taller, larger, and heavier children and adults compared to past generations. Studies of other skeletal-dental dimensions have shown increases across generations, and our perception is that teeth now are forming faster. The purpose of this study is to test for a secular trend towards faster tempos of tooth mineralization in a sample of U.S. white adolescents over the past quarter century (1980-85 to 2005-10).
\end{abstract}

Materials: Two cohorts of 200 children each were identified, each with an age range of 10-to-15 years, one group from 1980-85 and the more recent group from 2005-10. Children all were phenotypically normal American whites from the same dental clinic. Stages of tooth mineralization were scored for the lower 8 permanent tooth types using the 8-grade Demirjian system (Demirjian A, Goldstein H, Tanner JM. A new system of dental age assessment. Hum Biol 1973;45:211-27). Proportional hazards analysis was used to test for cohort differences while controlling for sexual dimorphism in tooth formation tempos.

Results: In the age interval studied, 10 tooth-stage combinations could be analyzed statistically. Median ages of the stages were characteristically younger in the recent (2005-10) cohort, and 5 of these 10 comparisons achieved statistical significance $(\mathrm{P}<0.05)$. The difference between the cohorts is larger in girls than in boys. Faster tempos of development are on the order of $1 / 2$ year.

Conclusion: Faster growth tempos mean that age-sensitive procedures-such a serial extraction or harnessing adolescent growth-occur at younger ages and that published standards for tooth formation and emergence probably now are biased. Faster maturation also suggests that children of the same chronological age are biologically more mature than in the past. It remains to be seen how widespread these secular quickenings are, both geographically and across segments of the population. 


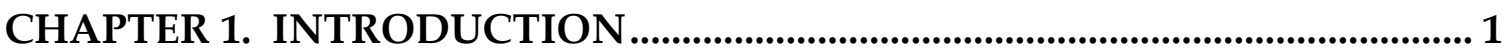

CHAPTER 2. REVIEW OF THE LITERATURE ................................................ 4

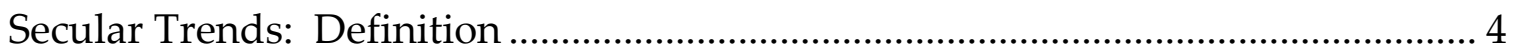

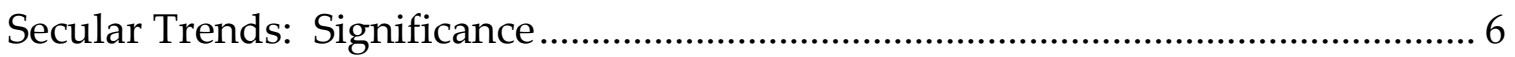

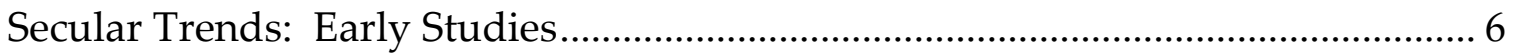

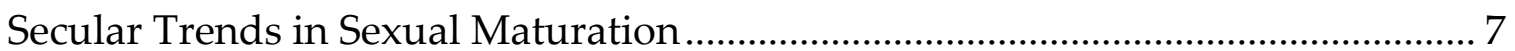

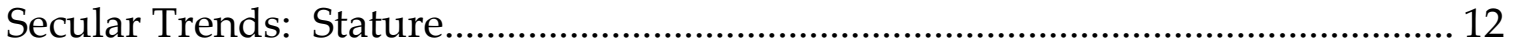

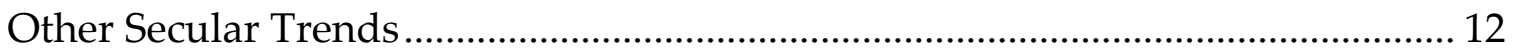

Secular Trends in the Dentition: Tooth Size.......................................................... 14

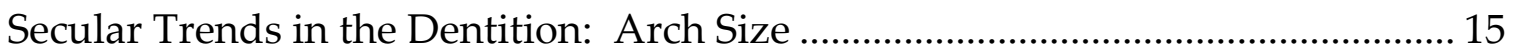

Secular Trends in the Dentition: Tooth Emergence ………................................... 16

A Natural Experiment in Modulating Tempos ………………………………...... 21

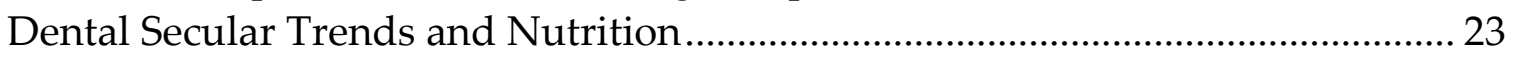

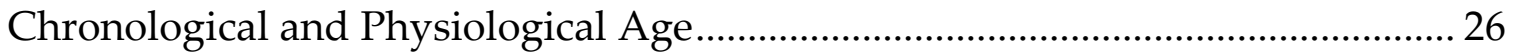

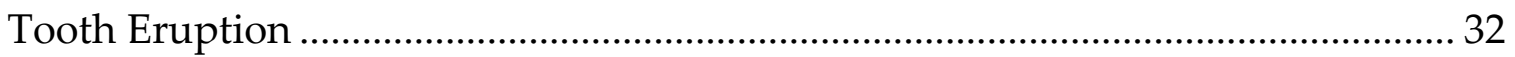

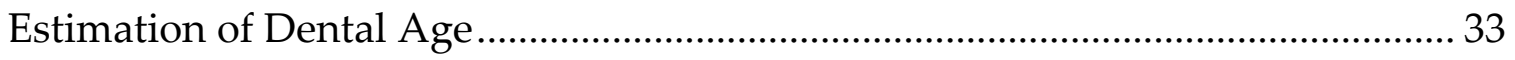

Competing Systems of Grading Mineralization........................................................ 36

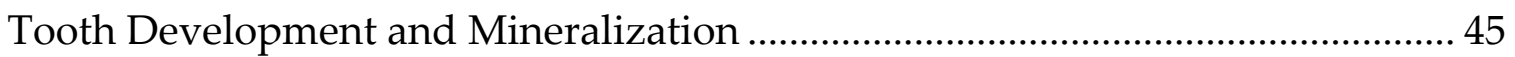

Sex Differences in Tempos of Maturation ................................................................. 47

CHAPTER 3. MATERIALS AND METHODS ..................................................49

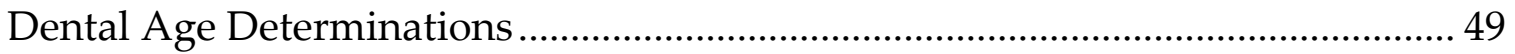

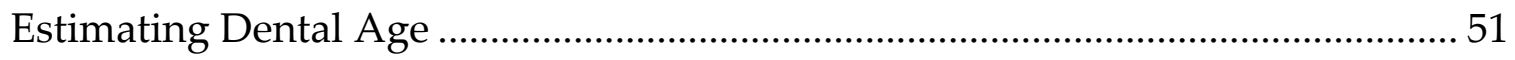

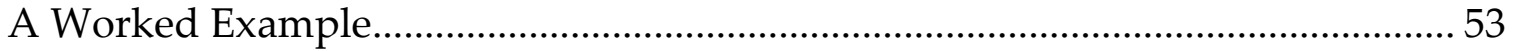

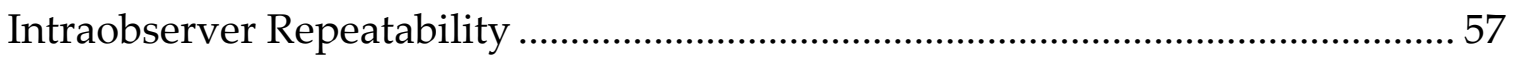

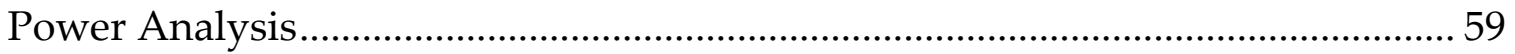

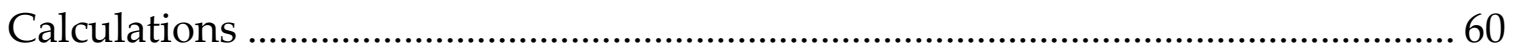

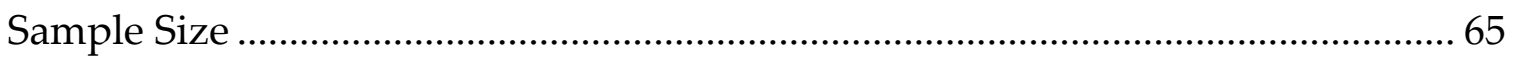

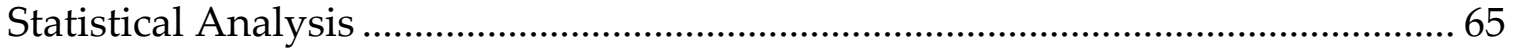

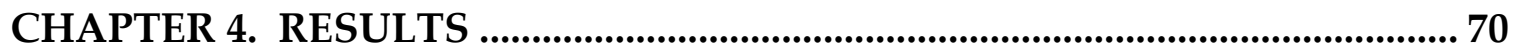

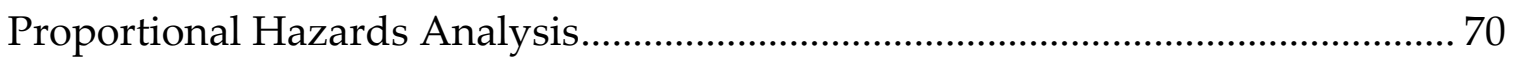

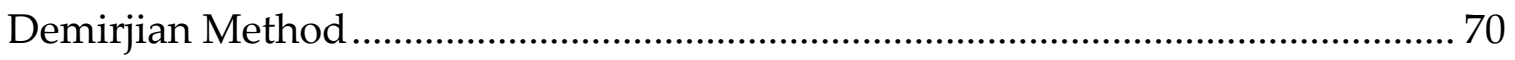

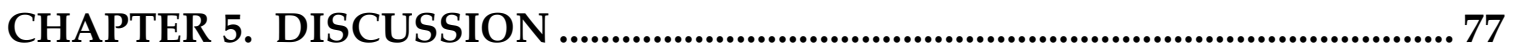




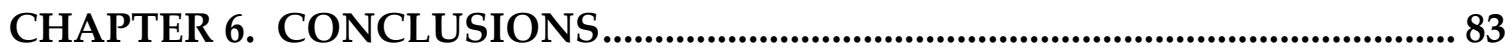

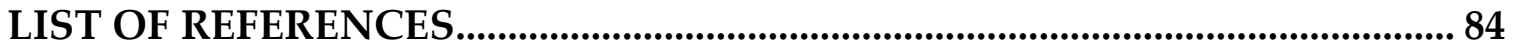

APPENDIX A. SURVIVAL ANALYSIS BY TOOTH AND GRADE............... 104

APPENDIX B. PLOTS OF SURVIVAL ANALYSIS ........................................... 113

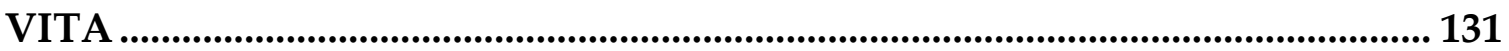




\section{LIST OF TABLES}

Table 1. Descriptions of the eight stages used by Demirjian et al. (1973)............50

Table 2. The sex-specific weighting coefficients developed by Demirjian et al. (1973).

Table 3. Weighting coefficients used to determine dental age in boys................55

Table 4. Weighting coefficients used to determine dental age in girls................56

Table 5. Example of calculating the Demirjian dental maturity score..................58

Table 6. Results of scoring 103 mandibular teeth on two occasions. ....................58

Table 7. Prior estimates of standard deviations (sexes pooled).............................60

Table 8. Prior estimates of the coefficient of determination $\left(\mathrm{r}^{2}\right)$ between chronological age and dental age. ............................................................61

Table 9. Sample size estimates (per group) based on power analysis. .................63 


\section{LIST OF FIGURES}

Figure 1. Girls from high income families begin menstruation at an earlier age than those girls from low income families ........................................ 8

Figure 2. Early menarche in European countries from 1840 to 1970 ..................... 9

Figure 3. Decrease in age of menarche from 1920 to 1985 .................................... 11

Figure 4 Secular trend in growth of height of Swedish boys and girls.............. 13

Figure 5. Test of secular trend in tooth eruption in girls...................................... 17

Figure 6. Test of secular trend in tooth eruption in boys ..................................... 18

Figure 7. Plot of mean ages at eruption for 12 permanent tooth types in boys. 19

Figure 8. Plot of mean ages at eruption for 12 permanent tooth types in girls.. 20

Figure 9. Graphs of the declines in the number of permanent upper second molars in Norway for three one-year cohorts ........................................ 22

Figure 10. Graph of the percentages of 8-year old children with retained primary mandibular second molars

Figure 11. Graphs of the declines in decayed plus filled primary teeth across three cohorts in Norway. 25

Figure 12. Plot of the distribution of chronological ages at which the permanent first molars emerge in children (sexes pooled).

Figure 13. The median number of permanent teeth emerged into the oral cavity by chronological age and by sex....

Figure 14. Plot of the number of primary teeth emerged against chronological age (in months) 
Figure 15. Plot of the number of permanent teeth emerged against chronological age (in years) based on data from Hägg and Taranger (1985)

Figure 16. Illustration of the 11 tooth mineralization stages defined by Nolla (1960)

Figure 17. Schematic drawings of the stages of tooth mineralization used by Moorrees, Fanning and Hunt (1963a) 40

Figure 18. Illustrations of the 11 stages used by Haavikko (1970) to score tooth formation

Figure 19. Sketches of the seven stages of tooth mineralization used by Liliequist and Lundberg (1971)

Figure 20. Sketches of the seven stages of tooth mineralization used by Liliequist and Lundberg (1971)

Figure 21. Schematic figures of tooth formation 46

Figure 22. Plots of the sex-specific patterns of dental maturity developed by Demirjian, Goldstein and Tanner (1973) 54

Figure 23. Plot of the associations between chronological age and dental age (derived from the Demirjian method)

Figure 24. Plot of the sample sizes (per group) needed with an alpha of 0.05 and a beta of $80 \%$. 64

Figure 25. Example of the age distributions of stages $C$ through $G$ (sexes pooled) for the lower second molar to illustrate the method... 67

Figure 26. Schematic depiction of the S-shape ogive that reflects the nature of the cumulative increase in the percentage of a sample achieving a maturational event as chronological age progresses. 68

Figure 27. Box plots for the distributions of DA-CA for the two age cohorts (sexes combined). 
Figure 28. Plot of dental age against chronological age in the two cohorts (sexes pooled)

Figure 29. Plot of dental age by chronological age in the two cohorts of girls .... 74

Figure 30. Plot of dental age by chronological age in the two cohorts of boys.... 75 


\section{CHAPTER 1. INTRODUCTION}

It is a common perception in the United States that people have gotten taller and heavier by adulthood and that children are maturing faster. Girls reach menarche at progressively younger ages, whereas today's professional basketball players seem to tower over their counterparts of years past. These sorts of changes in height, weight, and overall maturity from generation to generation are referred to as "secular trends" (Tanner 1990) or what Kuczmarski (1993) terms changes over time. Malina (1990) explains that secular trends are the result of an interaction between human genetic predisposition and environmental influences.

Researchers continue to debate as to why such changes in the human body occur. Van Wieringen (1978) discusses the idea that humans are getting closer to reaching their genetic potential because improved nutrition and diminished incidence of childhood disease allow humans to attain their "optimal health." In the age of worldwide travel and communication, greater genetic intermixing of cultures could lead to more favorable genetic conditions in offspring, so-called "hybrid vigor" (e.g., Kozieł et al. 2011). For example, Hulse (1957) found that grown-up sons of parents who came from different Swiss villages were $2 \mathrm{~cm}$ taller than sons of parents who came from the same village. The inference is that out-breeding seemingly leads to more favorable growth in sons due to increased heterozygosity. Secular changes also seem to impact the developing dentition. Researchers have found increasing tooth size, earlier eruption, faster calcification rates, and changes in arch dimension over time. George Nadler (1998) suggests that orthodontists are initiating orthodontic treatment of American adolescents earlier than they did 20 years ago. He suggests that earlier treatment is not necessarily due to differences in mechanotherapy or a general lack of patients, but to earlier dental maturation of adolescents.

Treatment planning for the pediatric and adolescent patient can depend on the level of dental maturation the child has achieved. More broadly and more commonly, the orthodontist needs to be aware of how the child's growth is progressing relative to group-appropriate norms. Chronological age is most commonly used to estimate a child's maturity, but this approach is imprecise because it does not account for differences in the tempos of development among children (Harris 1998). So-called dental age-the extent of tooth developmentis a useful measure of a child's progress towards maturity. 
Tanner et al. (1975, p. 1) recognized that maturity is a continuum that "takes an individual from a state of being wholly immature to another of being wholly mature." Maturity measures must be defined by achievement of defined morphological or structural stages that every individual passes through along the pathway from immaturity to maturity. Chronological age may not coincide with maturity levels since some children reach a given developmental milestone faster or slower than others of the same chronological age.

Tanner et al. (1975) stated that the use of an age scale to estimate maturity, and vice versa, is not advisable for the following reasons. First, it fails at the extremes. For example, in skeletal maturity no particular age can be associated with an individual whose teeth or bones are fully mature, even though his status of $100 \%$ skeletal maturity is unequivocal. Second, and more importantly, the relationship between chronological age and maturity varies from one population to another or from one age interval to another, so unless the maturity scale is continuously redefined and updated in relation to actual age, the result will be that the maturity scale and age do not correspond to each other (Eveleth and Tanner 1990). Tanner et al. (1975) contend that it is more proper to view maturity in a manner that does not refer directly to age, but rather to investigate maturity and its relation to age as a second step in any given population assessment. Maturity estimates based on the percentage of adult form that has been achieved are also problematic when examining a child because his final endpoint in maturity is unknown. For instance, a child who appears tall for his age may be more mature than his peers or just a child of average maturity who will be a tall adult. Such determination can only be made retrospectively when final adult height becomes available.

Physiological age is a more informative measure of maturity than chronological age. Moorrees et al. (1963, p. 1490) defined physiological age as "the degree of maturity of the biologic tissue and organ systems an individual has achieved." Most children are average maturers, meaning that their chronological and physiological ages coincide fairly closely. Other children lag behind in biologic maturity with regard to their chronological age. Still others develop faster than indicated by their chronological age (e.g., Acheson and Dupertius 1957). Chronological age only provides a rough estimate of developmental status, and it cannot be relied upon solely because of varying tempos of growth among children of the same chronological age. 
Developmental status - the degree of adult form that has been attainedcan be estimated in several ways and expressed as an age. Examples of physiological methods reviewed by Steel (1965) and Krogman (1968) are: (1) skeletal age; (2) dental age; (3) morphological age based on height or weight; and (4) age estimates from secondary sex characteristics. Skeletal age dominates much of the health care literature on the subject. However, dental age is of particular interest to dental specialists since it is derived specifically from the development of the teeth. Additionally, dental age is useful in forensic science to determine the age at death of unknown individuals (e.g., Harris et al. 2009). Teeth are among the least destructible body tissues and are often the most reliable indicator of age in corpses (Johanson 1971; Harris et al. 2009).

Anderson et al. (1975) stated that tooth mineralization stages are less affected by nutritional (e.g., Garn 1965a; Riesenfeld 1970; Tonge and McCance 1965,1973 ) and endocrine (Garn 1965b) variations and provide a more accurate indication of chronological age than do developing bones (also see Demirjian 1978). Thus, dental age constitutes an important measure in the dental specialties and in forensics and anthropology. Dental age also is useful in gauging the ages of children without documentation (e.g., Brook and Barker 1973) as well as older persons who claim to be minors (e.g., Mincer et al. 1993).

The present study analyzes the tempos of permanent tooth development in a cohort of American white children from the Mid-South United States to contribute to understanding of secular changes in tempos of tooth formation. This project provides contemporary, sex-specific norms for dental development in the Mid-South United States. This project is similar to one performed by George Nadler (1998) who suggested a difference in dental age of maturation between adolescents treated in the 1970s compared to these in the 1990s. 


\section{CHAPTER 2. REVIEW OF THE LITERATURE}

\section{Secular Trends: Definition}

The word secular is an adjective referring to a prolonged period of time. A secular trend is a change in direction or tendency of something or some event over successive periods of time (e.g., Garn 1987). Secular trends occur in the absence of genetic changes; they occur within the same population over time due to changes in the environment (such as levels of childhood morbidity and of nutrition). It is important to distinguish between changes over generations due to changing environments versus changes in the population, such as would occur with significant immigration of people with different genetic backgrounds. Secular trends can be positive-a quickening of growth and increases in size due to favorable environments - or negative--a slowing of growth tempos and diminished size due to an adverse environment.

In terms of growth, secular trends have been noted most often for children becoming taller and heavier over time (e.g., Gordon-Larsen et al. 1997; Tanner 1968). The noted increases in height and body mass of children from successive generations may be related to earlier maturation (Tanner 1968; Wyshak and Frisch 1982). Connecting the dots, Thompson et al. (2002) explain that greater stature and body mass are observed at earlier chronological ages in those who are more advanced biologically. Not surprisingly, research has shown that for both males and females born in the late 1900s peak height velocity, a measure of morphological maturity (Thompson et al. 2002), occurs at a younger chronological age than those born in the early 1900s (Hauspie et al. 1996, 1997; Murata and Hibi 1992; Roche 1979; Vercauteren and Susanne 1985). Furthermore, girls have experienced increased tempos of maturation as shown by earlier onsets of menarche over this same time interval (Hauspie et al. 1997; Huen et al. 1997; Lin et al. 1992; Tanner 1968; Wyshak and Frisch 1982).

Secular trends are reversible, not universal, occur sporadically, exhibit ethnic and geographic differences, seem to respond to genetic and environmental influences, and can be described as positive, negative, or absent (Van Wieringen 1978; Malina 1990). The guiding theme is that the tempo of growth responds to the quality of the environment in which a cohort of children grows up. A positive secular trend is illustrated by the common observation that children today are taller, heavier, and mature earlier than children of generations past. A negative secular trend would occur if children and adults of more recent generations were 
of shorter stature than children and adults of generations past. Unchanging stature from generation to generation would indicate the absence of a secular trend. Malina (1990) notes that the absence of a secular trend indicates two likely scenarios: (1) the population in question may have attained its genetic potential for size and timing of maturation or (2) the population is living under environmental conditions that have not improved enough to allow a positive secular trend, however, is not impoverished enough to undergo a negative trend.

It is worth articulating the point that a secular trend is a cross-generational effect seen at the level of the group (sample) or population. A secular trend affects individuals, but can only be seen at the level of the group. As such, it is a statistical concept, not a directly measurable phenomenon. Moreover, studies reveal that not all individuals (nor all components of a group) respond the same (Hauspie et al. 1997). For example, raising average body size across generations has been due to the reduction of very small (short, thin subjects) that have been particularly disadvantaged by society or the environment rather than uniformly enhancing growth across all subjects (Tanner 1962). This recalls the aphorism that "a rising tide lifts all boats." Improving the health and nutrition of the least advantaged segments of a society often have the biggest "pay off" for the population at large. This has been documented as well for the transition over the past two centuries in industrialized countries from most causes of illness being acute-onset high-mortality diseases such as scarlet fever, rubella, and malaria to chronic, generally adult-onset problems such as type II diabetes, hypertension, and Alzheimer's disease (Omran 1971, 1983). Substantive reductions in acute child-onset diseases (which are more prevalent in lower socio-economic strata of populations) have the effect of raising the average health (and growth) of the population. In other words, there can be a greater effect on the population average of improving the well-being of the least-advantaged segments of a population compared to further-enhancing the growth of those who are already well off (Cameron 1993).

Secular trends have only been briefly touched upon but they are welldocumented in the characteristics of height, weight, and sexual maturation (Van Wieringen 1978), all of which are important parameters for assessing growth over time. Numerous other features of growth also exhibit trends, such as head circumference (Nellhaus 1970) and thorax width, hemoglobin level (Owen et al. 1970), blood chemistry, skeletal age (de Wijn and Tusbach 1961), and dental development (Garn and Russell 1971). Although some use the term secular to denote the specific time frame of a century, secular shifts can occur across shorter periods (Van Wieringen 1978). 


\section{Secular Trends: Significance}

Van Wieringen (1978) notes that the importance of studying secular growth changes is threefold: First, a close interrelationship has been established between shifts in growth and in patterns of morbidity and mortality. From an epidemiological standpoint, secular growth trends are an indicator of public health based on comparing regional and nationwide growth patterns. Secondly, secular growth trends can be used to assess the growth of an individual child compared to the population to which the child belongs. The main characteristics of growth and somatic differentiation are height, weight, and sexual maturation. A child is deemed short or tall, underweight or overweight, sexually delayed or advanced when plotting his or her individual growth measures against established norms. These norms, however, must be periodically updated to account for a population's tempo of growth that shifts over time. Thirdly, the social impact of a secular growth shift is important. For example, Garn (1966) noted that the proportions that humans create in their world are largely determined by the distance between their feet and the top of their head. Changes in stature over time affect clothing, furniture, the tools we use, architecture of houses, schools, and offices. An earlier development of maturation characteristics, and thus biological adulthood, may have an effect on legislation, jurisdiction, education and treatment timing.

\section{Secular Trends: Early Studies}

Van Wieringen (1978) relates that interest in human growth gave rise to nonscientific, emotional assumptions as well as scientific research. Such assumptions included the belief that the uncivilized enemy was much taller and stronger than the civilized society. This generally served as an excuse in defeat and a great triumph in the case of victory. As cited in Van Wieringen (1978), several researchers indicate that the ancient Romans classified their soldiers based on height and were interested in the heights of soldiers of countries with whom they were at war (Kiil 1939; Oppers 1963; Udjus 1964).

According to Van Wieringen's scholarly review, early epidemiological growth studies of note were performed by Villermé and by Quételet. Villermé (1829) studied official statistical data of French soldiers drafted between 1800 and 1810 as to height, age at which adult physical development was attained, 
percentage of rejections on account of ill health, and occupational status. Villermé also collected data concerning the standards of life in the various French districts from which the recruits were drafted, along with mean height, and percentage of rejected conscripts. He conjectured that when the age of conscription was lowered, there was an increase in the number of "undersized" conscripts from poor areas compared to regions of high prosperity, indicating that growth in poor regions was slower. He noted that when the standard for minimum height was lowered, the percentage of rejections on account of ill health increased, which suggests that small persons tended to be less healthy than tall persons. Villermé further remarked that the majority of French men did not attain the average adult height of $164.4 \mathrm{~cm}$ before 20 or 21 years of age, and, in regions where living conditions were unfavorable, this height was not attained before the ages of 22 or 23 . He suggested that government could promote a population's health and growth by improving general living conditions.

Villermé's publication interested the astronomer and statistician Quételet, who proceeded to study a sample of 900 Belgian conscripts. Quételet (1830, 1831, cited in Van Wieringen 1978) found that men from the countryside were on average $2 \mathrm{~cm}$ shorter than those in the city. He established an association in height according to socioeconomic level, whereby those who lived in the city lived in more favorable conditions. According to Van Wieringen, both Villermé and Quételet interpreted their results as indicating that changes in living conditions are accompanied by changes in linear growth, morbidity, and mortality.

\section{Secular Trends in Sexual Maturation}

A frequently studied secular change involves sexual maturation. Pubic hair, breast development, and the onset of menstruation are the most prominent characteristics of sexual maturation in girls, whereas pubic hair and growth of the genitalia and testes are the characteristics used to monitor sexual maturation in boys (e.g., Marshall and Tanner 1969, 1970). Berenberg (1975) showed that menarche in many countries in Europe began 2 to 4 years earlier roughly a century ago. In other words, girls have begun menstruation at a rate of 3 to 4 months earlier per decade (Figures 1 and 2). The shortcoming of Berenberg's study is that data collected before the 1920s is the recollected age of menarche, meaning the actual event had occurred and recalled years later. 


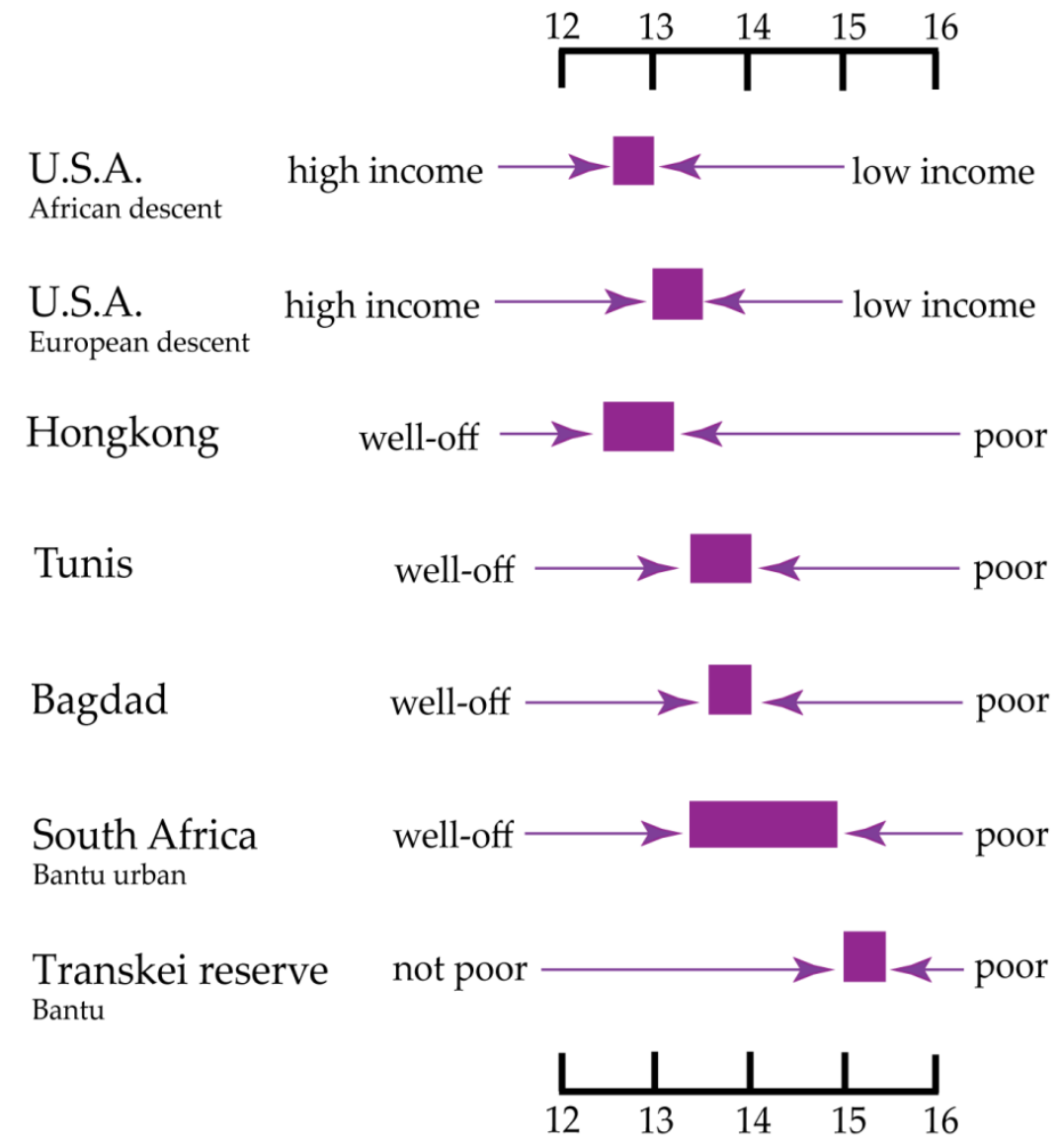

Figure 1. Girls from high income families begin menstruation at an earlier age than those girls from low income families.

Reprinted with permission. Berenberg SR. Puberty, biologic and psychosocial components. Leiden: Stenfert Kroese; 1975, p. 35. 


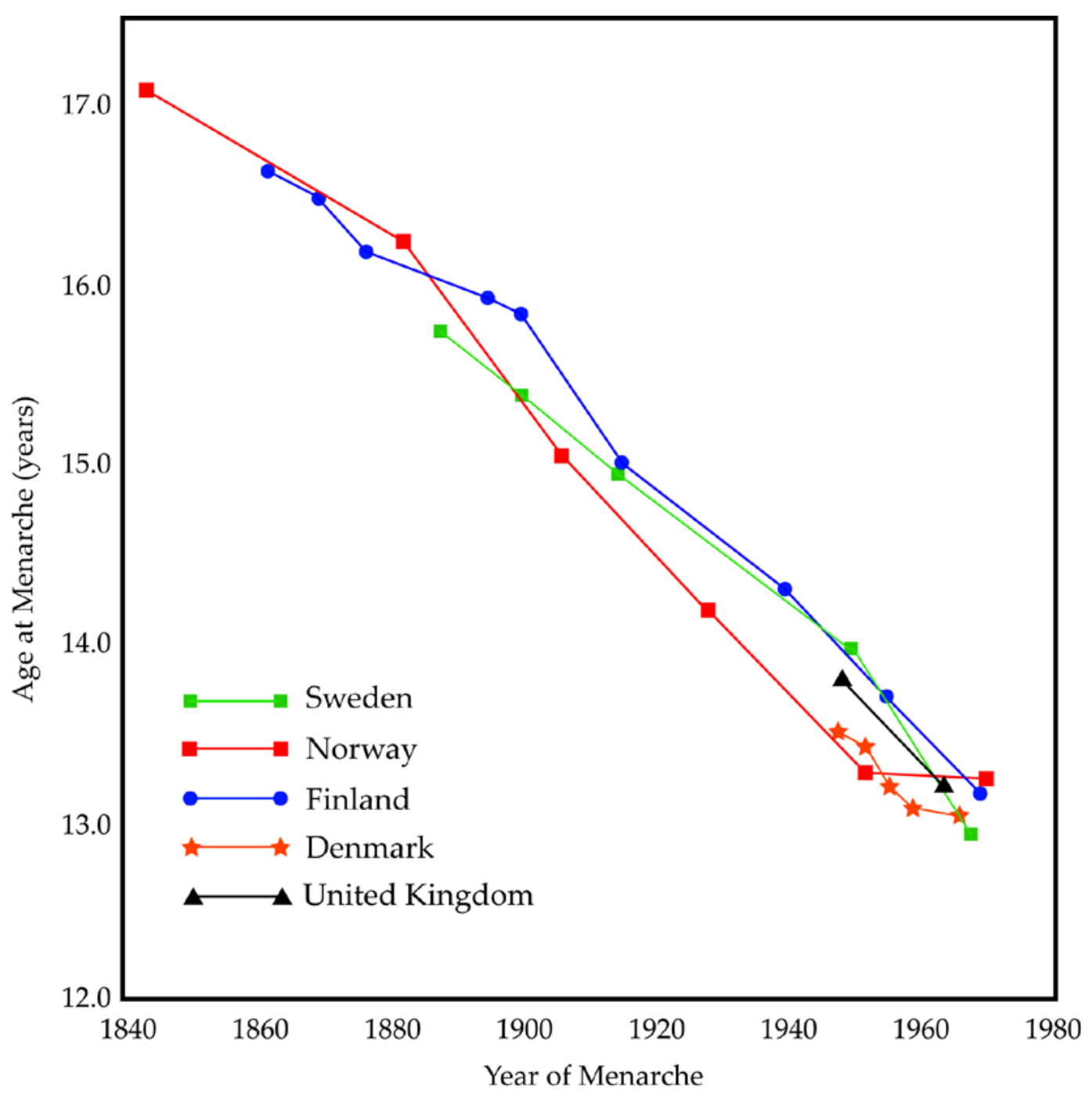

Figure 2. Early menarche in European countries from 1840 to 1970.

Reprinted with permission. Berenberg SR. Puberty, biologic and psychosocial components. Leiden: Stenfert Kroese; 1975, p. 36. 
A more recent study by Cho et al. (2009) shows that the mean age of menarche decreased from 16.9 years for Korean women born between 1920 and 1925 to 13.79 years for women born between 1980 and 1985, indicating a downward trend in age of menarche of 0.7 years per decade (Figure 3 ). Furthermore, Cho and colleagues found the mean age at menarche of girls born between 1986 and 1995 to be 13.1 years. The authors attributed the trend to many factors including higher body mass indexes, lower maternal menarcheal age, lower maternal age at birth, and better nutrition as measured by greater intake of protein, sugar, fiber, ash, phosphate, natrium, thiamine, riboflavin, and niacin for menarcheal girls. O'Connell et al. (2009) found similar results in Ireland, finding that the mean age at menarche decreased from 13.5 years in 1986 to 12.5 years in 2006. Jones et al. (2009) found a statistically significant decrease in age of menarche for Black women in South Africa born in 1956 compared to those born in 1990.

Although less commonly studied than menarche, the Copenhagen Puberty Study found statistically significantly earlier breast development among girls born more recently (Aksglaede et al. 2009). Such studies indicate that women initiate their sexual development at an earlier chronological age than in past generations.

Menarche has also been known to be influenced by nutrition and, indirectly, socioeconomic status. Many researchers have found that girls in disadvantaged families achieve menarche later than girls in well-off families (summaries in Eveleth and Tanner 1975, 1990). Carfagna et al. (1972) reported such results in Naples, Italy; Indira Bai and Vijayalakshmi (1973) in Tirupati, South India; and Neyzi et al. (1975) in Istanbul, Turkey. Also, a study from Constanza, Romania, found that menarche arrived 2.1 months later for every additional sibling in the respective family (Štukovsky et al. 1967). A report by Leenstra et al. (2005) studied rural areas with endemic malaria in western Kenya with high levels of malnutrition and found that menarche was delayed 1.5 to 2.0 years compared to a US reference population. Similarly, a 3-year delay in menstruation of Senegalese adolescents was described by Simondon et al. (1997) and attributed to malnutrition. These studies suggest that decreases in socioeconomic and nutritional conditions are associated with prolonged onset of menarche. 


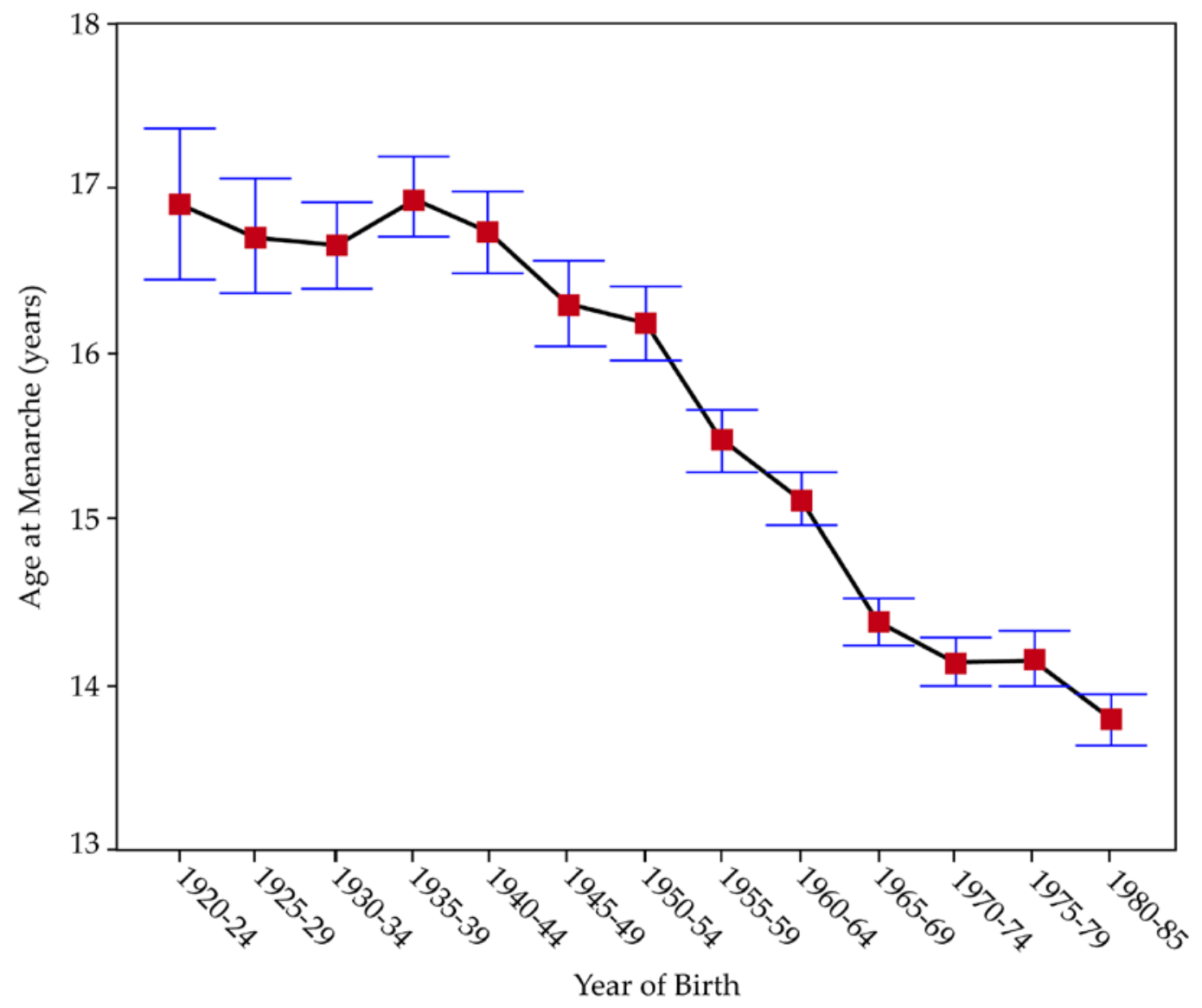

Figure 3. Decrease in age of menarche from 1920 to 1985.

Reprinted with permission. Cho GJ, Park HT, Shin JH, Hur JY, Kim YT, Kim SH, Lee KW, Kim T. Age at menarche in Korean population: secular trends and influencing factors. Eur J Pediatr 2010;169:89-94. 


\section{Secular Trends: Stature}

Studies of secular trends in height are numerous. Over the past century, the trend is that people are not only getting taller, but also reaching taller statures at an earlier age. Tanner's (1966) review of more than a hundred publications dealing with secular changes in growth and maturation brought forth the following remarks: (1) The positive trend in height in the 19th century coincided with the moment industrialization improved socioeconomic conditions. (2) The trend began after birth and at the age of 5 to 7 , height increased 1 to $2 \mathrm{~cm} /$ decade. (3) The gain in weight was proportional to the gain in height, so there was a change in size rather than proportion. (4) War and hunger slow gains in height and weight. (5) Adult height increased by $10 \mathrm{~cm}$ and was reached at an earlier age (18 years compared to 26 years). (6) Swedish boys reached their peak height velocity one year earlier in 1938 than in 1883, and Norwegian boys had their growth spurt at 14 in the 1930s compared to 17 between 1825 and 1837. Tanner (1966) suggested that the trends in adult height were due to some combination of genetic and environmental factors.

Further studies extend Tanner's discoveries. Ljung et al. (1974) found that Swedish children and adults became taller at all ages from 1883 to 1939 (Figure 4). Brundtland et al. (1975) found the same positive secular trend in height over a two decade period in Oslo school children and adolescents aged 7 to 16 years. De Wijn (1975, cited in Van Wieringen 1978) found an increase in median height for Dutch school children from 1965 to 1974. Baynouna et al. (2009) reported an increase in height of $8.2 \mathrm{~cm}$ in men and $7.2 \mathrm{~cm}$ in women in two different cohorts 40 years apart from the United Arab Emirates, the younger generation being the taller. They postulated that the increase in height of the more recent generation was due to the discovery of oil in the late 1960s and the ensuing wealth and increase in standard of living. Similarly, Papadimitriou et al. (2009) found a secular increase in height for all ages of Greek schoolchildren in 2005 compared to a 1994-1995 cohort.

\section{Other Secular Trends}

Secular trend studies extend to numerous other body dimensions and features. Little et al. (2006) analyzed the secular changes in craniofacial dimension among indigenous children in an isolated community in Oaxaca, Mexico, between 1968 and 2000. They measured four craniofacial dimensions (head length and breadth, and bizygomatic and bigonial breadths) of 

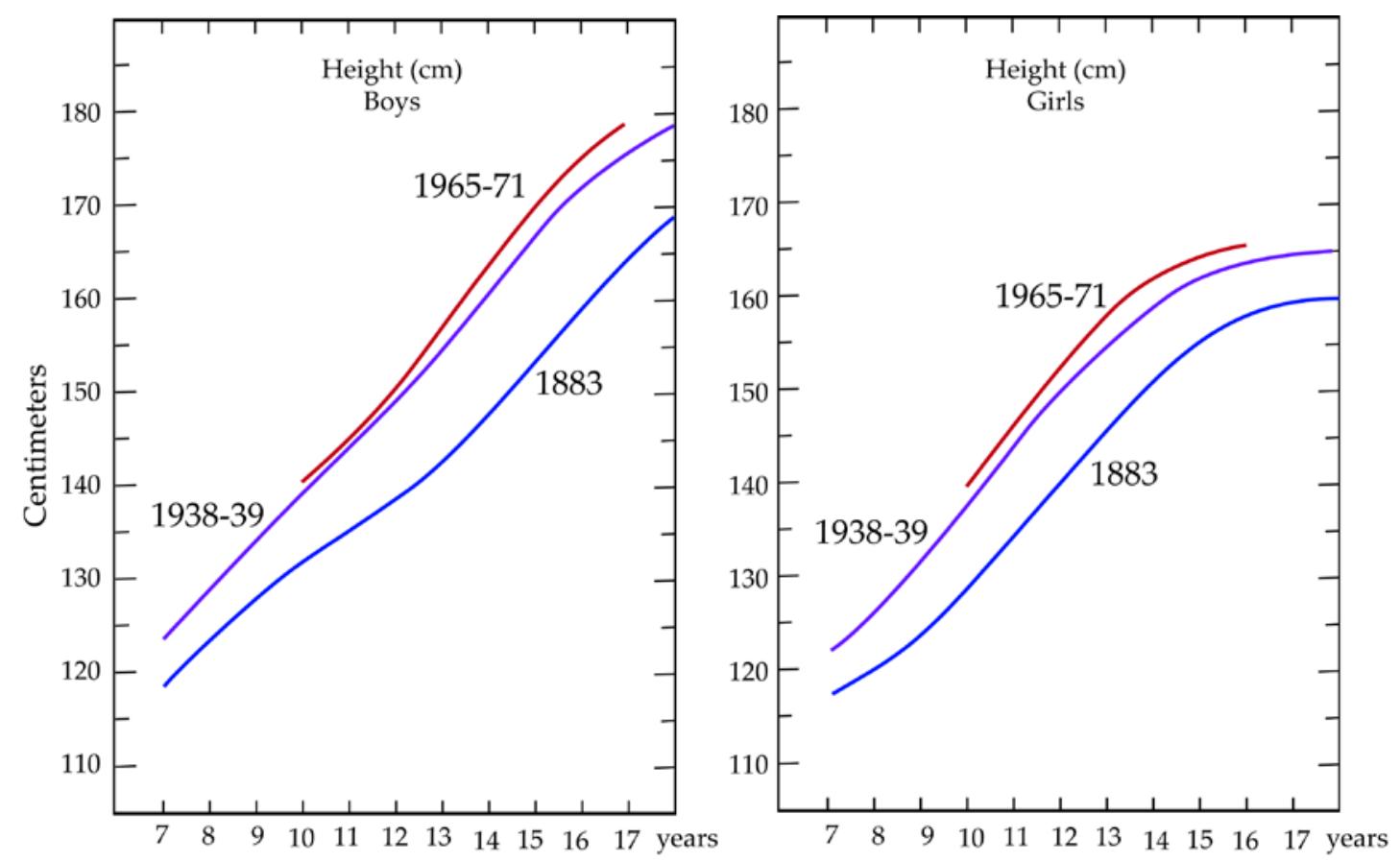

Figure 4. Secular trend in growth of height of Swedish boys and girls. Chronological age is shown along the $\mathrm{X}$-axis. The data make it clear that the secular trends involve children of all ages. It is not just the adult heights that differ.

Reprinted with permission. Ljung BO, Bergsten-Brucefors A, Lindgren G. The secular trend in physical growth in Sweden. Ann Hum Biol 1974;1:245-56. 
schoolchildren aged 6 to 13 years in 1968, 1978, and 2000. Over this 32-year interval there were significant secular changes in the following craniofacial dimensions: (1) head length became shorter both in boys and in girls; (2) bizygomatic breadth became narrower in both sexes; (3) head breadth increased over time, but only among girls; (4) brachycephalization increased significantly in both sexes; and (5) zygomatic index decreased significantly in boys. Overall, the craniofacial complex changed to a shorter head length and narrower face, with the midface and lower face (mandible) changing at approximately the same rates. The authors attributed these secular changes to decreased food coarseness and relaxed natural selection that led to a greater developmental plasticity.

Bodily secular trends are not only found in the skeleton but also in integumental structures. Henneberg and George (1995) found a positive secular trend in the occurrence of the median artery in the forearm. The incidence of the median artery found in adult cadavers before the 1960s was between 4 and $8 \%$, whereas its prevalence rose to $53 \%$ in 1980 to 1991 . The authors point out that since the artery normally dwindles around the 7th week of intrauterine life, its increased prevalence into adult life indicates a trend in intrauterine development.

\section{Secular Trends in the Dentition: Tooth Size}

Studies have found secular trends in tooth size. Garn et al. (1967) compared 46 fathers with 49 of their sons and found the mesiodistal crown diameters to be significantly greater in 8 of 28 permanent tooth types. They found a mean increase in tooth size of $0.12 \mathrm{~mm}$ in sons across this one generation. Lavelle (1973) studied 150 British Caucasian families and found an average effect of $0.08 \%$ increase in tooth size in the mesiodistal dimension and $0.06 \%$ increase in the buccolingual dimension from parent to offspring. A study by Lindsten et al. (2002) compared tooth size between a sample of 48 skulls from the Schreiner Collection at the University of Oslo to three contemporary samples and found that the skeletal sample had smaller permanent tooth crown sizes. Another study by Lindsten et al. (2001) reported that mandibular incisors were less aligned in 9-year-olds born in the 1980s compared to a cohort born in the 1960s. They concluded that larger teeth could indicate a secular trend toward increased prevalence of malocclusion in the present population. Overall, the research suggests that tooth size is increasing over time. 
A two-generation study by Harris et al. (2001) documented significantly increased buccolingual tooth dimension in the premolars and molars of children in stable post World War II China compared to their parents who experienced development during and after the economic instability in China during World War II. It is likely that nutritional deficiencies during the development of the premolars and molars in the older generation were responsible for the smaller teeth. This study contended that economic and nutritional hardships can result in a physical change in tooth size.

Some controlled animal studies have also looked at the effects of altered environments: Paynter and Grainger (1956) showed that exposing pregnant and lactating rats to nutritional deficiencies resulted in an altered size and shape of the offspring's first molars. Specifically, the mesiodistal diameter was smaller and the shape and size of the mesial-occlusal fissure was altered. Similarly, Shaw and Griffiths (1963) documented that pregnant and lactating rats fed a protein-deficient diet experienced reduced molar size, especially of third molars. The third molars had a high percentage of distortion of the mesiolingual cusp, delayed eruption and increased caries susceptibility (Shaw 1969).

\section{Secular Trends in the Dentition: Arch Size}

Secular trends have also been found in dental arch dimensions (Lindsten 2003). The transverse dimension of a dental arch can be measured from different landmarks; for example, the distance between the buccal crowns of canines or the distance between the mesiolingual cusps of the first molars. In order to attain the ideal overbite and overjet in the posterior buccal segments, the maxillary transverse dimension must be larger than the mandibular transverse dimension. A decrease in the difference between the arches could lead to a malocclusion, such as a posterior crossbite. Lindsten et al. (2001) compared two cohorts of 9year-old children born in the 1960s and 1980s and compared their transverse arch dimensions. They found that the transverse intermaxillary difference was smaller in boys and in girls in the 1980s than in the 1960s. This is noteworthy because this trend increases the likelihood of malocclusion, particularly posterior crossbites, in the younger generation. Similar results were found by Lindsten $e t$ al. (2002) when comparing skeletal samples from the 14th and 19th century to contemporary Norwegian samples. They found a larger intermaxillary difference in intercanine distance and intermolar distance in the skeletal group as compared to the contemporary samples. 
Studies have found a secular trend in lateral arch length. Lateral arch length is defined as the distance between the mesial surface of the first permanent molar to the distal surface of the permanent lateral incisor. Lindsten et al. (2000) studied the lateral arch spaces between two cohorts of 9-year-olds born 20 years apart. They found that children born in the 1980s had significantly larger lateral arch spaces in the maxillary and mandibular dental arches than the children born in the 1960s. They attributed the increase in arch length to the recent decline in dental caries prevalence and resultant preservation of interproximal tooth structure.

\section{Secular Trends in the Dentition: Tooth Emergence}

Secular trends have been found in tooth emergence. A study by Helm (1969) analyzed the mean eruption times for canines, premolars, and second molars for two cohorts of Danish school children, one in 1913 and the other in 1965. Helm found that the recent sample displayed an earlier eruption of the second molar and canine in the maxilla and mandible and the first premolar in the mandible. He also found the interval between the first and last erupting tooth was appreciably shorter in the recent, 1965 sample and that the emergence sequences differed between the cohorts. Notably, this study shows a change in pattern of eruption over the 50 year span (Figures 5 and 6).

Höffding et al. (1983) analyzed schoolchildren aged 6 to 15 years of age to provide mean times of emergence of permanent teeth in Japan. They found earlier mean times of emergence when comparing the results with data from Japanese children in 1934 (Figures 7 and 8).

In contrast to Helm and Höffding, two longitudinal studies by Parner et al. (2000) of Danish children compared cohorts from 1969 to 1982 and found a slight statistically significant increase in mean emergence times for both sexes in almost all teeth for the more recent cohort. The authors found a mean increase in age of 1.5 days per year for boys and 2.6 days per year for girls. Parner and colleagues mention that although it is well known that a general acceleration in physical development has been observed over time, this had no acceleratory effect on the emergence of permanent teeth in their sample. 


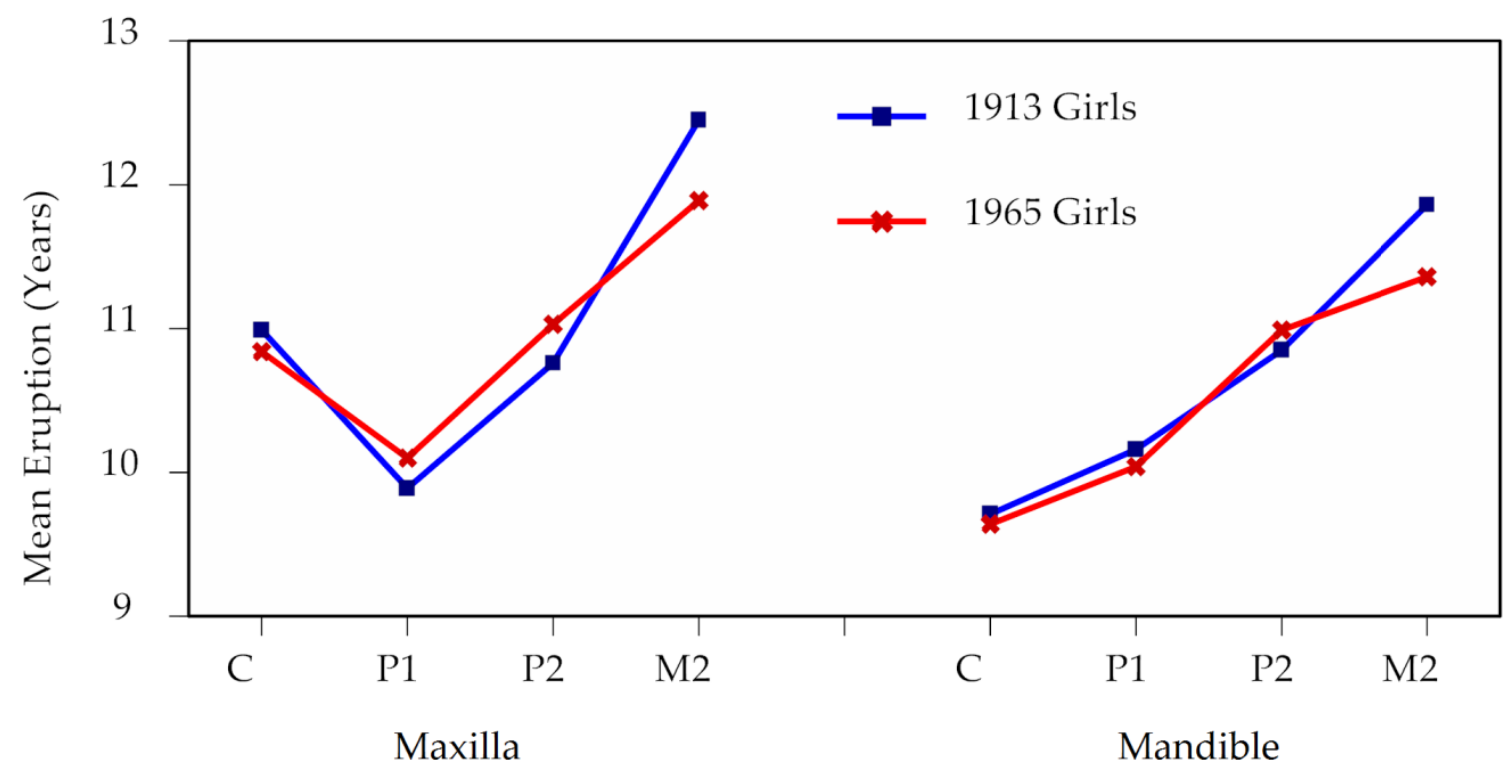

Figure 5. Test of secular trend in permanent tooth eruption in girls.

Reprinted with permission. Helm S. Secular trend in tooth eruption: a comparative study of Danish school children of 1913 and 1965. Arch Oral Biol 1969;14:1177-91. 


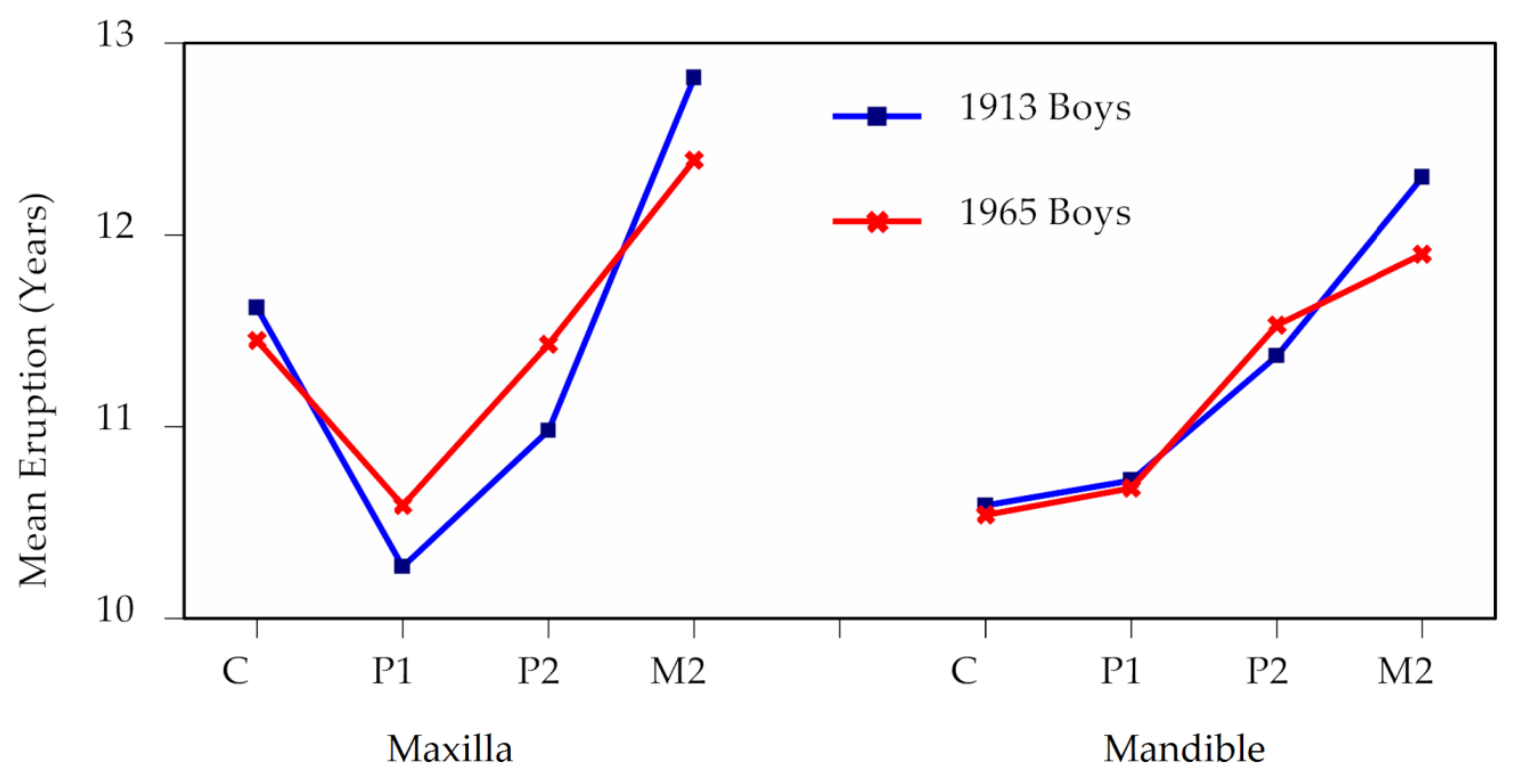

Figure 6. Test of secular trend in tooth eruption in boys.

Reprinted with permission. Helm S. Secular trend in tooth eruption: a comparative study of Danish school children of 1913 and 1965. Arch Oral Biol 1969;14:1177-91. 


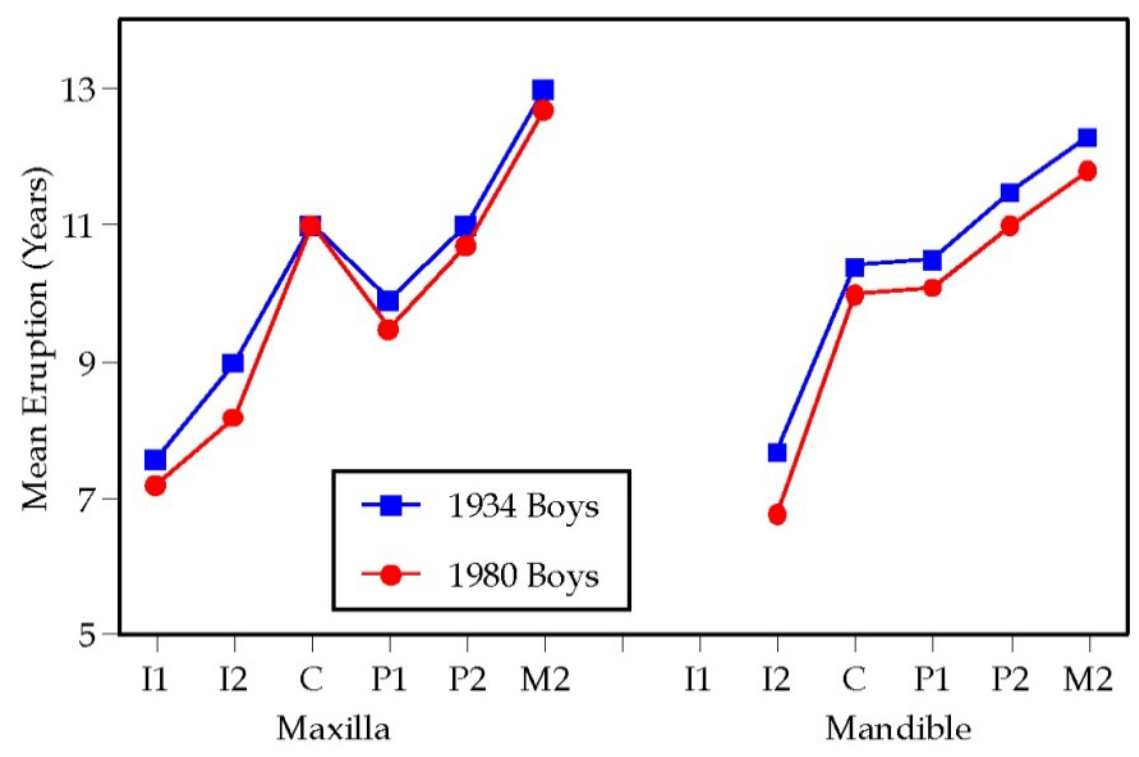

Figure 7. Plot of mean ages at eruption for 12 permanent tooth types in boys.

Reprinted with permission. Höffding J, Maeda M, Yamaguchi K, Tsuji H, Kuwabara S, Nohara Y, Sadahiro Y. Emergence of permanent teeth and onset of dental stages in Japanese children. Community Dent Oral Epidemiol 1984;12:558 . 


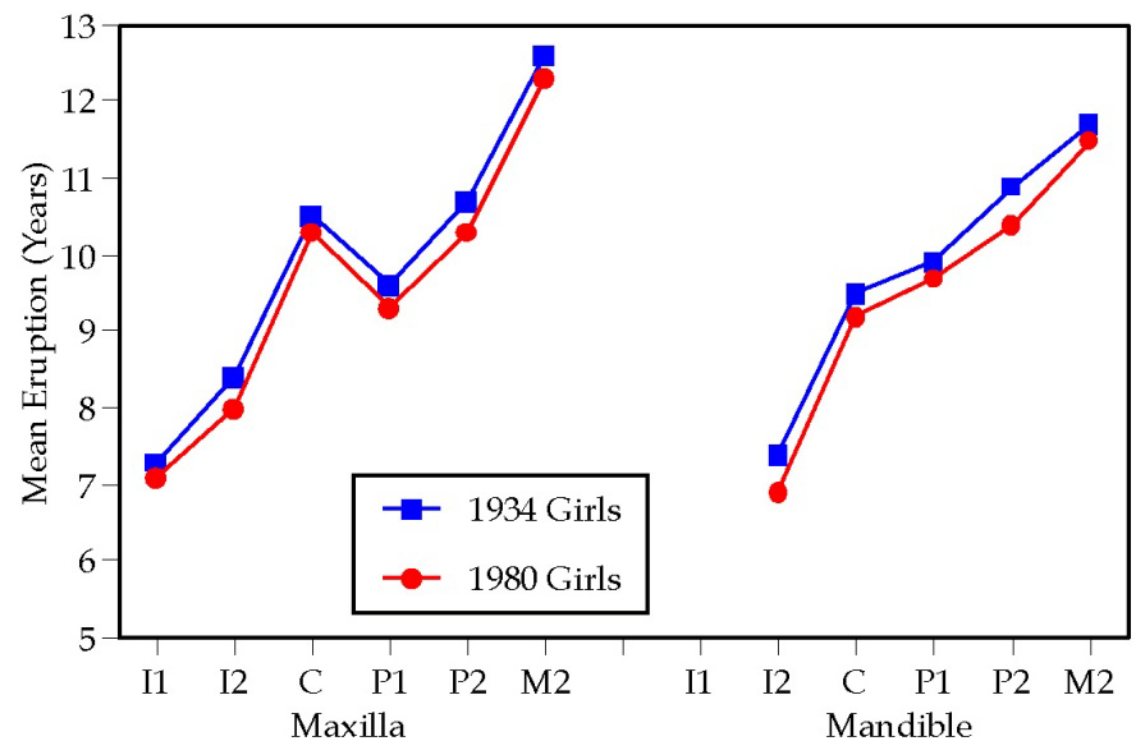

Figure 8. Plot of mean ages at eruption for 12 permanent tooth types in girls.

Reprinted with permission. Höffding J, Maeda M, Yamaguchi K, Tsuji H, Kuwabara S, Nohara Y, Sadahiro Y. Emergence of permanent teeth and onset of dental stages in Japanese children. Community Dent Oral Epidemiol 1984;12:558. 


\section{A Natural Experiment in Modulating Tempos}

Much of the literature on secular trends focuses on statue and body weight because there is a long history of national surveys of these variables and they are fairly simple to obtain in a systematic manner (e.g., Garn 1987; Malina 2004). In contrast, few data are available regarding aspects of the dentition such as tooth emergence and caries rates. This makes the prospective study of the dental status of Norwegian children (Toverud 1956, 1957a,b) of particular interest relative to the theme of the present study.

Toverud (1956) relates that prior studies in Europe following the First World War (and following the Spanish Civil War) described marked reductions in dental caries of children-evidently because of food restrictions, especially of cariogenic foods. Rather heroically, the Norwegian State Dental School planned a dental study that would proceed through and following the upcoming Second World War (WW II). The dentists' intent was to test whether (A) primary tooth exfoliation, (B) permanent tooth eruption, and/or (C) caries rates would be affected by the wartime conditions. Norway was invaded by the Germans in April of 1940, and dental data were collected annually for the school years of 1940-1941 through 1948-1949, and subsequently in 1951-1952 and 1952-1953. (WW II ended in Europe on May 8, 1945.) Toverud (1956, 1957a,b) provides extensive analyses of data from the dental examinations, and only a few key issues are described here.

The two themes of the analysis are that, due to food-rationing during the German Occupation of 1940-1945, (1) caries rates declined and (2) permanent tooth emergence was delayed. After the war, these rates returned towards their prewar levels.

As an aside, caries was rampant in Norway in this pre-fluoride era, and substantial percentages of deciduous teeth were lost prematurely, which can hasten eruption of the successors (e.g., Fanning 1961). This can confound interpretation of the nutritional impact on tooth eruption, so the following examples focus on the permanent molars that are unaffected by this factor because they have no predecessors.

Eruption of the permanent second molars provides an obvious example of the delayed emergence due to nutritional declines (Figure 9). These data had been collected each year on 9 year olds. Toverud (1956, p. 416) noted that, "the need for calories was not met by a large proportion of the children. The 


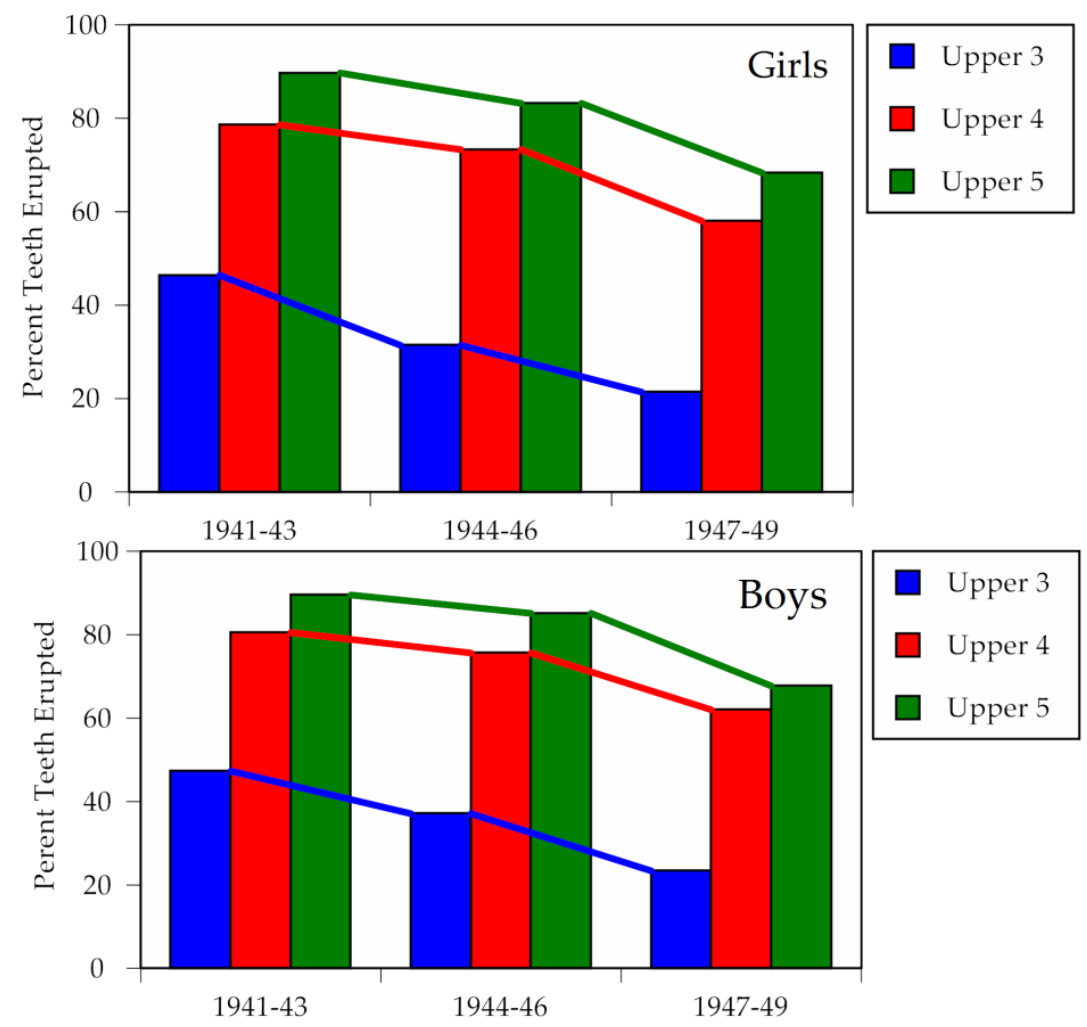

Figure 9. Graphs of the declines in the number of permanent upper second molars in Norway for three one-year cohorts. (Top) Data for boys. (Bottom) Data for girls. Interpretation is that tempos of growth slowed during WW II, primarily because of food restrictions. These permanent molars (without predecessors) are not affected by alterations in timing of the primary teeth.

Reprinted with permission. Toverud G. The influence of war and post-war conditions on the teeth of Norwegian school children. I. Eruption of permanent teeth and status of deciduous dentition. Milbank Memorial Fund Quarterly 1956;34:376. 
insufficiency of the diet was particularly marked for children in the ages of prepuberty, periods of rapid growth." Interpretation of Figure 10 is that second molar eruption was progressively delayed in children as the war progressed, and this is reflected in lower percentages of emerged second molars in both sexes across the three sets of years examined. Indeed, by chi-square analysis, all six of the trends plotted in Figure 9 show highly significant differences.

In concert with delays in permanent tooth emergence, Toverud shows that percentages of retained primary teeth increased in response to the wartime conditions. For example, in 8-year-olds (Figure 10), the percentages of children with primary first molars in place increased across time. The graph shows that the response is quite similar in boys and girls, and both sexes exhibit some recovery at the latest, 1952-1953 examination.

Percentages of decayed and filled teeth (DF scores) are a coarse measure of nutrition, and these rates decreased significantly as the war progressed. The trends are consistent for the primary canines, first molars, and second molars in each arch and in both sexes. Data for the mandibular teeth are graphed in Figure 11. Tooth decay depends on a food source for the bacteria to consume, so the logical scenario is that under-nutrition reduces the availability of plaque for the bacteria to feed upon.

In sum, Toverud's analysis provides one of the most extensive studies in humans showing how restricted nutrition impacts dental development. Nutritional effects of WW II on children's growth is a "natural experiment" where there is no control of the conditions of specific individuals or groups examined, but it shows directly the response of humans, so it complements controlled animal experiments (e.g., Shaw 1970) where the specimens' lifestyles are well regimented but they are not human.

\section{Dental Secular Trends and Nutrition}

The reigning explanation as to why researchers have found increasing tooth size as well as earlier dental emergence and earlier tooth formation over time is altered nutrition. Thompson et al. (2002) examined the development of fatness, as measured by skinfold thicknesses, in healthy white children and adolescents from Canada in the 1960s and 1990s. The authors collected data from two previous longitudinal studies spaced 30 years apart. When they matched sex, height, body mass, and maturity between the two studies, they 


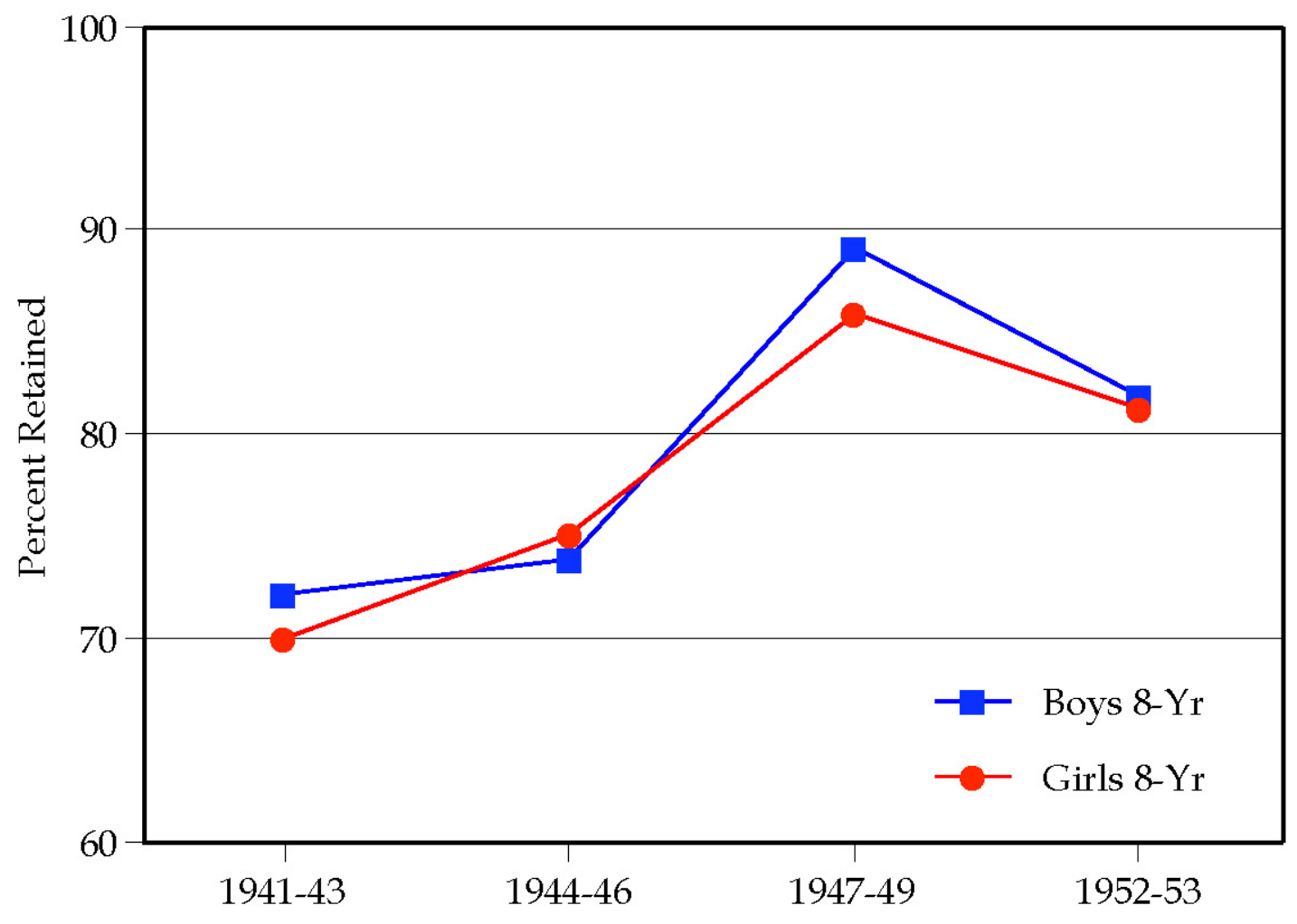

Figure 10. Graph of the percentages of 8-year old children with retained primary mandibular second molars. Interpretation is that restricted-nutrition during WW II is reflected in slower tempos of dental maturation. After the War, there is a slight return toward the pre-War status.

Reprinted with permission. Toverud G. The influence of war and post-war conditions on the teeth of Norwegian school children. I. Eruption of permanent teeth and status of deciduous dentition. Milbank Memorial Fund Quarterly 1956;34:391-2. 

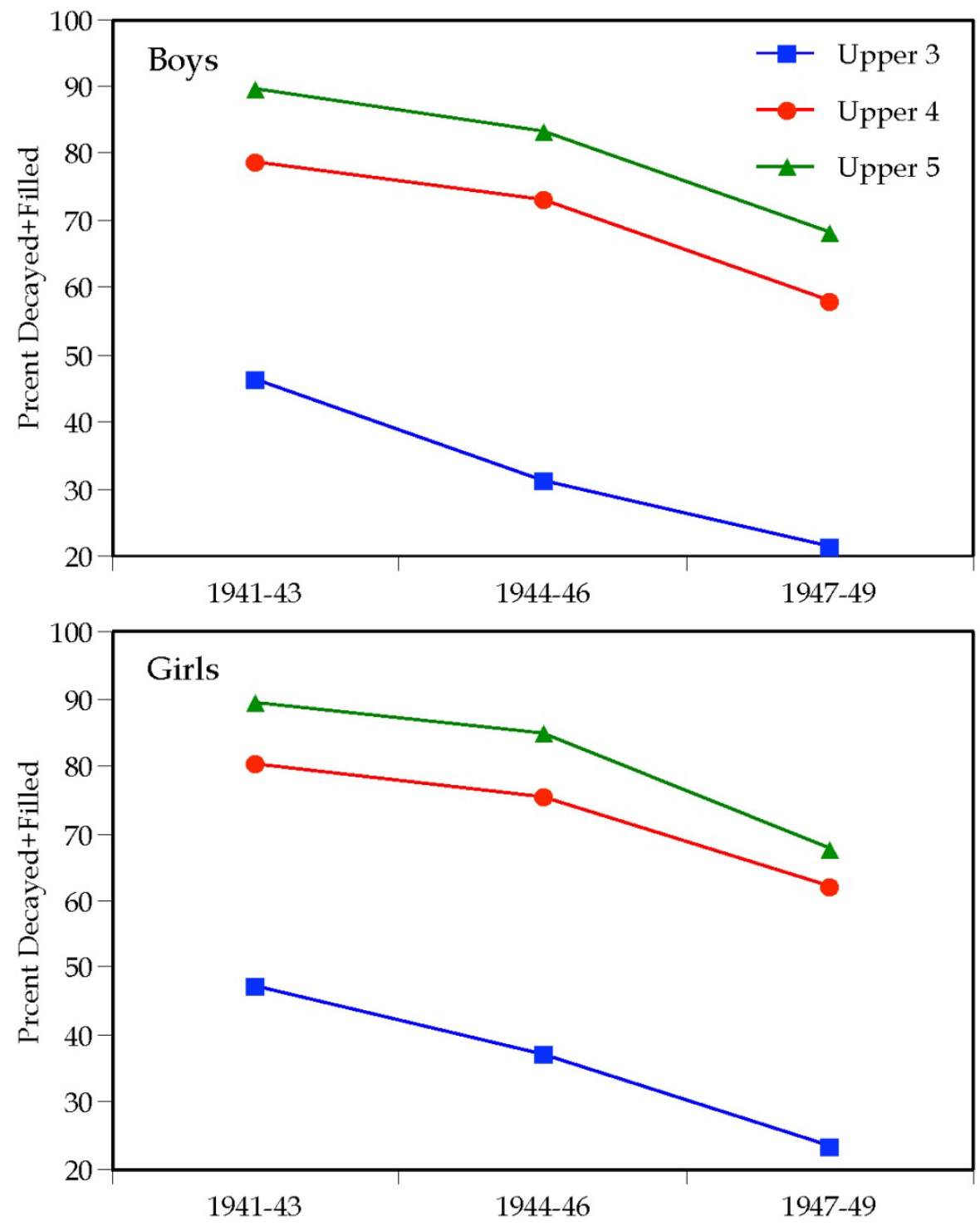

Figure 11. Graphs of the declines in decayed plus filled primary teeth across three cohorts in Norway. (Top) Data for boys across the three-year cohorts. (Bottom) Data for girls. The progressive declines are interpreted as enhanced dental health due to restricted diets during WW II and afterwards.

Reprinted with permission. Toverud G. The influence of war and post-war conditions on the teeth of Norwegian school children. I. Eruption of permanent teeth and status of deciduous dentition. Milbank Memorial Fund Quarterly 1956;34:402. 
found that skinfold thicknesses of the males and females in the more recent cohort was significantly greater than the previous. The fatness of children and adolescents had increased over the 30-year interval. The increased trend of childhood obesity has dental consequences. Hilgers et al. (2006) looked at the difference between chronological age and dental age (per the Demirjian method) of 104 children, and analyzed this difference against body mass index (BMI), age, and the child's sex. Dental development was accelerated in overweight and in obese children by 1.51 and 1.53 years, respectively. The secular increase in childhood obesity is one good reason to expect a secular change in tooth size, mineralization tempos, and thus timing of tooth emergence.

At the other end of the spectrum, studies have shown that malnutrition tends to slow dental development. Bastos et al. (2007) studied a sample of 359 Brazilian children born in 1993 . These authors set out to determine the best predictors of pairs of emerged teeth at 6 and 12 months of age and emergence of first permanent molars at 6 years of age. Gestational age is predictive of the number of pairs of emerged teeth at 6 months. Birth length and growth stunting at 6 months of age are associated with the number of pairs of emerged teeth in children aged 12 months. Growth stunting at 6 months of age predicts the emergence of the first permanent molars at 6 years. Growth stunting is defined as the reduction in final stature at adulthood due to past chronic malnutrition (Waterlow et al. 1977). Bastos and colleagues found a link between malnutrition, as reflected in low birth length and stunting, and delayed tooth emergence. These results are not surprising in that delayed dental emergence has been reported to be associated with malnutrition, low socioeconomic status, low birthweight, and prenatal diseases (Enwonwu 1973; Ondarza et al. 1987; Ondarza et al. 1997; Robinow 1973). Some studies, however, have found no statistical link between nutrition and dental development (Flores-Mir et al. 2005; Cameriere et al. 2007), whereas others such as Garn and Russell (1971) contend that tooth eruption is only modestly delayed in instances of malnutrition and slightly advanced in obesity. Obviously, differences among these studies are readily explained by the actual levels of "malnutrition" observed in these various samples.

\section{Chronological and Physiological Age}

When dealing with growing patients, the dentist ought to be aware of whether the child is developmentally advanced, normal, or delayed in relation to the child's chronological age. This is important in orthodontics because it guides 
treatment planning and allows the clinician to monitor the child's overall tempo of development. Population norms provide benchmarks against which the sequence and timing of tooth formation and tooth emergence (clinical eruption) can be gauged. Additionally, dental development is a useful, convenient way for the dentist to evaluate whether a child's growth is appropriate and, quantitatively, how deviant it is. Chronological age (CA) is the same as calendar age. In western cultures, birth is defined as the start of life (age zero), which ignores the prenatal period of roughly 9 months (actually an average of 266 days from conception). Chronological age ignores variations that occur during the gestational time interval. Importantly, CA provides no measure of the rate or tempo of biological maturation - which commonly does not coincide with the child's CA (e.g., Tanner 1962, 1990).

Tanner et al. (1975, p. 1) define biological (or physiological) maturity as the "normal growth process that takes every individual from one common condition of being wholly immature to another of being wholly mature." Referencing a child to developmental "milestones" offers greater accuracy in assessing the degree of maturity as opposed to stature or size comparisons that lack endpoints, except possibly in retrospect when the adult value is known.

An example helps clarify this issue. It is expected that a child's permanent first molars will emerge at six years of age (e.g., Hurme 1949), which gives rise to calling them the "six year molars," but this is just a statistical average. Modally, when children are six years old, they have matured biologically to the point that their first molars emerge into the oral cavity. Graphing the actual ages of emergence, however, shows that even this well-documented average (the "six year" molar) exhibits appreciable variability. Figure 12 is a plot of actual emergence ages obtained from the large longitudinal study of children by Sadakatsu Sato (Sato and Parsons 1990). It is evident that the modal age of emergence is indeed during the sixth year. A few children are developmental quite advanced and achieve this biological maturity marker (tooth emergence) during year 4, and several more children (ca. $15 \%$ for upper M1 and $30 \%$ for lower M1) are developmentally advanced with emergence during year 5 instead of year 6. Conversely, some children (ca. 15\% for lower M1 and 25\% for upper M1) do not experience emergence till year 7 , and a very few are delayed until year 8 .

The concept here is that the rate of development-while poorly understood (e.g., Tanner 1963; Smith 2003; Boughner and Hallgrimsson 2008) - is primarily regulated by the child's genotype (Garn et al. 1960; Hughes et al. 2007) 


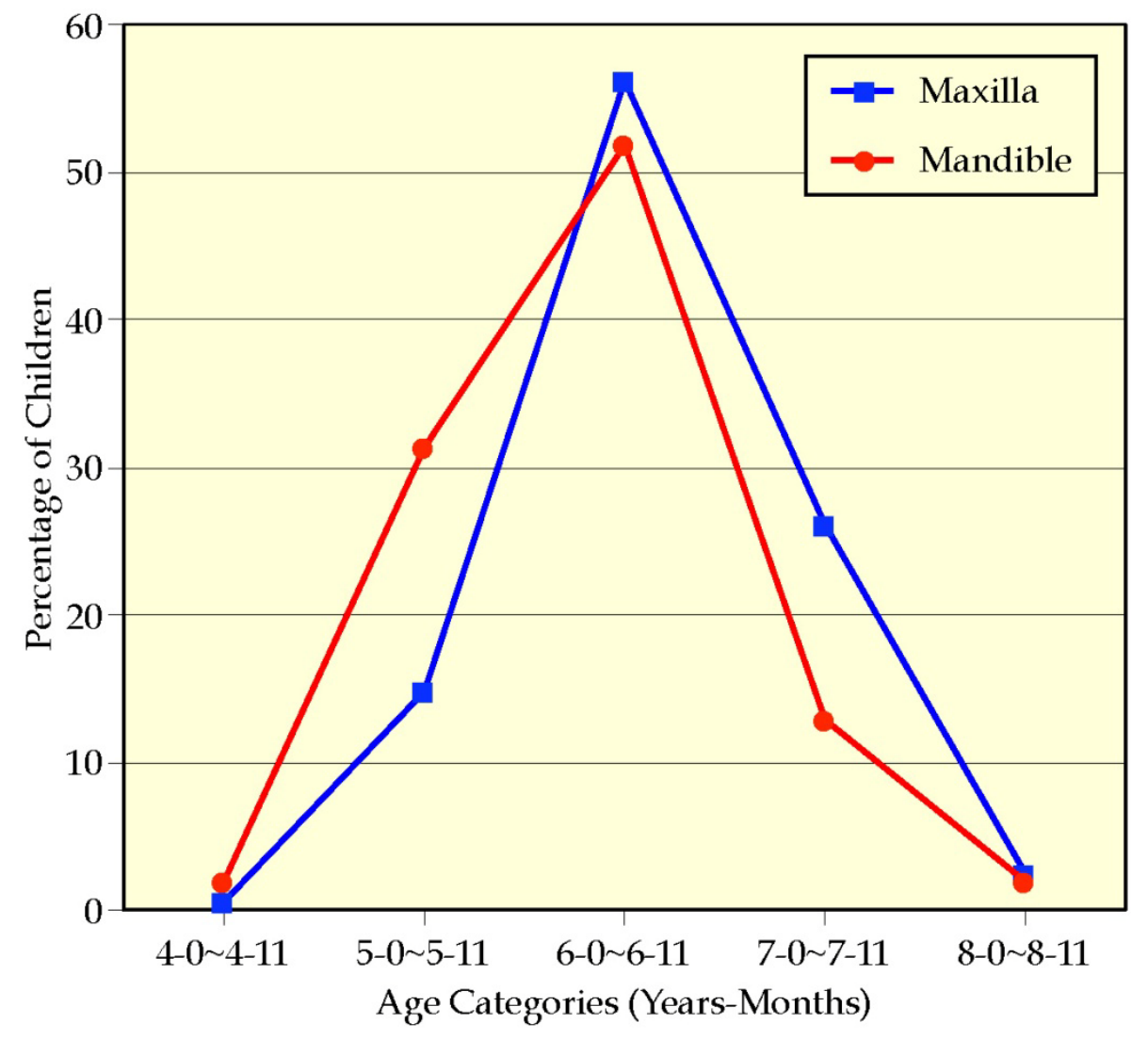

Figure 12. Plot of the distribution of chronological ages at which the permanent first molars emerge in children (sexes pooled). Data are from Sato and Parsons (1990). Chronological ages displayed along the horizontal axis are coded as years-and-months.

Reprinted with permission. Sato S, Parsons P. Eruption of permanent teeth: a color atlas. St. Louis: Ishiyaku EuroAmerica, Inc., 1990, p. 26. 
though it is modified by the environment. Emergence of a tooth is a measure of a child's level of biological development. Children who experience tooth emergence sooner than the average are termed early maturers. Their "dental age" is ahead of their chronological age. Children who experience emergence after the mode are maturing slower than average. All children experience molar eruption, but the pace or tempo of their biological development varies from child to child. This causes some biological measure of maturity, such as bone age or dental age, to be a more accurate estimate of development than calendar age. Biological measures of developmental age provide recognition of the range of normal variation and, thus, a quantitative measure of how deviant a child's development is from the norm.

As an historical aside, most dentists have heard of the publication by Saunders (1837) who presented a plan to the British Parliament to enforce child labor laws that prohibited young children from working in factories. Saunders argued that the status of tooth emergence "could be used for more accurate determination of the actual age of a child, frequently falsified by parents in the exploitation of their children for financial gain" (Fanning 1961, p. 202).

The historically important work of Psyche Cattell (1928) can be mentioned here as an example of the method. Cattell reported on a cross-sectional study of American white school children from an area of Boston, Massachusetts. Figure 13 is a plot of her data of the median number of teeth emerged into the oral cavity assessed against chronological age, divided into 6-month intervals. There are several notable findings here, but we note just two of them. One, sexual dimorphism is evident in these data in that girls exhibit a faster tempo of tooth emergence than boys throughout the age interval studied. Cattell's findings of a sex difference already were well-known at the time (e.g., Röse 1909; Matiegka 1921) but her data make this difference quite evident. The greatest sex differences are at the end of childhood ( $c$ a. 10-11 years in these data) when girls have as much as three more teeth emerged compared to boys. Two, most of the permanent teeth emerge during two rather short intervals within the 10-year span shown in Figure 13. There is an evident steepening in the rates of tooth emergence between about 6 and 8 years and a second from about 10 to 12 years. These two intervals are termed the first and second transitions (van der Linden and Duterloo 1976). These conjugations of emerging teeth detract from the utility of using the number of teeth to estimate dental age because no teeth are emerging during several intervals of a child's development. 


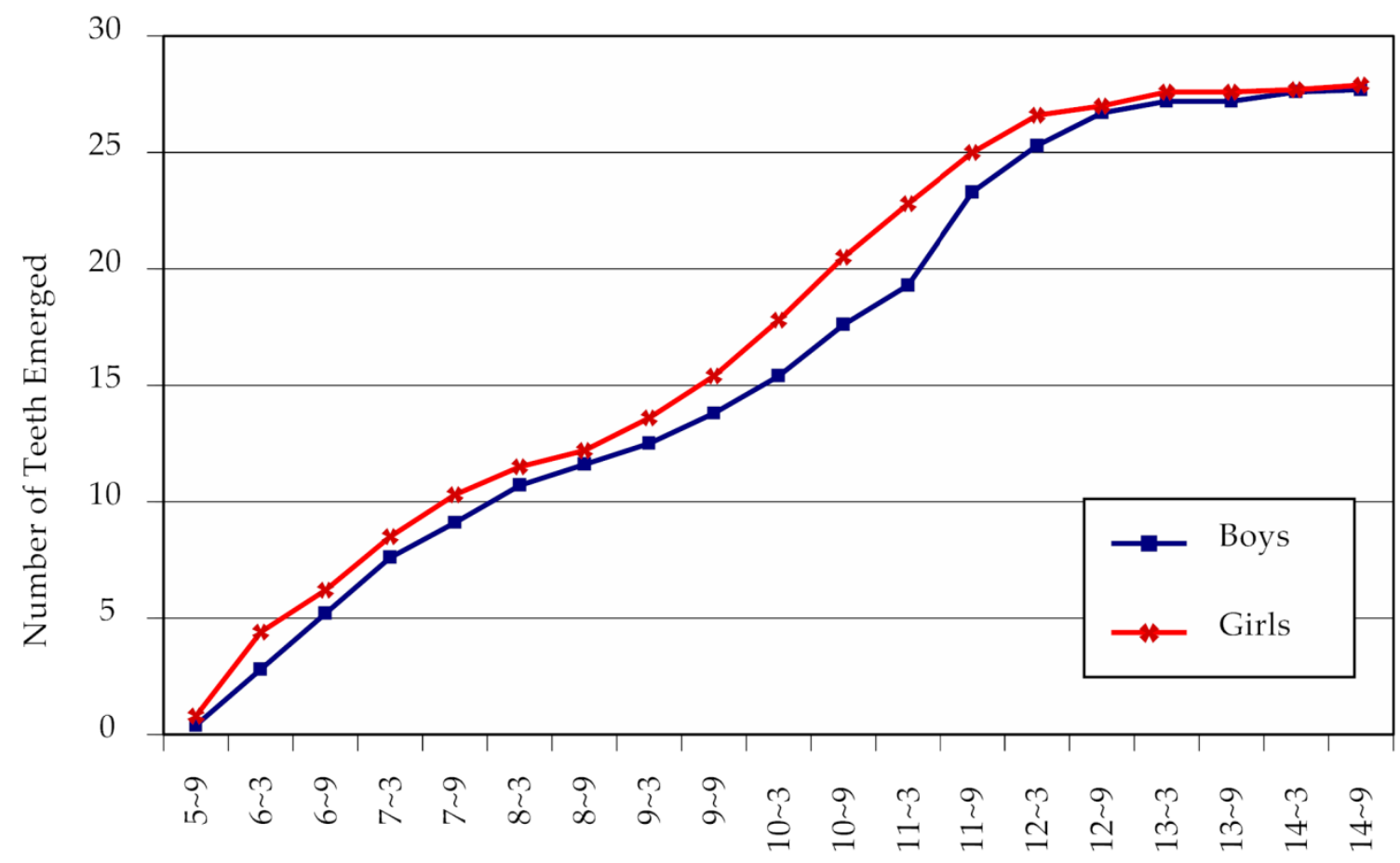

Chronological Age (Years, Months)

Figure 13. The median number of permanent teeth emerged into the oral cavity by chronological age and by sex. Girls are statistically ahead of boys at all ages. Two "spurts" of tooth emergence are evident, one from about 6 to 8 and the other between about 10 and 12. These periods of rapid increases in the number of teeth emerged reflect what van der Linden and Duterloo (1976) term, respectively, the first and second transitions.

Reprinted with permission. Cattell P. Dentition as a measure of maturity. Harvard Monographs in Education. Harvard University Press, 1928, p. 54. 
As discussed below, this same ageing concept is more broadly applicable to tooth formation (i.e., crown-root mineralization) in place of tooth emergence. Formation occurs across a broader age interval and, thus, can be applied more broadly than emergence (e.g., Demirjian 1978; Harris et al. 2010).

Physiological age (or its frequently used synonyms of biological age and developmental age) is an estimate of the status of an individual's level of development (e.g., Krogman 1968a,b,c). It is a more informative measure of maturity than chronological age because physiological age accounts for the differing growth tempos that children undergo. Physiological age is estimated by the maturation of one or more tissue systems, and it is expressed in terms of each system studied (e.g., Moorrees et al. 1963a; Liliequist and Lundberg 1971). Notably the systems do not need to correspond within a child. Lack of correspondence is a complex issue that involves considerations of what ages are studied, whether (and to what degree) the children studied have been stressed (in the sense of Selye 1976), and which tissue systems are analyzed. Perhaps the best-studied example is that hand-wrist bone age and dental age both respond to stressors in the child's environment (e.g., Garn et al. 1965), but bone age is far more susceptible to the environment than tooth development. Put differently, tooth development is much better canalized than the growth of bone (Waddington 1942, 1957).

A child's developmental status can be estimated in several ways and expressed as an age equivalent, such as (1) skeletal age, (2) dental age, (3) morphological age, and (4) secondary sex characteristics age (Steel 1965; Eveleth and Tanner 1990). Of these, skeletal age is the most widely used and most broadly applied method. Skeletal age is a measure of the progress that a complex of bones (such as the hand and wrist) has made towards attaining adult form, typically as recorded radiographically. Skeletal age (bone age) commonly is estimated from a hand-wrist radiograph, though other structures such as the knee (Pyle and Hoerr 1969) or the foot and ankle (Hoerr et al. 1962) can be used. With reference to the hand and wrist, the Greulich and Pyle atlas (1959)-coded as GP2-continues to be the most appropriate reference for children in the United States (Fry 1968). Pyle et al. (1971) provide a simplified version of the GP2 atlas as does Fishman (1987). British children are more accurately evaluated using the Tanner-Whitehouse atlas (Tanner et al. 1975). Of note, there are no published standards for non-whites in the United States, forcing clinicians and researchers to use one of the white-based atlases (e.g., Zhang et al. 2008; Ontell et al. 1996). It has been shown by Tanner et al. (1975) that phenotypically normal boys at the age of 14 may be skeletally advanced or delayed by upwards of two 
years in comparison to their chronological age. Of course, children with growth disorders can show a much broader range (e.g., Garn et al. 1965a,b). The deviation of physiological age from chronological age needs to be taken into account during patient evaluation and treatment planning.

\section{Tooth Eruption}

Tooth eruption is the movement of a tooth from its site of development within the alveolar process to its functional position in the oral cavity (Massler $e t$ al. 1941; Grøn 1962; Smith and Buschang 2010). Developing teeth actually move in all three planes of space and increase in size within the alveolar process prior to active eruption (e.g., Logan and Kronfeld 1933; Carlson 1944).

Tooth eruption is complex, and several mechanisms may be involved (e.g., Steedle and Proffit 1985; Proffit and Frazier-Bowers 2009; Wise 2009). Numerous in vivo animal experiments and human radiographic studies have been conducted to better understand the process of tooth eruption. Although several theories have been advanced, the factors responsible for the eruption of the teeth are not fully understood. Factors that have been related to the eruption of teeth include elongation of the root, forces exerted by the vascular tissues around and beneath the root, growth of the alveolar bone, growth of dentine, growth and pull of the periodontal membrane, hormonal influences, presence of a viable dental follicle, pressure from the muscular action, and resorption of the alveolar crest. The fact that active eruption begins only after crown formation is complete suggests a role of the enamel organ. Gorski et al. (1988) suggest that not only is the enamel organ responsible for amelogenesis, but also for initiating eruption.

At birth, the jaws contain the partially mineralized crowns of all 20 deciduous teeth and the beginning of mineralization of the permanent first molars and some incisors (e.g., Kraus and Jordan 1965; Infante 1974). Eruption of the deciduous dentition, beginning on the average of 7.5 month of age, and terminates on an average of 29 months of age (e.g., Falkner 1957; Friedlaender and Bailit 1969). Dental eruption is then quiescent for nearly 4 years. Beginning around 6 years of age, the 8 deciduous incisors are exfoliated, and 12 permanent teeth erupt within about a two year interval. After this activity, eruption goes into another period of quiescence until around 9 to 10 years of age, when the remaining 12 deciduous teeth are exfoliated, and 16 permanent teeth erupt within a two year period. The 6 year period of the mixed dentition, roughly 6 to 12 years of age, is the most complicated period of dental development and the 
one in which the development of malocclusions is most likely to occur (e.g., van der Linden 1982).

\section{Estimation of Dental Age}

Dental age is of particular interest to dentists since it is based specifically on the development of the teeth. Two main methods have been used to estimate dental age, namely tooth emergence and tooth mineralization. Tooth emergence is easily observed on oral examination. Obtaining a tooth count at an examination and comparing it to appropriate standards estimates the child's dental age. Several group-appropriate standards are available (see review by Liversidge 2003), though the time-honored statistics of Hurme (1948, 1949, 1951) still are commonly cited. Hägg and Taranger (1985) also report reference data on tooth emergence (Figures 14 and 15). These authors support the method as being "simple and convenient," and it is a method that is useful in a cross-sectional examination.

Notably, several intrinsic and environmental factors can alter the emergence of teeth. Eruption has been found to be influenced by local infection, injury, obstruction, crowding, and extraction of primary predecessors (Schroff 1959; Fanning 1962). Premature exfoliation of the primary predecessor may either retard or speed up the eruption of the permanent tooth (Fanning 1962). Ankylosis of a primary tooth can delay the eruption of the permanent successor (e.g., Frank 2000; Sabri 2008).

Demirjian (1978) and others have also pointed out that tooth emergence is only useful during those short childhood periods when teeth actually are emerging into the oral cavity. All 20 primary teeth typically emerge between 6 and 30 months of age, with no new teeth until onset of the mixed dentition at around 6 years of age, followed by a two-year interval of quiescence during the intertransitional phase (van der Linden and Duterloo 1976). The second interval of emergence also lasts about two years, ending with emergence of the second molars at about age 12 .

In contrast, the tempo of tooth mineralization is not affected by the premature loss of the deciduous teeth (Fanning 1962). Mineralization can, however, be affected by all sorts of genetic and environmental issues. One such congenital condition is hypodontia. Hypodontia is the consequence of the congenital absence (failure to form) of one or more teeth (McDonald and Avery 


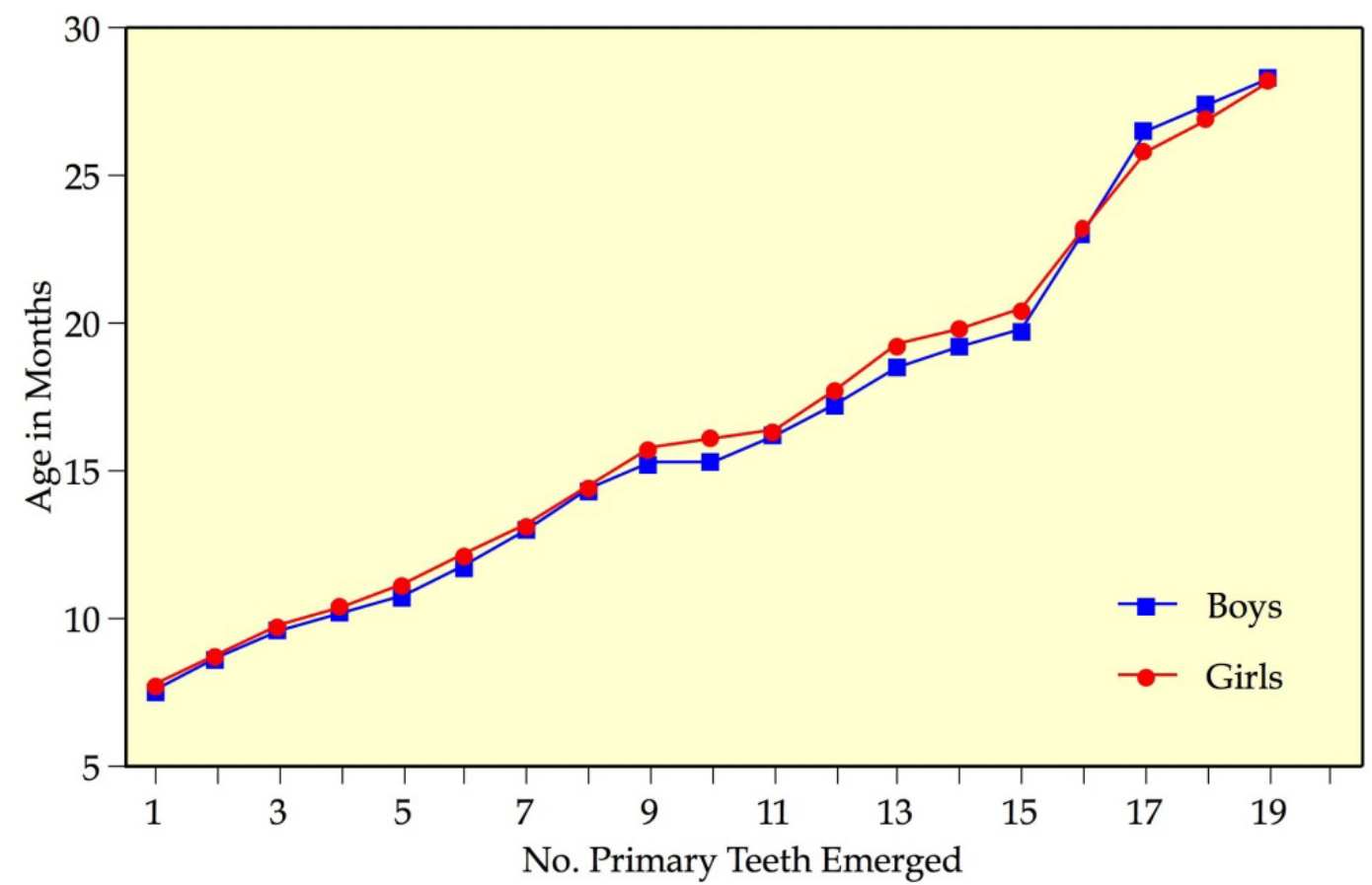

Figure 14. Plot of the number of primary teeth emerged against chronological age (in months). The data are from Swedish children born in the mid-20th century.

Reprinted with permission. Hägg U, Taranger J. Dental development dental age and tooth counts. Angle Orthod 1985;55:93-107. 


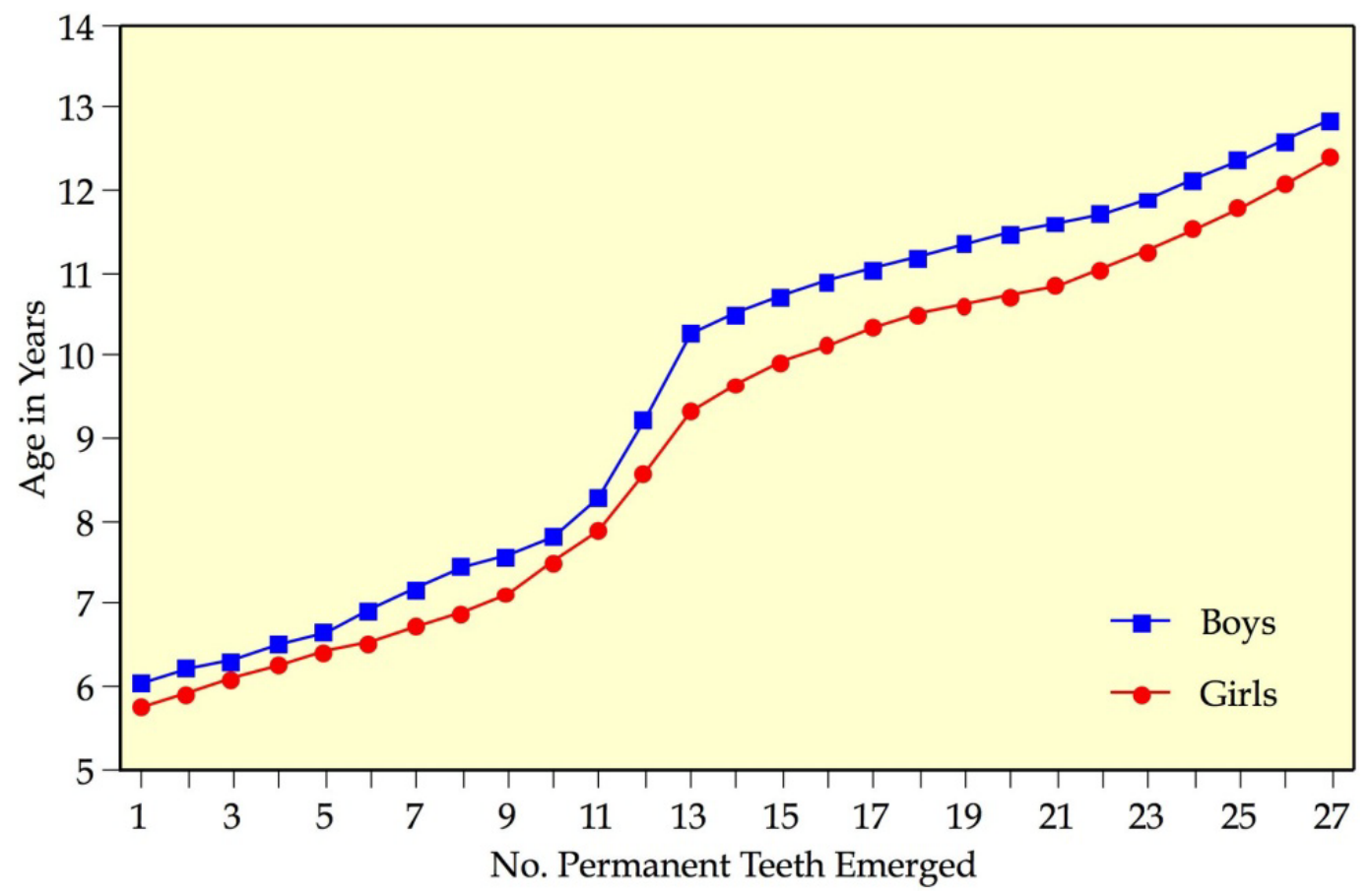

Figure 15. Plot of the number of permanent teeth emerged against chronological age (in years) based on data from Hägg and Taranger (1985).

There is an evident sex difference throughout, with girls temporally ahead of boys. The data are from Swedish children born in the mid-20th century.

Reprinted with permission. Hägg U, Taranger J. Dental development dental age and tooth counts. Angle Orthod 1985;55:93-107. 
1994). Furthermore, hypodontia now is recognized as part of a more complex entity, involving not only aberrations in number, size and shape of the remaining teeth, but also abnormalities in the overall rate of dental development and time of eruption (Brook 1984; Evans 2010). Hypodontia of the mandibular third molar is associated with delayed calcification of P1 and M2 (Garn, Lewis and Bonné 1961). Uslenghi et al. (2006) concluded that "tooth formation in children with hypodontia was significantly delayed compared to the matched group."

Tooth emergence is commonly defined as the penetration of the oral gingival by some part of the tooth crown, however slight, such that part of the crown (normally the mamelons or cusp tip) is visible on intraoral examination, so-called clinical emergence. Other definitions are used, such as eruption coronal to the alveolar margin or emergence into functional occlusion (Harris et al. 2010). In any event, emergence "is a single, fleeting event in the continuous process of tooth eruption; and the chance that the time of inspection coincides with the actual moment of emergence is, as a rule, small" (Fanning 1961, p. 202).

Moorrees et al. (1963a, p. 1490) state that, "tooth formation is superior to tooth emergence for assessing dental maturation, because the majority of teeth can be studied at each examination." Also, since mineralization of the developing teeth is a continuum, starting at crypt formation and ending in the completion of the root apex, it can be used over a much longer period of timefrom birth through adolescence (Demirjian et al. 1973; Demirjian 1978).

Dental age can be assessed by comparing the degree of mineralization that an individual tooth has achieved relative to established developmental stages that a tooth must pass through. For instance, a tooth that has completed crown mineralization but has yet to commence root formation is given one score and a tooth with a closed root apex, another. These scores can then be compared to the expected ages at which the same stages are met in the reference population. The comparison of the child's age to the age expected for their level of maturity indicates whether they are average, advanced, or delayed, as well as the extent of any deviation.

\section{Competing Systems of Grading Mineralization}

A great benefit of clinical radiography is that it is noninvasive; internal structures - such as teeth encased in their bony crypts - can be visualized without harming the structures. Conventional radiography depends on the 
strong attenuation of $\mathrm{x}$-rays by the radiodense minerals in enamel and dentine. Radiographs are useful for monitoring tooth mineralization, which is the progressive process of dentinogenesis and amelogenesis. Predictably (e.g., Logan and Kronfeld 1933; Johanson 1971), the radiographic record of tooth formation lags behind what is occurring histologically ahead of the mineralized stages of tissue formation.

Tooth mineralization is a continuous process. Dentine formation always progresses ahead of enamel formation of the crown, and mineralization only occurs in the coronal-to-apical direction. An obvious approach to assessing the extent of mineralization would be to measure the length of the radiodense portion. This can be done (e.g., Israel and Lewis 1971; Liversidge et al. 1993), but there are several detractions:

- Teeth are three-dimensional objects, so their orientation imaged onto twodimensional film can be distorted.

- Conventional radiographic images are magnified because of variable sourceto-object, object-to-film, and source-to-film distances - and these distances are rarely recorded.

- Films are grainy to one degree or another (even their digital analogs depending on pixel or voxel size), so defining the margins of these small objects involves error-and the apparent margins can be affected by $\mathrm{x}$-ray exposure.

- There is considerable inter-individual variation in final tooth dimensions, and adult size can only be determined after the fact. Sex and race differences also have to be taken into account.

Consequently, millimetric measurements have been avoided. In their place, observers have relied on dividing the formation process into visually distinguishable stages. These anthroposcopic determinations are ordinal scale data, meaning that the stages occur in a known, invariant order, but the stages cannot be assumed to be equally spaced or of equal duration. The number of stages as well as their defining criteria differ considerably among observers, and even though Demirjian (1978) and others have attempted to relate various systems one to another, they are generally not comparable because different criteria are used.

Elizabeth Fanning's work (1960, 1961) is noteworthy because she developed probably the greatest number of formation stages. She defined 20 stages for multi-rooted teeth. The more ambiguous stages were omitted for the 
commonly-referenced study by Moorrees, Fanning and Hunt (1963a), which recognized 13 stages (and 14 for multi-rooted teeth).

The controlling issue is that when numerous stages are used, differences between them are necessarily small and confusion between adjacent grades is more likely. At the other extreme, using just a few stages ensures that the differences between them are clear-cut and obvious, which lessens misrecognition. Conversely, with many stages, the gradations are of shorter duration. Using few stages forces each stage to encompass a greater age interval, which reduces precision of the age estimation. Consider that the permanent teeth begin mineralization at about term delivery and all teeth except the third molars have completed root apexification by about 16 years of age. Consider too that just three stages of formation could be used, such as (1) crown initiation, (2) crown completion, and (3) root completion. At best, then, each stage would encompass a few years (and more for root formation than crown formation). The "dental age" of a subject could, then, only be assigned to a few broad age intervals. Partitioning formation into more stages creates smaller, more precise age intervals. The "tension" in developing a staging system is (A) to develop a classification that uses several stages to enhance precision but (B) restrain the number of stages to reduce mis-recognition.

Different developmental stages have been defined by different authors (reviewed in Demirjian 1978). Stages are defined by distinguishing shape characteristics, from the beginning of calcification through the final level of root maturation. The earliest study to assess dental maturity radiographically was by Hess, Lewis and Roman (1932). They evaluated the physiological maturity of children based on permanent tooth formation. Hess et al. (1932, p. 1058) concluded that, based on anatomical as well as radiographic studies, "the major calcification even of the deciduous teeth takes place subsequent rather than previous to birth and that in regard to the first permanent molars, that calcification must be regarded as a postnatal phenomenon."

Numerous classification systems have been proposed. Nolla (1960) divided the continuum into 11 stages (Figure 16). One of the more commonly cited method is that of Moorrees, Fanning and Hunt (1963a). Moorrees et al. recognized 13 successive stages of tooth mineralization for single-rooted teeth and 14 stages for molars (Figure 17). Moorrees et al. (1963a) outlined 5 factors that may affect the assessment of dental maturation: (1) the applicability of these data to which the population that a child belongs; (2) variations in the rate of development of different teeth in an individual child; (3) the experience of the 


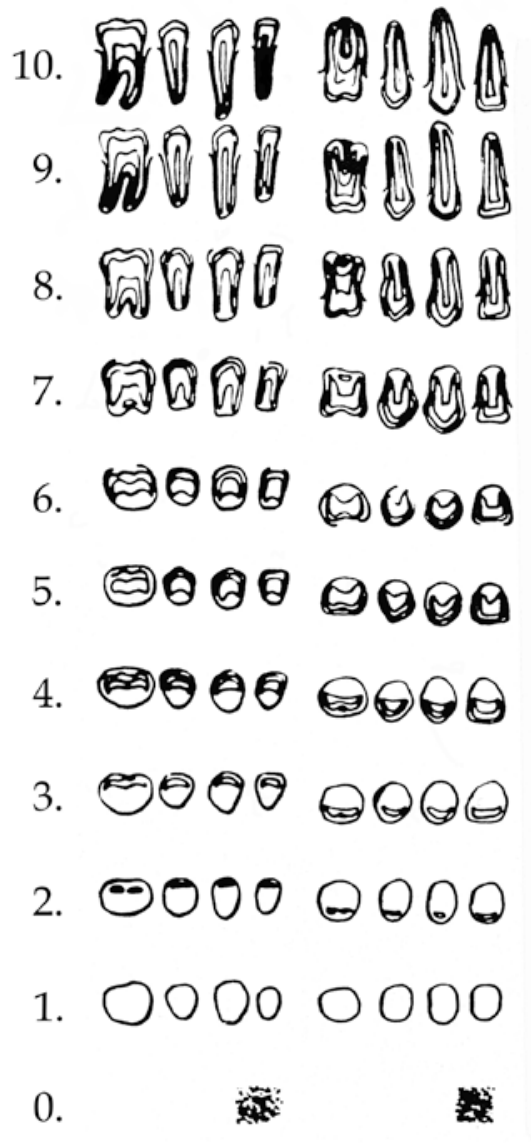

Figure 16. Illustration of the $\mathbf{1 1}$ tooth mineralization stages defined by Nolla (1960). The stages are given numeric values progressing from absence of crypt formation (0) through root apex closure (10). Each row in the diagram depicts mandibular (left) and maxillary (right) examples of each tooth type (molar, premolar, canine, and incisor).

$\begin{array}{ll}0 & \text { Absence of crypt } \\ 1 & \text { Presence of crypt } \\ 2 & \text { Cusps calcified } \\ 3 & \text { Crown } 1 / 3 \text { complete } \\ 4 & \text { Crown } 2 / 3 \text { complete } \\ 5 & \text { Crown almost complete }\end{array}$

6 Crown complete

7 Root $1 / 3$ complete

8 Root $2 / 3$ complete

9 Root complete, apex open

10 Root complete, apex closed

Reprinted with permission. Nolla CM. Development of the permanent teeth. J Dent Child 1960;27:254-66. 
Single-Rooted Teeth

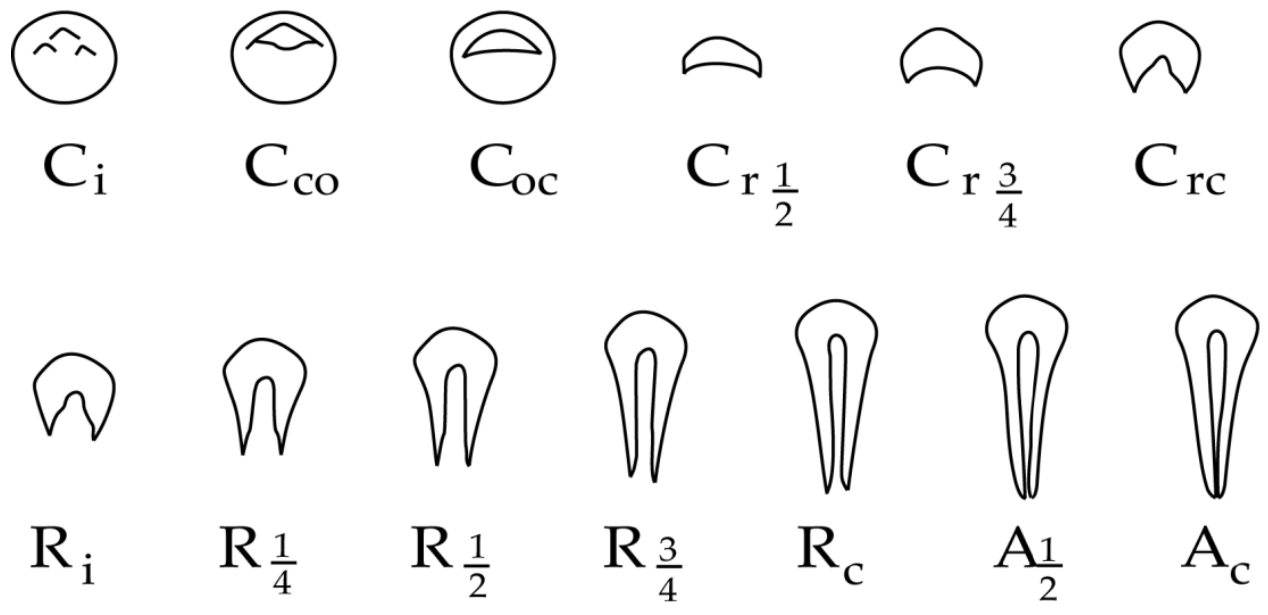

Multi-Rooted Teeth
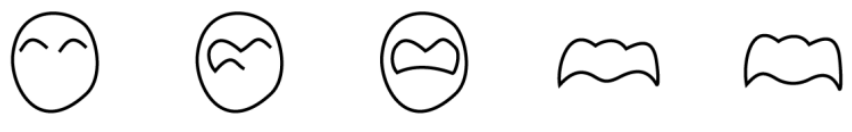

$m$<smiles>C1=CCCCCC1</smiles><smiles>[AlH2]</smiles>

$\mathrm{C}_{\mathrm{co}}$

$\mathrm{C}_{\mathrm{OC}}$

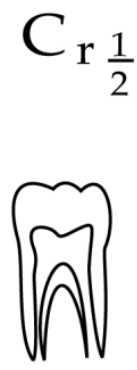

$C_{r \frac{3}{4}}$

$C_{\text {rc }}$

$\mathrm{R}_{\mathrm{i}}$<smiles>C1CCC2CCCCC2C1</smiles><smiles>C1CCCCC1</smiles><smiles>C=CCCCCCCC</smiles>
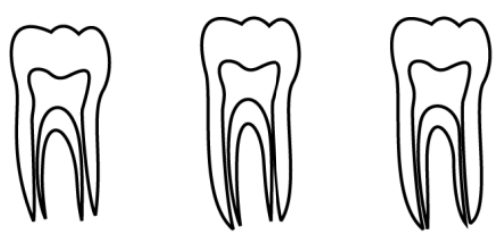

$\mathrm{Cl}_{\mathrm{i}} \mathrm{R}_{\frac{1}{4}}$

$\mathrm{R}_{\frac{1}{2}}$

$R_{\frac{3}{4}}$

$\mathrm{R}_{\mathrm{c}}$

$\mathrm{A}_{1}$

$\mathrm{A}_{\mathrm{C}}$

Figure 17. Schematic drawings of the stages of tooth mineralization used by Moorrees, Fanning and Hunt (1963a). There are 13 stages for single-rooted teeth and 14 stages for multi-rooted teeth, the difference is the addition of cleft initiation for the multi-rooted molars. Diagram supplied by E. F. Harris.

Reprinted with permission. Moorrees CFA, Fanning EA, Hunt EE Jr. Age variation of formation stages for ten permanent teeth. J Dent Res 1963a;42:14901502. 
rater in recognizing sequential stages of tooth formation; (4) the availability of earlier or later records of the same child to serve as a basis of reference when rating tooth development; and (5) the span of time between the occurrence of one stage of development and the next.

Haavikko (1970) simplified the Moorrees system to 11 grades by eliminating those that seemed hard to distinguish. Her system is illustrated in (Figure 18).

Liliequist and Lundberg (1971) proposed another system for scoring the extent of crown-root mineralization. They conducted a longitudinal study of 287 children based on the radiographic assessment of the mandibular teeth (excluding third molars) and the maxillary anterior teeth. The classification scheme consists of 8 stages of development between the non-mineralized crown (tooth crypt) and the completion of mineralized root development. As an aside, the Liliequist and Lundberg study is an example where the authors mistook the numerical labels of the stages as actually signifying quantitative data. They treated the numbers of the stages (Figure 19) as if they were ratio-side data, ignoring the ordinal-grade nature of the morphologically-defined stages. This is one reason that Demirjian and coworkers were so conscientious about labeling their mineralization stages using letters rather than numerals.

Demirjian et al. (1973) and others have criticized methods that are based on absolute sizes of root length, which make it difficult to apply the systems in the absence of longitudinal data. For example, labeling a root as "half formed" presumes that the researcher has rather precise information about that root's final length, which is hardly likely. Demirjian et al. proposed an 8-grade scoring system for the dentition that parallels the methodology developed by Tanner and coworkers (1975) that used hand-wrist radiographs (Figure 20). The system avoids the use of absolute measurements of anticipated adult crown and root lengths. Demirjian et al. (1973) contend that a useful maturity scale must be composed of easily recognizable stages that all teeth must pass through. They state that since stages are indicators of maturity and not of size, they should not be defined by any absolute dimension. Their resulting classification is based on the visual assessments of morphological criteria, such as the amount of dentine deposit, shape of the pulp chamber, and other distinguishable criteria.

The research of Gustafson and Koch (1974) merits mention here. Although they compiled and synthesized prior reports rather than describing new data, they developed a chart that has received wide use, especially by 
Single-Rooted Teeth

(2)

Multi-Rooted Teeth

(2)

Figure 18. Illustrations of the 11 stages used by Haavikko (1970) to score tooth formation. The stages are different for single-rooted teeth (top) and multi-rooted teeth (bottom). Diagram supplied by E. F. Harris.

Reprinted with permission. Haavikko K. The formation and the alveolar and clinical eruption of the permanent teeth: an orthopantomographic study. Proc Finn Dent Soc 1970;66:103-70. 


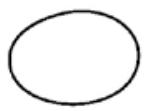

0

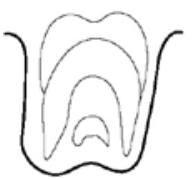

3

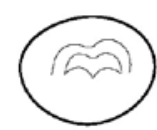

0.5

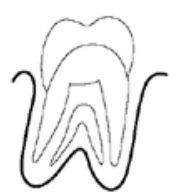

4

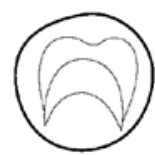

1

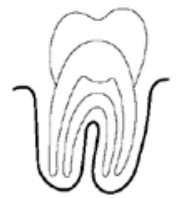

5

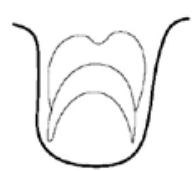

2

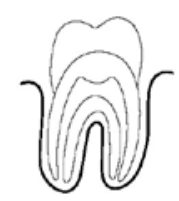

6

Figure 19. Sketches of the seven stages of tooth mineralization used by Liliequist and Lundberg (1971). Grades were assigned numeric labels:

0 Presence of crypt, no crown calcification

0.5 Crown $1 / 2$ complete

1 Crown complete

2 Root length less than crown height

3 Root length about equal to crown height

$4 \quad$ Root tapered (pointed)

5 Root longer than crown; apex rounded

6 Root complete

Reprinted with permission. Liliequist B, Lundbert M. Skeletal and tooth development: a methodologic investigation. Acta Radiol 1971;11:97-112. 


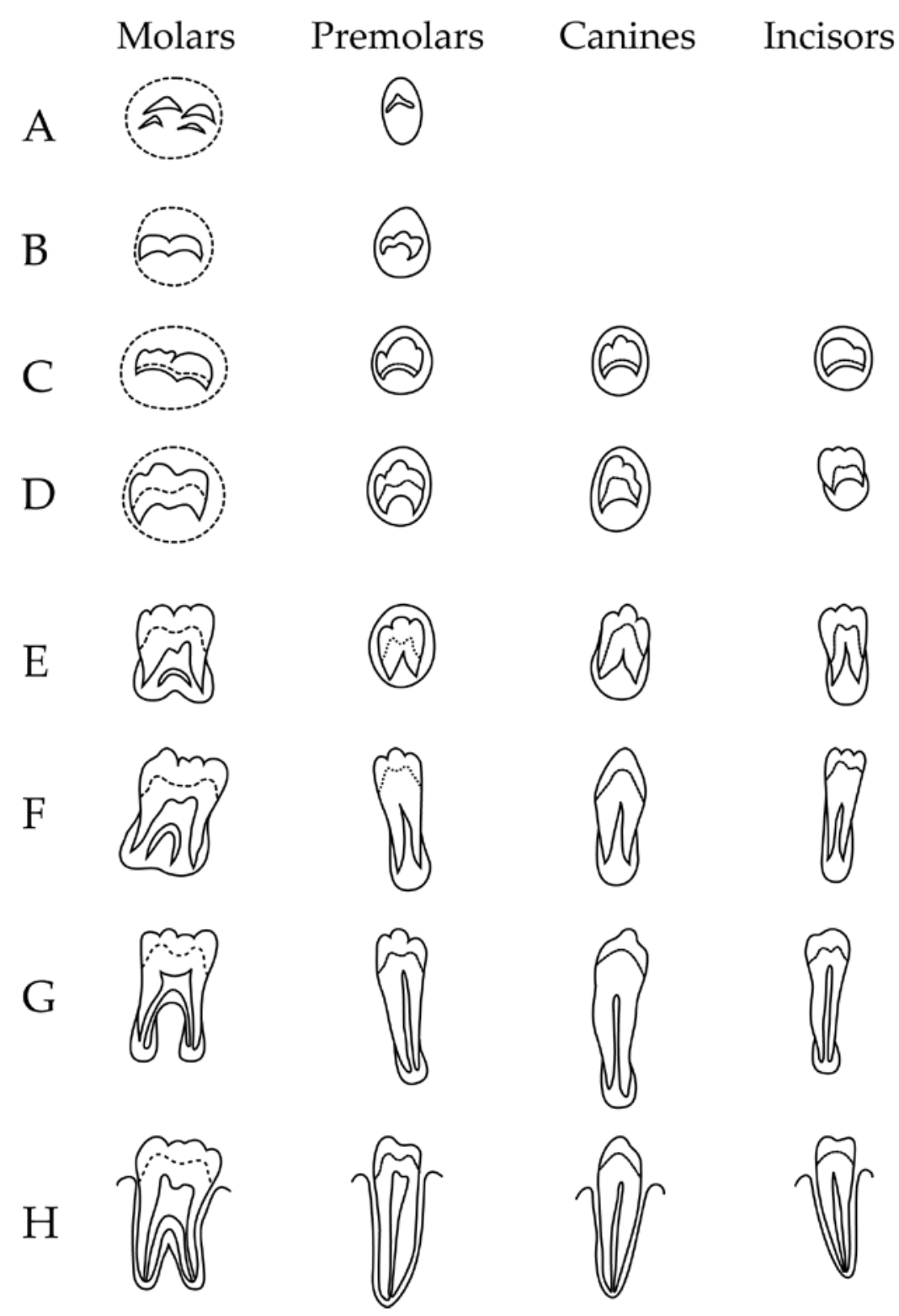

Figure 20. Sketches of the seven stages of tooth mineralization used by Liliequist and Lundberg (1971). The authors were careful to use letters to label tooth stages in order to avoid any suggestion that the ordinal grades are equidistant. Diagram supplied by E. F. Harris.

Reprinted with permission. Demirjian A, Goldstein H, Tanner JM. A new system of dental age assessment. Hum Biol 1973;45:220. 
forensic odontologists. The chart depicts just four stages of tooth development, namely (1) the initiation of mineralization, (2) the completion of crown mineralization, (3) the gingival emergence of the tooth, and (4) completion of the root (apexification). Their chart depicts the range and modal ages of each of the four stages. Data for 24 tooth types are plotted, namely all 10 primary teeth and the 14 permanent tooth types (omitting third molars). The chart provides a handy one-page summary of key developmental stages, and, again, it has seen widespread use. Limitations are that (A) the data combine biological and histological data that actually reflect different events, (B) sexual dimorphism is ignored, and (C) the data are compiled from "whites" but uses samples drawn from Europe, Great Britain, and the United States.

\section{Tooth Development and Mineralization}

Teeth are derived from two of the primary germ layers, ectoderm and mesoderm, with a neural crest contribution. The enamel of the teeth is derived from oral ectoderm. Ectomesenchyme provides material for the dentine and pulp, and mesoderm forms the cementum and the periodontal complex (e.g., Corliss 1976; Avery 1994).

Ten enamel organs, corresponding with the number of deciduous teeth, initially develop in each jaw. The dental papilla, of neural crest origin, and the dental follicle, of mesodermal origin, are the anlagen of the dental pulp and periodontal tissue complex, respectively (Osborn and Ten Cate 1976).

Each enamel organ alters its initially small bud shape by enlarging and flattening out as a result of disproportionate mitosis of the basal cells into a cap shape, and later cupping into a large bell shape (Figure 21). Concomitant with these morphological alterations, histodifferentiation occurs within the enamel organ. Its external layer forms the outer enamel epithelium, which is a layer of cuboidal cells subjacent to the developing follicle. The stellate reticulum, composed of stellate cells in a fluid matrix, constitutes the central bulk of the early enamel organ. The inner layer lining the dental papilla forms the inner enamel epithelium, part of which differentiates into the secretory columnar ameloblasts responsible for enamel formation. The recurrent continuity of the inner and outer enamel epithelia at the cervical loop elongates into Hertwig's epithelial root sheath, which will form the root(s) of the tooth (Osborn and Ten Cate 1976). 

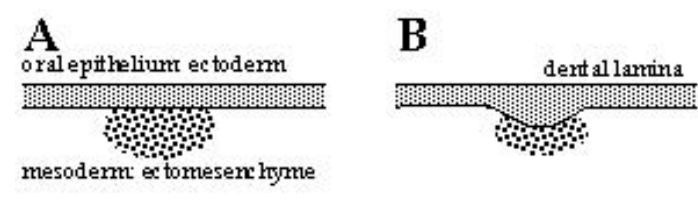

C
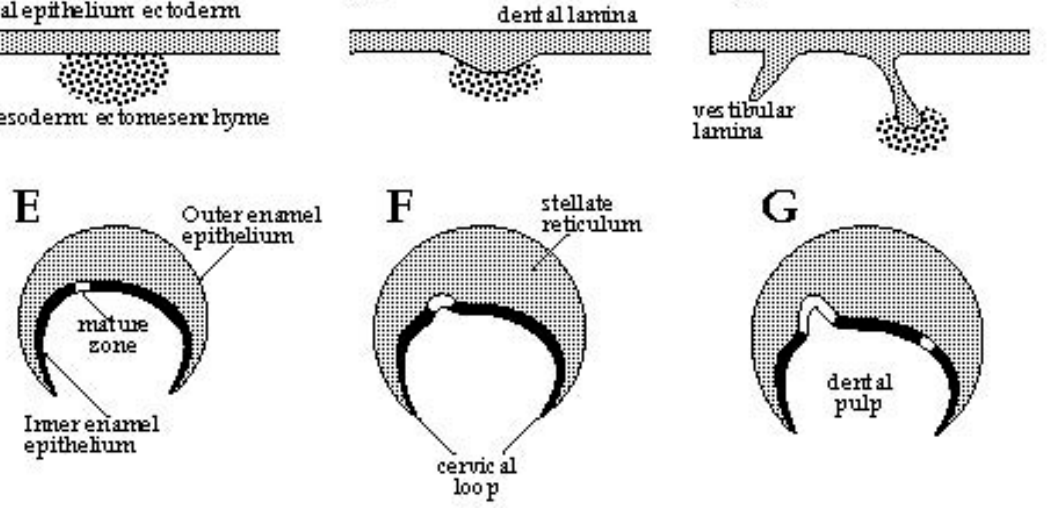

D
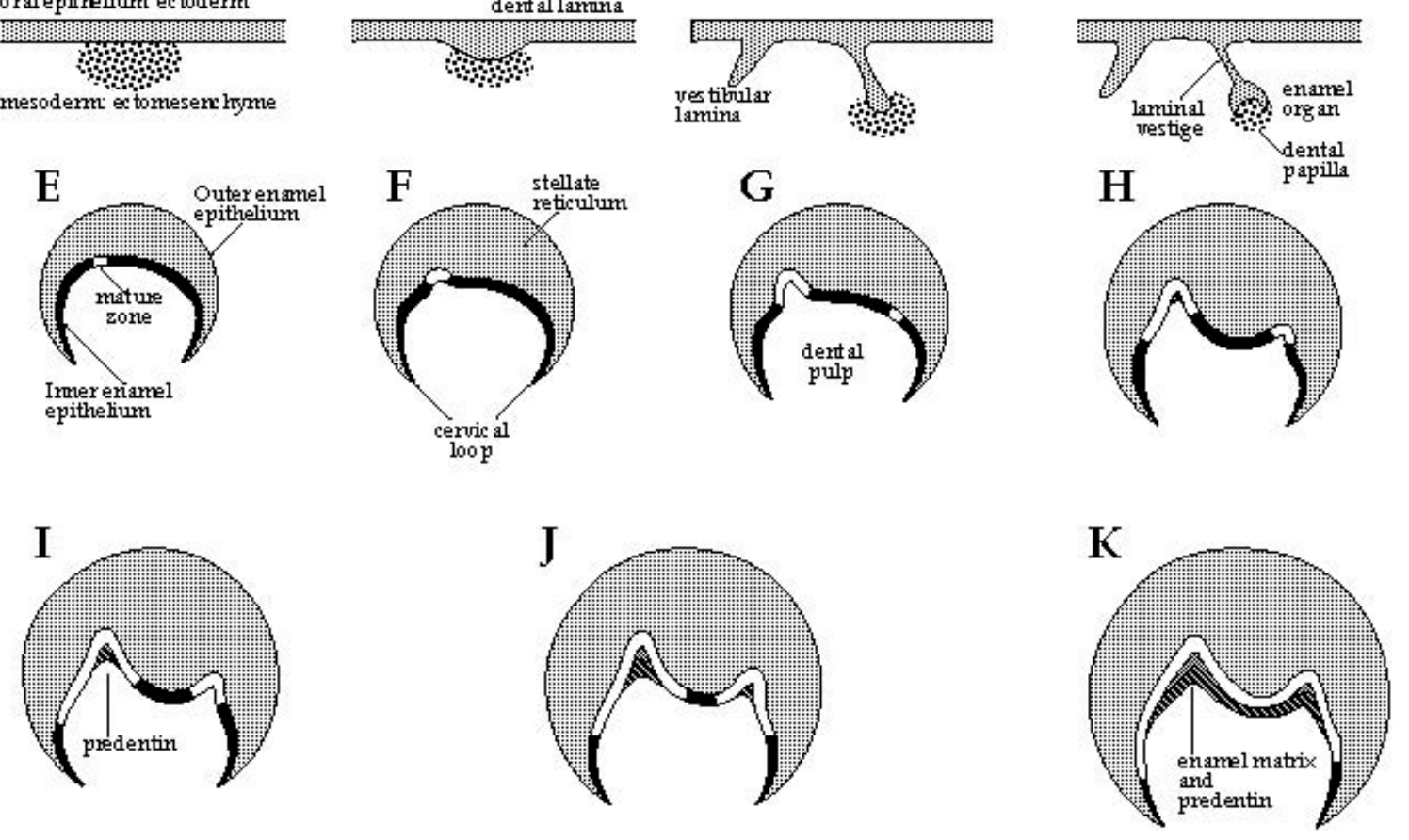

Figure 21. Schematic stages of tooth formation: A. Teeth are derived from ectoderm and ectomesenchyme.

B. Formation of the primary dental lamina (bud stage). C. Proliferation of dental lamina. D-F. Formation of enamel organ and dental papilla (cap stage). G-K. Cap continues to enlarge and then becomes more bell shaped until final tooth shape is determined (bell stage).

Reprinted with permission. Harris EF. Dental development and anomalies in craniosynostosis and facial clefting. In: Mooney MP, Siegel MI, editors. Understanding craniofacial anomalies: The etiopathogenesis of craniosynostosis and facial clefting. New York: John Wiley-Liss, 2002, pp 425-67. 
The inner enamel epithelium (IEE) interacts with the ectomesenchymal cells of the dental papilla to differentiate the peripheral cells of the papilla into odontoblasts. Formation of dentine by the odontoblasts proceeds, and dentine is necessary for the further induction of ameloblasts to produce enamel. The IEE of the root sheath induces odontoblast formation, but, lacking a stratum intermedium, the IEE fails to differentiate into enamel-forming ameloblasts, which explains the absence of enamel on tooth roots. Instead, the outer enamel epithelium of the root sheath induces cementum formation in the adjacent portions of the dental follicle (Osborn and Ten Cate 1976).

The ameloblasts of the IEE lying adjacent to the odontoblasts together form a double-layered amelodentinal membrane (Osborn and Ten Cate 1976). This amelodentinal membrane provides the blueprint for the future shape of crown of the tooth, which is elaborated on by the subsequent deposition of enamel and dentine in opposite directions against this junctional membrane. The ameloblasts secrete enamel rods or prisms as they grow away from the membrane, while the odontoblasts organize the matrix of the dental papilla into predentine, which later mineralizes into dentine. Enamel formation is restricted to the preeruptive phase of odontogenesis and is terminated by the deposition of an organic layer, the primary enamel cuticle. The stellate reticulum disappears, and the inner and outer enamel epithelium come together to form the reduced enamel epithelium. It is this reduced enamel epithelium that fuses with the overlying oral mucous membrane to initiate the pathway for eruption (Osborn and Ten Cate 1976).

\section{Sex Differences in Tempos of Maturation}

Sexual differences in the dental maturation process have been well documented in the literature. The female precedence of faster tempos of tooth mineralization and emergence as compared to boys has become common knowledge (e.g., Cattell 1928; Hurme 1949; Stones et al. 1951; Liversidge 2003). It is intuitive that tooth mineralization would likewise show a female precedence since eruption is tied to formation (Bradley 1961; Grøn 1962), and early radiographic studies of tooth mineralization confirm sexual dimorphism in the tempos of tooth formation (e.g., Garn et al. 1958; Moorrees et al. 1963a; Haavikko 1970; Anderson et al. 1975). As a statistical average, girls achieve maturity stages at earlier chronological ages than boys. The actual amount of the male-female difference varies by tooth type and among populations (which suggests a genetic influence in the magnitude of the sex difference). 
This sex difference increases with age, and a difference often is hard to detect in infants and children. Indeed, it still is contentious whether eruption of the primary teeth is sexually dimorphic - probably because the nature and extent of the sex difference differ by population and by age interval (e.g., Infante 1974). The careful compilation of studies by Meredith (1946) found only a slight precedence in boys. Tanguay et al. (1984) found a highly significant difference, also with a male precedence, but only when applying multivariate statistics.

Sexual dimorphism in the permanent dentition is more obvious, with a female precedence throughout most of childhood (e.g., Stones et al. 1951; Moorrees et al. 1963a,b; Haavikko 1970). However, in the later stages of adolescence, the accelerating effects of anabolic steroids appear to enhance the attainment of some late features in boys. Specifically, the late forming third molar often exhibits male precedence in formation (e.g., Rantanen 1967; Harris 2007). Garn and coworkers (1958) found that, with regard to mineralization of permanent teeth, females are more advanced than males, with the greatest difference occurring in development of the canines. Hotz et al. (1959) found that females were more advanced than males by an average of 4 to 5 months, again with the canines exhibiting the greatest difference. Nolla (1960) and Anderson et al. (1975) both found that females had a faster tempo of tooth development than males for most stages of mineralization, except the later stages of third molar formation. 


\section{CHAPTER 3. MATERIALS AND METHODS}

Clinical materials were collected from the graduate program of the Department of Orthodontics at the Health Science Center, University of Tennessee, Memphis. In addition to simple demographic data (sex, birth date, clinical exam date), tooth maturation data were collected from one panoramic radiograph per person. Data from a total of 400 usable cases was obtained. Two cohorts were constructed of 200 patients each (100 males, 100 females), one cohort evaluated between 1980 and 1985 and the other between 2005 and 2010. Selected cases are American whites by self-identification, and all cases are between the chronological ages of 10.0 and 15.0 years of age. Cases have a negative significant medical history. Children with syndromes, cleft lip and/or palate and hypodontia (expect third molars) were excluded from the study. HIPAA authorization for the conduct of the study itself was approved. This study was also approved by the institutional review board, reference number 1101268-XM.

\section{Dental Age Determinations}

The investigators collected mineralization data on the eight mandibular tooth types by visually evaluating the panoramic radiographs using the standards described in Demirjian et al. (1973) as illustrated in Figure 20. Just the pretreatment x-ray of the subject was used. Observations were entered directly into an Excel $^{\circledR}$ spreadsheet (Microsoft Corporation, Redmond, WA). For each film, the clearer quadrant was used for scoring or, if there was no difference, the left side of the film was used. No study has found a systematic left or right precedence of tooth formation (reviewed in Demirjian 1978). All eight tooth types were given a letter grade of $\mathrm{A}$ through $\mathrm{H}$ based on the criteria set forth by Demirjian et al. (1973). Written criteria for each grade are listed in Table 1.

Four two-digit codes were used to denote teeth not capable of being scored. These are as follows: crypt formation but no crown mineralization (code 66), congenital absence or crypt not yet formed (code 77), tooth extracted or avulsed (code 88), and tooth present but not scorable due to poor film quality (code 99). These codes were treated in the analyses as missing values. One important issue for data collection is that only the highest score a given tooth has fully attained was recorded (Dahlberg and Menegaz-Bock 1958) and, thus, no interpolation or estimation of the "closest" grade was employed. 
Table 1. Descriptions of the eight stages used by Demirjian et al. (1973).

\begin{tabular}{l} 
Stage \\
\hline A Initial calcification is at the superior level of the crypt in the form of an \\
inverted cone or cones. There is no fusion of these calcified points. \\
B Fusion of the calcified points forms one or several cusps that unite to \\
give a regularly outlined occlusal surface. \\
a. Enamel formation is complete at the occlusal surface. Its \\
extension and convergence towards the cervical region is seen. \\
b. Beginning of dentinal deposit is seen. \\
c. Outline of pulp chamber has a curved shape at the occlusal \\
border. \\
a. The crown formation is completed down to the cementoenamel \\
junction. \\
b. The superior border of the pulp chamber in uniradicular teeth has \\
a definite curved form, being concave towards the cervical region. \\
Projection of the pulp horns is present, gives an outline shaped \\
like an umbrella top. In molars, the pulp chamber has a \\
trapezoidal form. \\
c. Beginning of root formation is seen in the form of a spicule.
\end{tabular}

a. The walls of the pulp chamber now form straight lines, whose continuity is broken by the presence of the pulp horn, which is larger than in the previous stage

b. The root length is less than the crown height.

Molars

a. Initial formation of the radicular bifurcation is seen in the form of either a calcified point or a semi-lunar shape.

b. The root length is still less than the crown height.

F Uniradicular Teeth

a. Pulp chamber walls form an isosceles triangle; apex is funnel shape.

b. Root length is equal to or greater than the crown height. Molars

a. The calcified region of the bifurcation has developed further down from its semi-lunar stage to give the roots a more definite and distinct outline with a funnel shaped endings.

b. Root length is equal to or greater than the crown height.

\section{Continued}


Table 1. Continued.

\begin{tabular}{|c|c|}
\hline Stage & Definition \\
\hline $\mathrm{G}$ & $\begin{array}{l}\text { a. Walls of the root canal are now parallel and its apical end is still } \\
\text { partially open (distal root in molars). }\end{array}$ \\
\hline $\mathbf{H}$ & $\begin{array}{l}\text { a. Apex of root canal is completely closed (distal root in molars). } \\
\text { b. Periodontal membrane has uniform width around the root and } \\
\text { apex. }\end{array}$ \\
\hline
\end{tabular}

Reprinted with permission. Demirjian A, Goldstein H, Tanner JM. A new system of dental age assessment. Hum Biol 1973;45:221-26.

\section{Estimating Dental Age}

It is useful to explicitly describe how the Demirjian dental ages are estimated: We had access to one panoramic radiograph per person (a crosssectional study). The stage of mineralization of each of the eight mandibular tooth types was scored as described, irrespective of quadrant. Prior studies show that there is no systematic left-right side bias in tooth development (e.g., Lysell et al. 1969; Krumholt et al. 1971). The tooth with a clearer radiographic image, in either the left or right quadrant, was scored using one of nine stages described by Demirjian et al. (1973); these are 0 (for crypt formation without any sign of tooth mineralization) and eight stages of crown-root formation, coded as A through $\mathrm{H}$ (Figure 20; Table 1). The mandibular third molars are not used in this system, but were scored here for completeness.

Demirjian, Goldstein and Tanner (1973) use a multiple linear regression technique without an intercept to estimate a subject's dental maturity score. The format is:

$$
\text { Score }=\mathrm{C}_{1}(\mathrm{I} 1)+\mathrm{C}_{2}(\mathrm{I} 2)+\mathrm{C}_{3}(\mathrm{C})+\mathrm{C}_{4}(\mathrm{P} 1)+\mathrm{C}_{5}(\mathrm{P} 2)+\mathrm{C}_{6}(\mathrm{M} 1)+\mathrm{C}_{7}(\mathrm{M} 2)
$$

where the sex-specific weighting coefficients are provided by these authors in a table (reproduced in Table 2). There is a numeric weighting coefficient for each stage of each tooth in each sex. For each of the seven tooth types, the sexappropriate weighting coefficient is found in the table for each stage of formation, and these are used in the equation above to determine a score that has been scaled to range from 0 to 100 . These scores have a sigmoid pattern that is 
Table 2. The sex-specific weighting coefficients developed by Demirjian et al. (1973).

\begin{tabular}{rllllrrrrr}
\hline Tooth & 0 & A & B & C & D & E & F & G & H \\
\hline & & & & \multicolumn{7}{c}{ Boys } & & & & \\
I1 & -- & -- & -- & -- & 0.0 & 1.9 & 4.1 & 8.2 & 11.8 \\
I2 & -- & -- & -- & 0.0 & 3.2 & 5.2 & 7.8 & 11.7 & 13.7 \\
C & -- & -- & -- & 0.0 & 3.5 & 7.9 & 10.0 & 11.0 & 11.9 \\
P1 & -- & -- & 0.0 & 3.4 & 7.0 & 11.0 & 12.3 & 12.7 & 13.5 \\
P2 & 0.0 & 1.7 & 3.1 & 5.4 & 9.7 & 12.0 & 12.8 & 13.2 & 14.4 \\
M1 & -- & -- & -- & 0.0 & 8.0 & 9.6 & 12.3 & 17.0 & 19.3 \\
M2 & 0.0 & 2.1 & 3.5 & 5.9 & 10.1 & 12.5 & 13.2 & 13.6 & 15.4 \\
& & & & & Girls & & & & \\
I1 & -- & -- & -- & -- & 0.0 & 2.4 & 5.1 & 9.3 & 12.9 \\
I2 & -- & -- & -- & 0.0 & 3.2 & 5.6 & 8.0 & 12.2 & 14.2 \\
C & -- & -- & -- & 0.0 & 3.8 & 7.3 & 10.3 & 11.6 & 12.4 \\
P1 & -- & -- & 0.0 & 3.7 & 7.5 & 11.8 & 13.1 & 13.4 & 14.1 \\
P2 & 0.0 & 1.8 & 3.4 & 6.5 & 10.6 & 12.7 & 13.5 & 13.8 & 14.6 \\
M1 & -- & -- & -- & 0.0 & 4.5 & 6.2 & 9.0 & 14.0 & 16.2 \\
M2 & 0.0 & 2.7 & 3.9 & 6.9 & 11.1 & 13.5 & 14.2 & 14.5 & 15.6 \\
\hline
\end{tabular}

Tooth codes are: central incisor (I1), lateral incisor (I2), canine (C), first premolar (P1), second premolar (P2), first molar (M1), and second molar (M2). Stage 0 indicates bony crypt formation but with no tooth mineralization.

Reprinted with permission. Demirjian A, Goldstein H, Tanner JM. A new system of dental age assessment. Hum Biol 1973;45:222. 
different for boys and girls (Figure 22). These scaled scores have corresponding dental ages ranging from 3 to 16 years of age. Demirjian et al. structured the scales so they range, in effect, from very immature at 3.0 years of age up to complete dental maturity at 16.0 years of age. In other words, the system was explicitly developed such that 3.0 is artificially set to the start of dental maturation ( $0 \%$ maturity) and 16 is set to the end of dental maturation $(100 \%$ maturity). (In practice, then, the system is not applicable to children less than 3 years of age.) These scales are reproduced here in Table 3 (boys) and Table 4 (girls). When the maturity score is obtained from the equation above, one examines the sex-appropriate table. Finding the maturity score provides the corresponding dental age. For example, if the score for a boy is 93.5, expectation is that his dental age is 11.7 years.

A useful way of conceptualizing "dental maturity" is on a percentage basis. In Demirjian's system, $0 \%$ maturity is set at 3 years of age, which is about as young as children are comfortable having a panoramic radiograph taken. Percent maturity then rises as the child develops, achieving $100 \%$ at 16 years of age when all 28 teeth (excluding third molars) have completed formation. Using this metric, a child's developmental progress towards dental maturity can be gauged quantitatively, moving from complete "immaturity" to complete "maturity." All people pass through these developmental stages, and the tempo of development is a measure of the speed of their progress compared to chronological age.

The sequence of steps is, then, (A) score tooth stages, (B) identify appropriate weighting coefficients for those stages, (C) calculate the dental maturity score, and (D) use this score to identify the associated dental age. These ages, of course, are based on the tempos of dental maturation that occurred in the French Canadian children (Centre de Recherché sur la Croissance Humaine at the University of Montreal) used by Demirjian and his coworkers to develop the maturity curves.

\section{A Worked Example}

Suppose the panoramic radiograph of a young white boy was taken when he was 7.23 years old (so $C A=7.23$ years). Crown-root formation stages were assigned to his 7 mandibular teeth. These weighting coefficients are provided in Demirjian et al. (1973, their Table 2) and are reproduced here as Table 3. The procedure is to use the part of the table for boys, and find that stage $F$ for the 


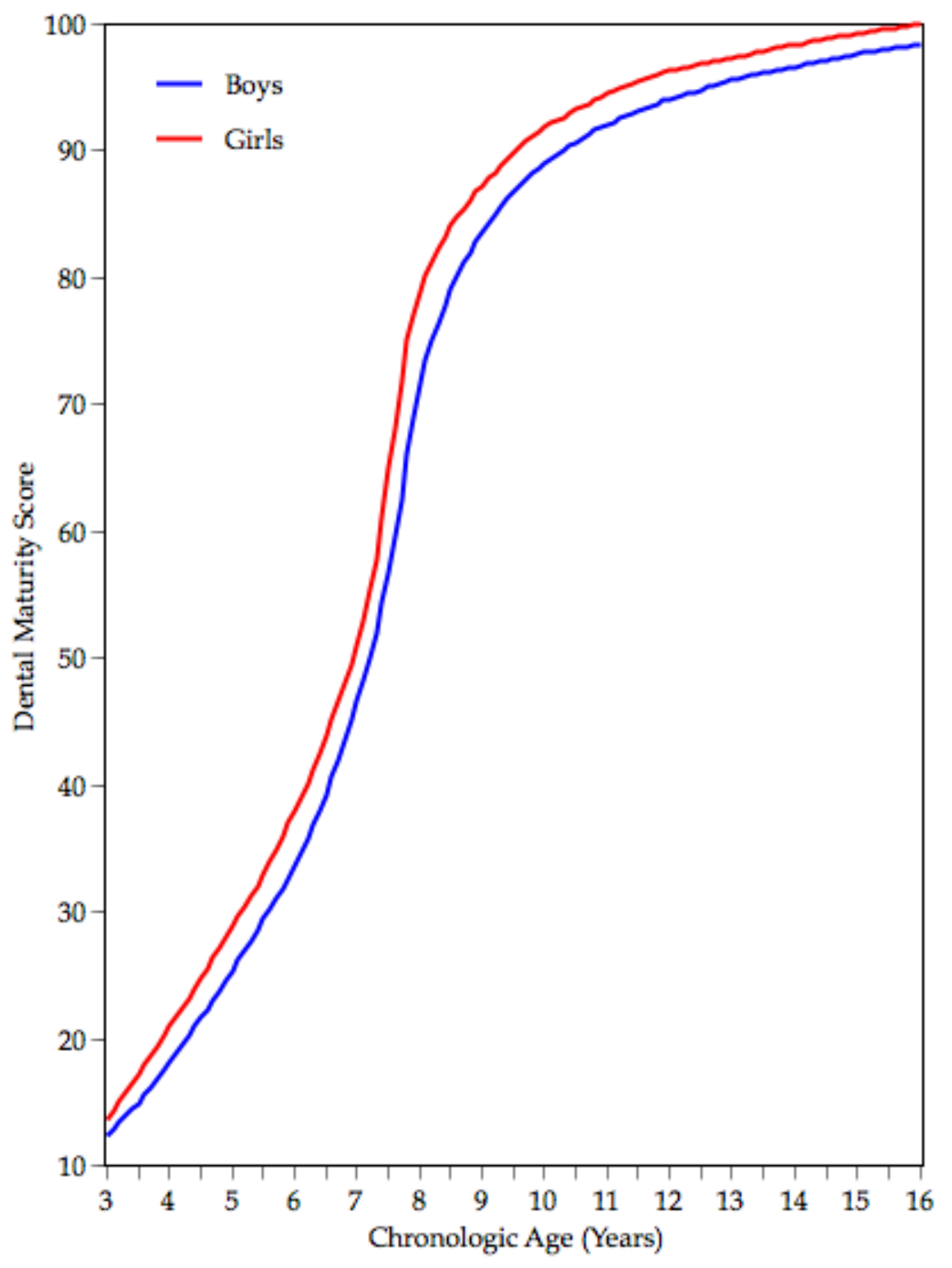

Figure 22. Plots of the sex-specific patterns of dental maturity developed by Demirjian, Goldstein and Tanner (1973). Steepness of a segment of the curve reflects the tempo of maturation, which ranges from 0 (near 3 years of age) to $100 \%$ at 16 years of age. Diagram supplied by Dr. E. F. Harris.

Reprinted with permission. Demirjian A, Goldstein H, Tanner JM. A new system of dental age assessment. Hum Biol 1973;45:211-27. 
Table 3. Weighting coefficients used to determine dental age in boys.

\begin{tabular}{|c|c|c|c|c|c|c|c|}
\hline Age & Score & Age & Score & Age & Score & Age & Score \\
\hline 3.0 & 12.4 & 6.3 & 36.9 & 9.6 & 87.2 & 12.9 & 95.4 \\
\hline 3.1 & 12.9 & 6.4 & 38.0 & 9.7 & 87.7 & 13.0 & 95.6 \\
\hline 3.2 & 13.5 & 6.5 & 39.2 & 9.8 & 88.2 & 13.1 & 95.7 \\
\hline 3.3 & 14.0 & 6.6 & 40.6 & 9.9 & 88.6 & 13.2 & 95.8 \\
\hline 3.4 & 14.5 & 6.7 & 42.0 & 10.0 & 89.0 & 13.3 & 95.9 \\
\hline 3.5 & 15.0 & 6.8 & 43.6 & 10.1 & 89.3 & 13.4 & 96.0 \\
\hline 3.6 & 15.6 & 6.9 & 45.1 & 10.2 & 89.7 & 13.5 & 96.1 \\
\hline 3.7 & 16.2 & 7.0 & 46.7 & 10.3 & 90.0 & 13.6 & 96.2 \\
\hline 3.8 & 17.0 & 7.1 & 48.3 & 10.4 & 90.3 & 13.7 & 96.3 \\
\hline 3.9 & 17.6 & 7.2 & 50.0 & 10.5 & 90.6 & 13.8 & 96.4 \\
\hline 4.0 & 18.2 & 7.3 & 52.0 & 10.6 & 91.0 & 13.9 & 96.5 \\
\hline 4.1 & 18.9 & 7.4 & 54.3 & 10.7 & 91.3 & 14.0 & 96.6 \\
\hline 4.2 & 19.7 & 7.5 & 56.8 & 10.8 & 91.6 & 14.1 & 96.7 \\
\hline 4.3 & 20.4 & 7.6 & 59.6 & 10.9 & 91.8 & 14.2 & 96.8 \\
\hline 4.4 & 21.0 & 7.7 & 62.5 & 11.0 & 92.0 & 14.3 & 96.9 \\
\hline 4.5 & 21.7 & 7.8 & 66.0 & 11.1 & 92.2 & 14.4 & 97.0 \\
\hline 4.6 & 22.4 & 7.9 & 69.0 & 11.2 & 92.5 & 14.5 & 97.1 \\
\hline 4.7 & 23.1 & 8.0 & 71.6 & 11.3 & 92.7 & 14.6 & 97.2 \\
\hline 4.8 & 23.8 & 8.1 & 73.5 & 11.4 & 92.9 & 14.7 & 97.3 \\
\hline 4.9 & 24.6 & 8.2 & 75.1 & 11.5 & 93.1 & 14.8 & 97.4 \\
\hline 5.0 & 25.4 & 8.3 & 76.4 & 11.6 & 93.3 & 14.9 & 97.5 \\
\hline 5.1 & 26.2 & 8.4 & 77.7 & 11.7 & 93.5 & 15.0 & 97.6 \\
\hline 5.2 & 27.0 & 8.5 & 79.0 & 11.8 & 93.7 & 15.1 & 97.7 \\
\hline 5.3 & 27.8 & 8.6 & 80.2 & 11.9 & 93.9 & 15.2 & 97.8 \\
\hline 5.4 & 28.6 & 8.7 & 81.2 & 12.0 & 94.0 & 15.3 & 97.8 \\
\hline 5.5 & 29.5 & 8.8 & 82.0 & 12.1 & 94.2 & 15.4 & 97.9 \\
\hline 5.6 & 30.3 & 8.9 & 82.8 & 12.2 & 94.4 & 15.5 & 98.0 \\
\hline 5.7 & 31.1 & 9.0 & 83.6 & 12.3 & 94.5 & 15.6 & 98.1 \\
\hline 5.8 & 31.8 & 9.1 & 84.3 & 12.4 & 94.6 & 15.7 & 98.2 \\
\hline 5.9 & 32.6 & 9.2 & 85.0 & 12.5 & 94.8 & 15.8 & 98.2 \\
\hline 6.0 & 33.6 & 9.3 & 85.6 & 12.6 & 95.0 & 15.9 & 98.3 \\
\hline 6.1 & 34.7 & 9.4 & 86.2 & 12.7 & 95.1 & 16.0 & 98.4 \\
\hline 6.2 & 35.8 & 9.5 & 86.7 & 12.8 & 95.2 & & \\
\hline
\end{tabular}


Table 4. Weighting coefficients used to determine dental age in girls.

\begin{tabular}{|c|c|c|c|c|c|c|c|}
\hline Age & Score & Age & Score & Age & Score & Age & Score \\
\hline 3.0 & 13.7 & 6.3 & 41.3 & 9.6 & 90.2 & 12.9 & 97.2 \\
\hline 3.1 & 14.4 & 6.4 & 42.5 & 9.7 & 90.7 & 13.0 & 97.3 \\
\hline 3.2 & 15.1 & 6.5 & 43.9 & 9.8 & 91.1 & 13.1 & 97.4 \\
\hline 3.3 & 15.8 & 6.6 & 45.2 & 9.9 & 91.4 & 13.2 & 97.5 \\
\hline 3.4 & 16.6 & 6.7 & 46.7 & 10.0 & 91.8 & 13.3 & 97.6 \\
\hline 3.5 & 17.3 & 6.8 & 48.0 & 10.1 & 92.1 & 13.4 & 97.7 \\
\hline 3.6 & 18.0 & 6.9 & 49.5 & 10.2 & 92.3 & 13.5 & 97.8 \\
\hline 3.7 & 18.8 & 7.0 & 51.0 & 10.3 & 92.6 & 13.6 & 98.0 \\
\hline 3.8 & 19.5 & 7.1 & 52.9 & 10.4 & 92.9 & 13.7 & 98.1 \\
\hline 3.9 & 20.3 & 7.2 & 55.5 & 10.5 & 93.2 & 13.8 & 98.2 \\
\hline 4.0 & 21.0 & 7.3 & 57.8 & 10.6 & 93.5 & 13.9 & 98.3 \\
\hline 4.1 & 21.8 & 7.4 & 61.0 & 10.7 & 93.7 & 14.0 & 98.3 \\
\hline 4.2 & 22.5 & 7.5 & 65.0 & 10.8 & 94.0 & 14.1 & 98.4 \\
\hline 4.3 & 23.2 & 7.6 & 68.0 & 10.9 & 94.2 & 14.2 & 98.5 \\
\hline 4.4 & 24.0 & 7.7 & 71.8 & 11.0 & 94.5 & 14.3 & 98.6 \\
\hline 4.5 & 24.8 & 7.8 & 75.0 & 11.1 & 94.7 & 14.4 & 98.7 \\
\hline 4.6 & 25.6 & 7.9 & 77.0 & 11.2 & 94.9 & 14.5 & 98.8 \\
\hline 4.7 & 26.4 & 8.0 & 78.8 & 11.3 & 95.1 & 14.6 & 98.9 \\
\hline 4.8 & 27.2 & 8.1 & 80.2 & 11.4 & 95.3 & 14.7 & 99.0 \\
\hline 4.9 & 28.0 & 8.2 & 81.2 & 11.5 & 95.4 & 14.8 & 99.1 \\
\hline 5.0 & 28.9 & 8.3 & 82.2 & 11.6 & 95.6 & 14.9 & 99.1 \\
\hline 5.1 & 29.7 & 8.4 & 83.1 & 11.7 & 95.8 & 15.0 & 99.2 \\
\hline 5.2 & 30.5 & 8.5 & 84.0 & 11.8 & 96.0 & 15.1 & 99.3 \\
\hline 5.3 & 31.3 & 8.6 & 84.8 & 11.9 & 96.2 & 15.2 & 99.4 \\
\hline 5.4 & 32.1 & 8.7 & 85.3 & 12.0 & 96.3 & 15.3 & 99.4 \\
\hline 5.5 & 33.0 & 8.8 & 86.1 & 12.1 & 96.4 & 15.4 & 99.5 \\
\hline 5.6 & 34.0 & 8.9 & 86.7 & 12.2 & 96.5 & 15.5 & 99.6 \\
\hline 5.7 & 35.0 & 9.0 & 87.2 & 12.3 & 96.6 & 15.6 & 99.6 \\
\hline 5.8 & 36.0 & 9.1 & 87.8 & 12.4 & 96.7 & 15.7 & 99.7 \\
\hline 5.9 & 37.0 & 9.2 & 88.3 & 12.5 & 96.8 & 15.8 & 99.8 \\
\hline 6.0 & 38.0 & 9.3 & 88.8 & 12.6 & 96.9 & 15.9 & 99.9 \\
\hline 6.1 & 39.1 & 9.4 & 89.3 & 12.7 & 97.0 & 16.0 & 100.0 \\
\hline 6.2 & 40.2 & 9.5 & 89.8 & 12.8 & 97.1 & & \\
\hline
\end{tabular}


mandibular central incisor (L1) has a weight of 4.1, stage E for the lateral incisor (L2) has a weight of 5.2, and so forth for the other five teeth. The sum of the 7 weights is 47.6 (Table 5). This value then is located in Demirjian et al.'s Table 2 (reproduced here as Table 3; note that Table 4 has the weights for girls), and one looks for the score 47.6 (Table 3). This exact value does not occur, but it occurs between the scores of 46.7 and 48.3. One could interpolate where 47.6 occurs between these two tabled values, but this seems excessive to us. Instead, we assign this child's dental age as 7.1, because the observed value (47.6) is numerically closer to 48.3 than to 46.7 . The "closest" score (48.3) corresponds in the table to a dental age of 7.1 years (so DA $=7.1$ years).

Two useful pieces of information are derived here: One, the dental maturity score of 47.6 means that the boy is almost halfway (47.6\%) in his progress towards complete dental maturity, which is defined as $100 \%$ at age 16 in the reference sample. Secondly-and clinically more useful-the score of 47.6 corresponds to a dental age of 7.1 years, meaning that, on the average, boys in the reference sample achieved this extent of dental development when they were 7.1 years of age. Since this particular boy has a chronological age very close to this, his tempo of dental development is shown to be typical for the reference group, thus his label as an "average maturer." For research purposes, we note that his DA is 0.1 years behind his CA, but this is a clinically insignificant difference.

\section{Intraobserver Repeatability}

Repeatability error was quantified by the author by scoring the mineralization stages of the eight mandibular tooth types of 13 panoramic radiographs on two occasions separated by several months. The resulting 103 pairs of scores are shown in Table 6, where it is evident that repeatability accuracy was high. Fourteen teeth $(14 / 103 ; 13.6 \%)$ had different scores, and these only differed by one grade. The most common ambiguities were between grades $\mathrm{G}$ and $\mathrm{H}$, which depends on whether the root apex is closed. This morphological detail requires the finest discrimination of the eight grades, and it was confused in 10 of the 76 cases (i.e., stages $\mathrm{G}$ and $\mathrm{H}$ ).

Intraobserver agreement was quantified using the Kappa statistic (Agresti 1996). Kappa can range from 0 (which is agreement due only to chance) up to 1 (which is perfect agreement). Kappa for these data was 0.796 (standard error $=$ 0.0509), which is quite high; indeed this level of agreement exceeds most 
Table 5. Example of calculating the Demirjian dental maturity score.

\begin{tabular}{|c|c|c|}
\hline Tooth & Stage & Coefficient \\
\hline L1 & F & 4.1 \\
\hline L2 & $\mathrm{E}$ & 5.2 \\
\hline L3 & D & 3.5 \\
\hline L4 & $\mathrm{D}$ & 7.0 \\
\hline L5 & C & 5.4 \\
\hline L6 & F & 12.3 \\
\hline \multirow[t]{2}{*}{ L7 } & D & 10.1 \\
\hline & & : $\quad 47.6$ \\
\hline
\end{tabular}

Table 6. Results of scoring 103 mandibular teeth on two occasions.

\begin{tabular}{cccccrcrc}
\hline Grade & B & C & D & E & F & G & H & Subtotal \\
\hline B & 2 & 0 & 0 & 0 & 0 & 0 & 0 & 2 \\
C & 0 & 6 & 0 & 0 & 0 & 0 & 0 & 6 \\
D & 0 & 1 & 2 & 1 & 0 & 0 & 0 & 4 \\
E & 0 & 0 & 0 & 1 & 0 & 0 & 0 & 1 \\
F & 0 & 0 & 0 & 0 & 12 & 0 & 0 & 12 \\
G & 0 & 0 & 0 & 0 & 2 & 19 & 3 & 24 \\
H & 0 & 0 & 0 & 0 & 0 & 7 & 47 & 54 \\
Subtotal & 2 & 7 & 2 & 2 & 14 & 26 & 50 & 103 \\
\hline
\end{tabular}


researchers' statistics reported in the literature. Fleiss (1981) suggests that values of kappa in excess of 0.75 or so represent "excellent agreement," so the muchhigher level of agreement found here provides considerable confidence that the data were obtained in a systematic, reliable fashion.

\section{Power Analysis}

There are, now, several studies that provide the statistics needed to calculate a power analysis, which is the calculation of the sample sizes needed to be fairly confident of finding a statistically significant difference between groups if one exists. Brom et al. (2007) recently have published a method of calculating power analysis for two samples tested with analysis of covariance (ANCOVA). Five pieces of data are needed for the power analysis:

1. The effect size, or the difference in Y-intercepts you hope to detect. This difference depends on how small a difference is considered to be "clinically significant." It is arguable that the effect size should be about $1 / 2$ year. If it is smaller than this, then using separate, group-specific norms probably is not important clinically - though what is "clinically" significant depends on the perspective of the researcher. For routine clinical examinations - and given the appreciable differences among children's growth pattern $-\mathrm{a} 1 / 2$-year different arguable seems small enough. (Smaller inter-cohort differences require larger sample sizes.)

2. The standard deviation. This is the standard deviation of all the $Y$ values within each group (without controlling for the $X$ variable). For example (Table 7) this is the standard deviation of chronological age or of dental age. In the span of 5-to-15 years, the standard deviation for both CA and DA is on the order of 3.0 or smaller (Table 7). (The age range is based on very few children being treated below 5 years of age, and the upper limit, 15 years, is defined by when all permanent teeth normally complete mineralization.)

3. Alpha, which is the significance level (usually 0.05).

4. Power (beta), which is the probability of rejecting the null hypothesis when the given effect size is true ( 0.80 is the common value). With beta set to 0.80 , the researcher would, in concept, find a statistically significant difference at the effect size $80 \%$ of the time. 
Table 7. Prior estimates of standard deviations (sexes pooled).

\begin{tabular}{lccc}
\hline \multicolumn{1}{c}{ Group } & $\begin{array}{c}\text { Sample } \\
\text { Size }\end{array}$ & $\begin{array}{c}\text { Chronological } \\
\text { Age }\end{array}$ & $\begin{array}{c}\text { Dental } \\
\text { Age }\end{array}$ \\
\hline American Blacks & $\sim 800$ & 2.90 & 3.10 \\
Vietnamese-Americans & $\sim 600$ & 2.20 & 2.84 \\
American Whites & $\sim 1,100$ & 2.77 & 2.82 \\
\hline
\end{tabular}

Reprinted with permission. From unpublished data from E. F. Harris.

5. The $\mathrm{r}^{2}$ (coefficient of determination) within groups. Observed values from prior studies are listed in Table 8 . For all three groups listed, $\mathrm{r}^{2}$ between chronological and dental age is close to 0.80 (sexes pooled).

\section{Calculations}

For the ANCOVA model, interest is on whether the Y-intercepts differ. Prior studies (e.g., Figure 23) suggest that the tempos of dental maturation (the slopes or tempos of maturation) do not differ as much as the vertical offsets ( $\mathrm{Y}$ intercepts). The estimates used are: (A) difference in Y-intercepts (0.5 year), (B) SD within groups (3.0), (C) $\mathrm{r}^{2}$ within groups (0.80), (D) alpha at 0.05 , and (E) power (beta) at 0.80 . These estimates were calculated for two-tail tests of significance. Results (Table 9; Figure 24) were run for a range of differences, from a high of 1 year down to 0.1 year. Required sample sizes (per group) increase geometrically as the effect size decreases.

Of note, a difference between groups of one-half year corresponds to a sample size of 114, and this is calculated using data for sexes pooled. Since there is a well-known trend for girls to achieve tooth mineralization stages ahead of boys (e.g., Thompson et al. 1975), sex-specific ANCOVA models (or where "sex" is included as a covariate) should be more efficient-more likely to discover a statistical difference if one exists.

The actual sample sizes for each sex and cohort exceeded 100, so there should be a discriminatory power between 0.6 and 0.5 years. Total sample size 
Table 8. Prior estimates of the coefficient of determination $\left(\mathrm{r}^{2}\right)$ between chronological age and dental age.

\begin{tabular}{lcc}
\hline \multicolumn{1}{c}{ Group } & $\mathrm{n}$ & $\mathrm{r}^{2}$ \\
\hline American Blacks & $\sim 800$ & 0.803 \\
Vietnamese-Americans & $\sim 600$ & 0.817 \\
American Whites & $\sim 1,100$ & 0.891 \\
\hline
\end{tabular}

Reprinted with permission. From unpublished data from E. F. Harris. 


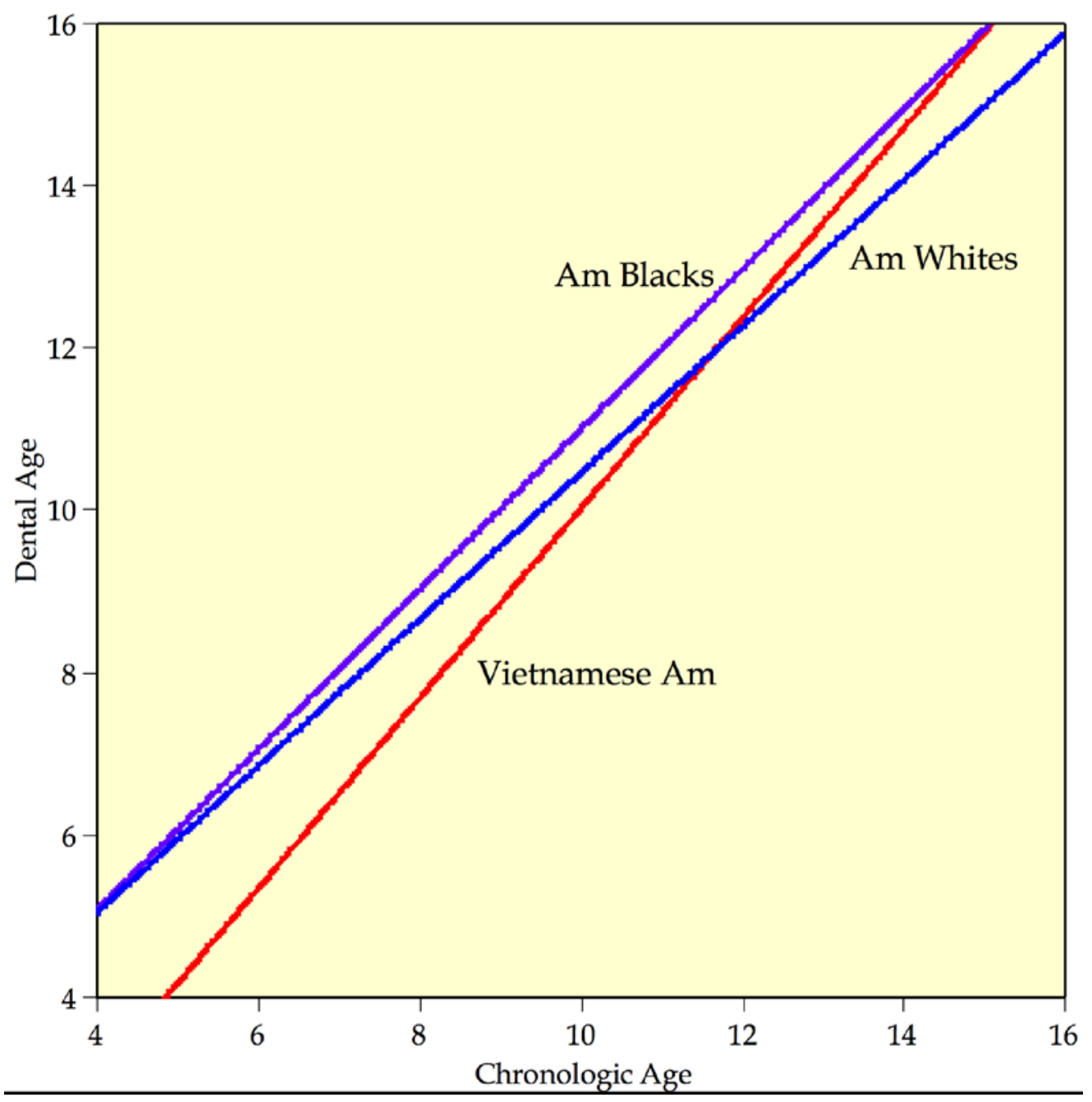

Figure 23. Plot of the associations between chronological age and dental age (derived from the Demirjian method). Fundamentally, these least-square lines are parallel, the major differences are differences in the Y-intercepts. Data are for sexes pooled.

Reprinted with permission. From unpublished data supplied by E. F. Harris. 
Table 9. Sample size estimates (per group) based on power analysis.

\begin{tabular}{ccc}
\hline $\begin{array}{c}\text { Y-Intercept } \\
\text { Difference }\end{array}$ & $\begin{array}{c}\text { Sample Size } \\
\text { Per Group } \\
(\mathrm{b}=0.8)\end{array}$ & $\begin{array}{c}\text { Sample Size } \\
\text { Per Group } \\
(\mathrm{b}=0.9)\end{array}$ \\
\hline 1.0 & 29 & 38 \\
0.9 & 35 & 47 \\
0.8 & 45 & 60 \\
0.7 & 58 & 78 \\
0.6 & 79 & 106 \\
0.5 & 114 & 152 \\
0.4 & 177 & 237 \\
0.3 & 315 & 421 \\
0.2 & 707 & 946 \\
0.1 & 2,826 & 3,783 \\
\hline
\end{tabular}




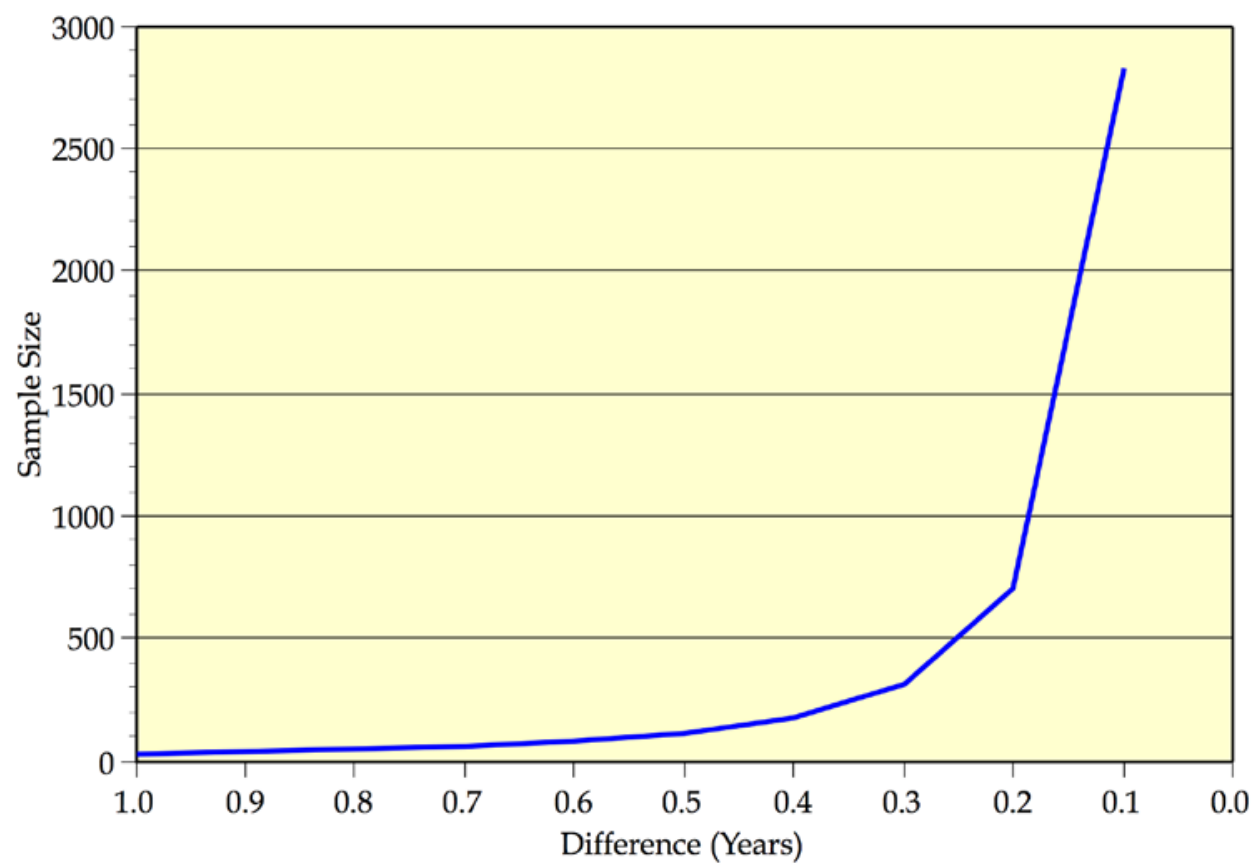

Figure 24. Plot of the sample sizes (per group) needed with an alpha of 0.05 and a beta of $\mathbf{8 0} \%$. Differences in the Y-intercepts are plotted on the horizontal axis. The required sample size increases geometrically as the effect (difference between groups) is reduced. 
was 446 individuals. In other words, with the sample sizes used, a secular difference of at least 0.6 years is likely (beta $=0.8$ ) to be detected statistically.

\section{Sample Size}

A total of 446 panoramic $x$-rays were scored, one from each individual in the age range of 10 and 16 years. In the older cohort (1980-85), there were 101 boys and 134 girls. In the more recent cohort (2005-10), there were 102 boys and 109 girls. All seven teeth were scorable on these films, which is necessary to calculate the dental age using Demirjian's system.

\section{Statistical Analysis}

Data were collated into an Excel $^{\circledR}$ spreadsheet (Microsoft Corporation, Redmond, WA) then transferred to the JMP ${ }^{\circledR}$ statistical package version 9 (SAS Institute Inc., Cary, NC). Exploratory data analysis (Tukey 1977) was performed, searching for outliers; those due to technical errors were corrected. Descriptive statistics (Sokal and Rohlf 1995) were computed, including the arithmetic mean $(\overline{\mathrm{x}})$, standard deviation (sd), standard error of mean (sem), upper and lower $95 \%$ confidence limit ( $\left.\mathrm{L}_{1}, \mathrm{~L}_{2}\right)$, sample size (n), sample variance $\left(\mathrm{s}^{2}\right)$, skewness $\left(\mathrm{g}_{1}\right)$, kurtosis $\left(\mathrm{g}_{2}\right)$, coefficient of variation ( $\mathrm{cv}$ ), number of cases missing, maximum value, median value (50th percentile), and minimum value.

Product-limit survival estimates (better known as Kaplan-Meier analysis; e.g., Elandt-Johnson and Johnson 1980; Allison 1995) were used to calculate the median chronological age of occurrence of each tooth's developmental stage, by sex and by cohort. Survival analysis estimates the average (median) time to an event, and "event" here is the attainment of a particular grade of crown-root mineralization. Some simple review articles on this topic in the health sciences are by Kachman (1999), Ahmed et al. (2007), and Rao and Shoenfeld (2007).

Girls characteristically have a faster tempo of dental maturation than boys (e.g., Dahlberg and Menegaz-Bock 1958; Haavikko 1970; Demirjian 1978), though the extent of the sex difference varies by tooth type and population (e.g., Harris 2007). Whether there is a statistically significant difference for a given tooth and stage between the two age cohorts (1980-1985 versus 2005-2010) while controlling

for sexual dimorphism was tested here using proportional hazards analysis (e.g., Cox and Oakes 1994; Allison 1995) using the JMP ${ }^{\circledR}$ statistical package. 
Survival analysis is not suitable for the terminal stage of formation (stage $\mathrm{H})$. On reflection, it should be evident that, once mineralization is complete, this stage persists throughout the individual's life, so "median age of occurrence" for stage $\mathrm{H}$ in a cross-sectional study is simply a function of the age distribution of those in the sample (the more biologically adult subjects; the greater the observed median.

Tooth formation is normally distributed as regards chronological age (e.g., Hayes and Mantel 1958; Smith 1991). This means that, for a given stage of tooth formation, the age distribution of attainment of this stage is normally distributed. An example is shown in Figure 25. This example is selected because of its large sample size. A normal distribution (blue line) is overlain on the empirical distribution. It is easy to conceptualize, that the normal distribution can be redrawn as cumulative distribution (also known as an ogive; Croxton and Cowden 1939).

An ogive has an S-shape configuration (Figure 26). The left-most portion, with a low slope contains the relative few early-maturers who achieve the stage at an early chronological age. The slope (steepness) of the curve increases to a maximum (at the median or 50th centile), where the density of the distribution tends to be greatest. Thereafter, the slope decreases, tapering to a nearly-flat slope at the far right where just a few individuals are slow to achieve the stage (the late maturers). The shape of the ogive often is taken to be symmetric about the median. This is not necessarily so. For example, a Verhulst equation can be used (Gershenfeld 1999), where the early and late maturers are distributed differently.

Statistically, the question in the present study is whether the median age of attainment of a tooth-formation stage changed over time (a secular trend). That is, we speculated that the median chronological age of attainment of a stage (the median) has diminished over time, presumably in consequence to improved nutrition and, possibly, reduced childhood morbidity. This actually could be evaluated as a one-tail test, because the secular trend, if one exists, is toward younger chronological ages at attainment. Still, as a conservative bias, the inferential tests are evaluated as two-tail tests.

The practical steps of analysis were (1) to use survival analysis to generate the medians and graphical output and then (2) to use proportional hazards analysis to test whether the difference in median ages between the two cohorts 


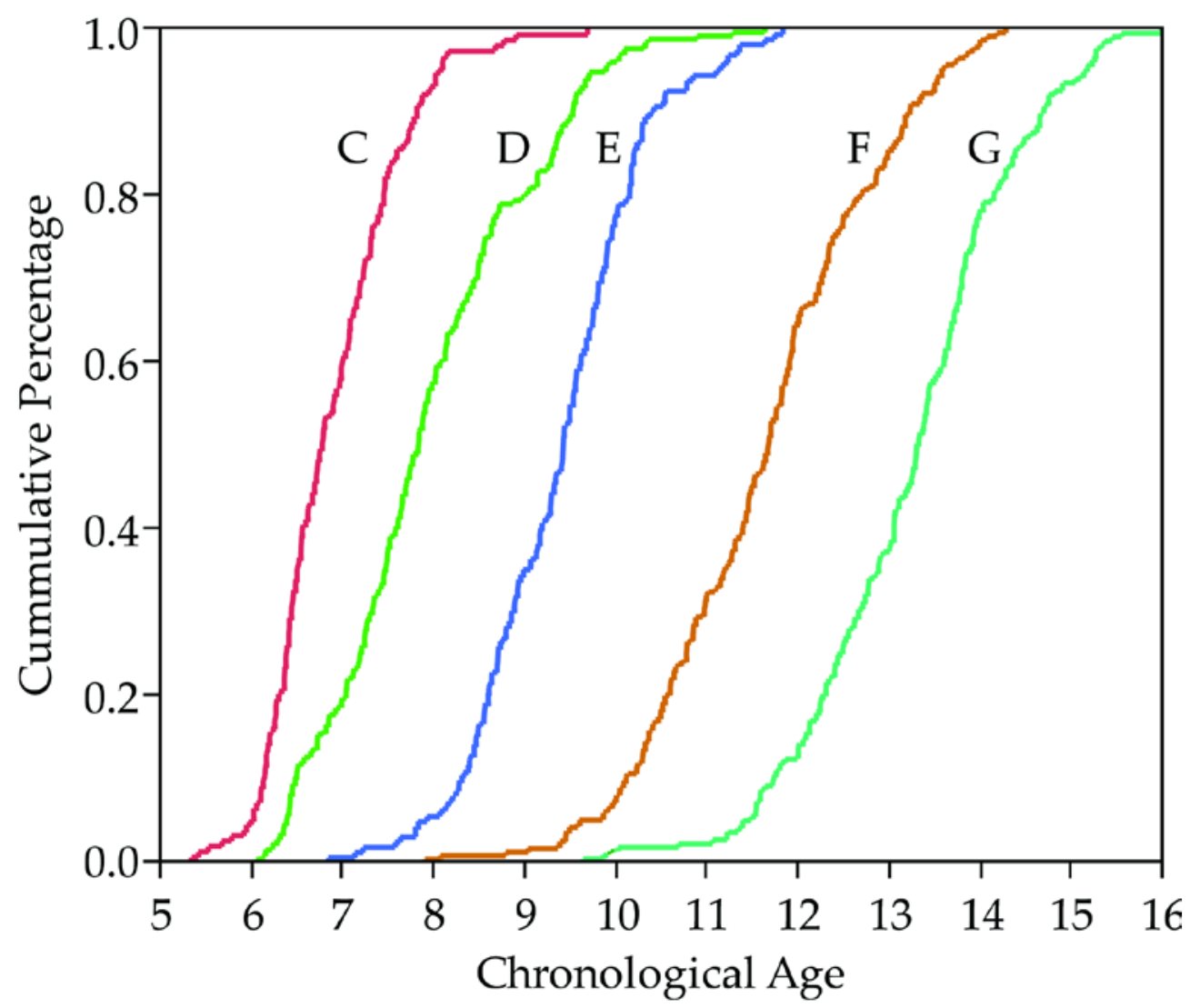

Figure 25. Example of the age distributions of stages $C$ through $G$ (sexes pooled) for the lower second molar to illustrate the method. Data are from a large sample of American white children.

Reprinted with permission. Unpublished figure supplied by E. F. Harris. 


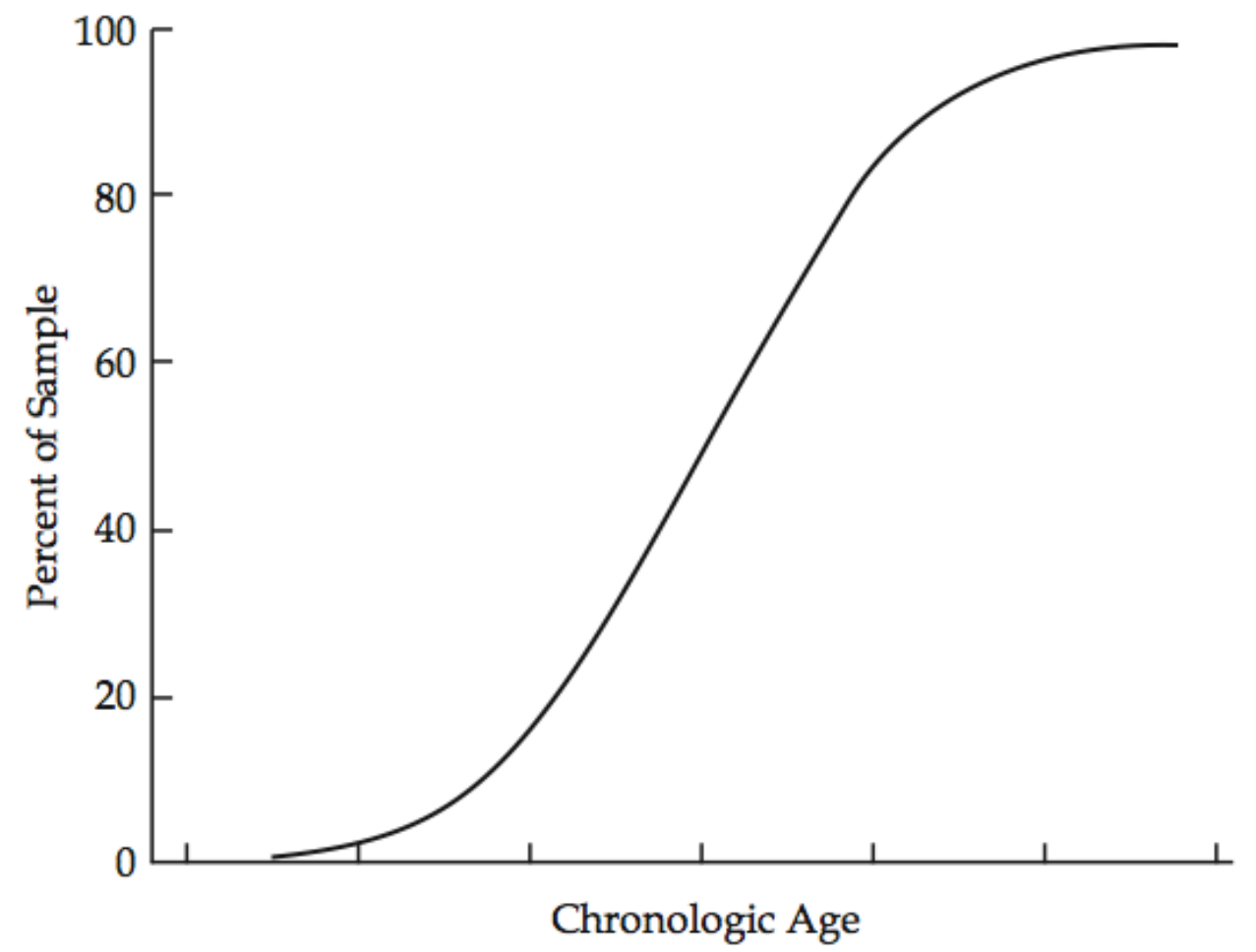

Figure 26. Schematic depiction of the S-shape ogive that reflects the nature of the cumulative increase in the percentage of a sample achieving a maturational event as chronological age progresses. Statistically, the issue is to estimate the median age and a measure of dispersion. 
achieved statistical significance. Actually, because it is necessary to take sexual dimorphism in attainment times into account (e.g., Garn et al. 1958; Anderson and Thompson 1973), we used a two-way ANOVA design that has this format of cohort and sex as the two main effects, and cohort-by-sex is the one interaction effect. Details of the proportional hazards analysis follow the descriptions by Hosmer and Lameshow (1989) and Allison (1995). Results of survival analysis by tooth and grade can be found in Appendix A (Tables A-1 through A-16). The plots of survival analysis can be found in Appendix B (Figures B-1 through B-17). 


\section{CHAPTER 4. RESULTS}

\section{Proportional Hazards Analysis}

The permanent tooth types begin mineralization by birth if not before (Kraus and Jordan 1965; Reid and Dean 2006), so, excluding the late-forming third molar (Rantanen 1967; Harris 2007), the crowns and much of the roots of all of the other tooth types have mineralized by the age of early permanent dentition, when children traditionally seek orthodontic treatment. For example, there are inadequate data to test any of the stages of tooth formation for either the mandibular central or lateral incisor because these events have already occurred by 10 years of age. This means that there are rather few stages of formation in the 10-to-16 age range for comparison between cohorts. Indeed, just 17 tooth-grade combinations had sufficient sample sizes to test for both cohort and sex effects - and 5 of these are for the third-molar that is not used in the Demirjian method.

Also, Stage H, the terminal stage persists throughout an individual's life, so testing for the differences in onset of this stage using cross-sectional data typically is biased. We go ahead and present the analysis for stage $\mathrm{H}$ noting that sample selection ceased at the chronological age of 16 , and this imposed upper limit makes the sex and cohort differences suggestive.

\section{Demirjian Method}

The sex-specific equations developed by Demirjian et al. (1973) were used to calculate each subject's dental age. Data analyzed in the prior section were the formation stages of each tooth; this section combines the stages for the mandibular seven teeth into a composite measure of "dental age" for the individual. Some researchers have found that Demirjian's method underestimates dental age in other groups (e.g., Hedge and Sood 2002; Leurs et al. 2005; Al-Emran 2008; Tunc and Koyuturk 2008), but that is immaterial here since the point is to use a common reference against which to compare the two Mid-South cohorts.

Perhaps the simplest comparison is to pool the results for the two sexes, and calculate DA-CA for the cases. DA-CA is, of course, how the person's dental age (using the Demirjian system) compared to his or her chronological age. If the 
average DA-CA is negative, then dental age tends to lag behind CA, whereas, if DA-CA is positive, then dental age exceeds CA. Results for the two cohorts are plotted in Figure 27, and it is evident that the older (1980-85) cohort had a median that was close to zero (using the Demirjian et al. standards), while the recent (2005-10) cohort has a median that is at about +1 year. By groupcomparison t-test (e.g., Woolf 1968), DA-CA for the two cohorts are highly significantly different $(\mathrm{t}=7.5 ; \mathrm{df}=405 ; \mathrm{P}<0.0001)$. Interpretation is that the recent (2005-10) cohort achieved tooth mineralization stages at significantly younger ages than the older cohort, and the average difference is 1.02 years ( $\mathrm{SE}=$ $0.137 ; 95 \%$ confidence limits: 0.75 and 1.29 years).

This simple comparison combines everyone in the 10-to-16 year age range, which is not particularly informative. A more insightful result occurs when dental age is plotted against chronological age for the two cohorts (Figure 28). It is evident that the more recent (2005-2010) group has visibly older dental ages at the corresponding chronological ages compared to the older cohort (1980-1985). That is, contemporary (2005-2010) children are reaching the same levels of dental maturation at least a year earlier than children a generation ago (1980-85). The typical 12-year-old child now has the dental maturation of a 13-year-old a generation ago. These results also mean that using older "standards" of tooth formation (e.g., Nolla 1960; Moorrees et al. 1963) will over-estimate contemporary children's dental age and, thus, under-estimate their growth potential.

Another effect of the secular trend is evident in Figure 28. There is a horizontal "line" of dots at the top of the figure at dental age 16. This clustering occurs because all seven mandibular teeth (teeth I1 through M2) complete tooth formation before about 16 years of age, so the dentition is fully mature, and the dental score for the Demirjian system is 100.0, which corresponds to 16.0 years of age-thus the clustering. With this method, all cases who are dentally adult have a dental age at the upper limit of 16 years. Notice that there is a scarcity of cases along the horizontal axis to the right of about 15 years of age. This is because most cases - and especially those in the recent cohort-who are at least 15 years of age have a totally mature dental age of 16 years.

These results are for sexes combined, which is reasonable since Demirjian and coworkers developed sex-specific equations that should remove the effects of sexual dimorphism in tooth formation (e.g., Thompson et al. 1975). However, it is possible (e.g., Roche 1979; Garn 1987) that boys and girls have experienced different secular trends. Figures 29 and 30 show the results when the data are tested in separate subsets of girls and boys, respectively. 


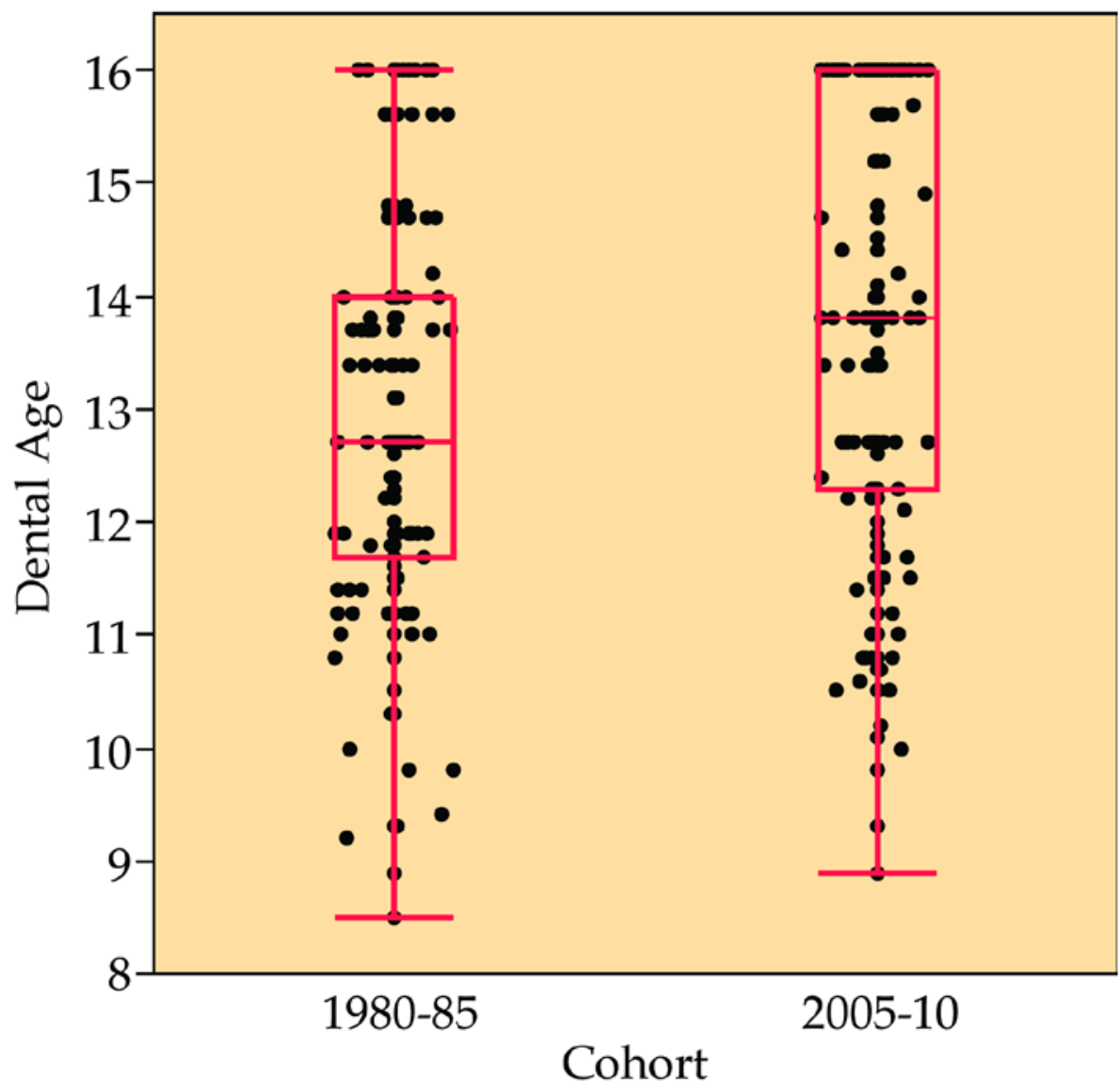

Figure 27. Box plots for the distributions of DA-CA for the two age cohorts (sexes combined). The difference between medians is 1.02 years, showing that the more recent (2005-10) cohort had a significantly faster tempo of tooth formation. 


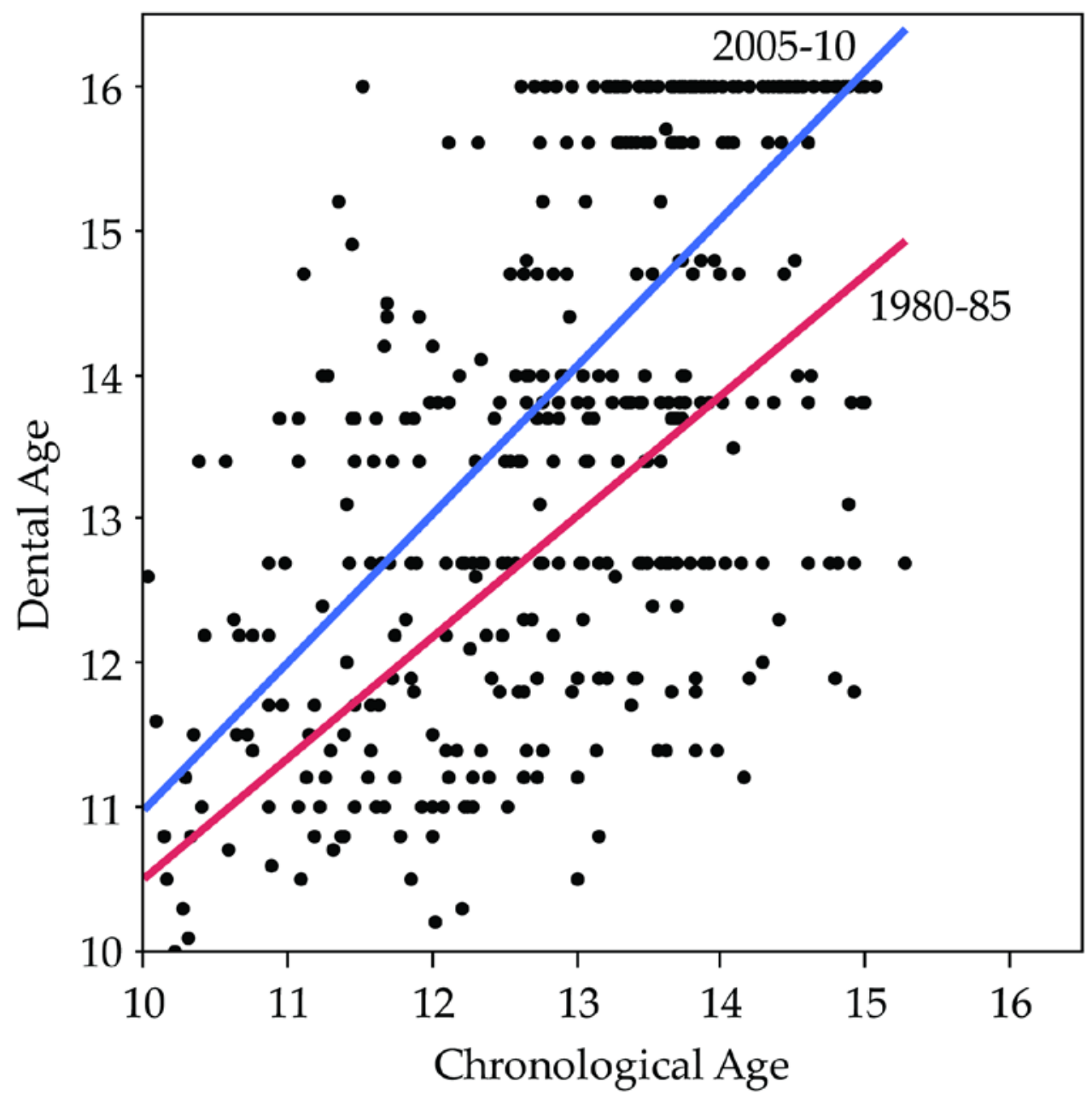

Figure 28. Plot of dental age against chronological age in the two cohorts (sexes pooled). Children in the recent (2005-10) cohort achieve mineralization stages (and, thus, dental ages) at significantly earlier chronological ages than in the older (1980-85) cohort. 


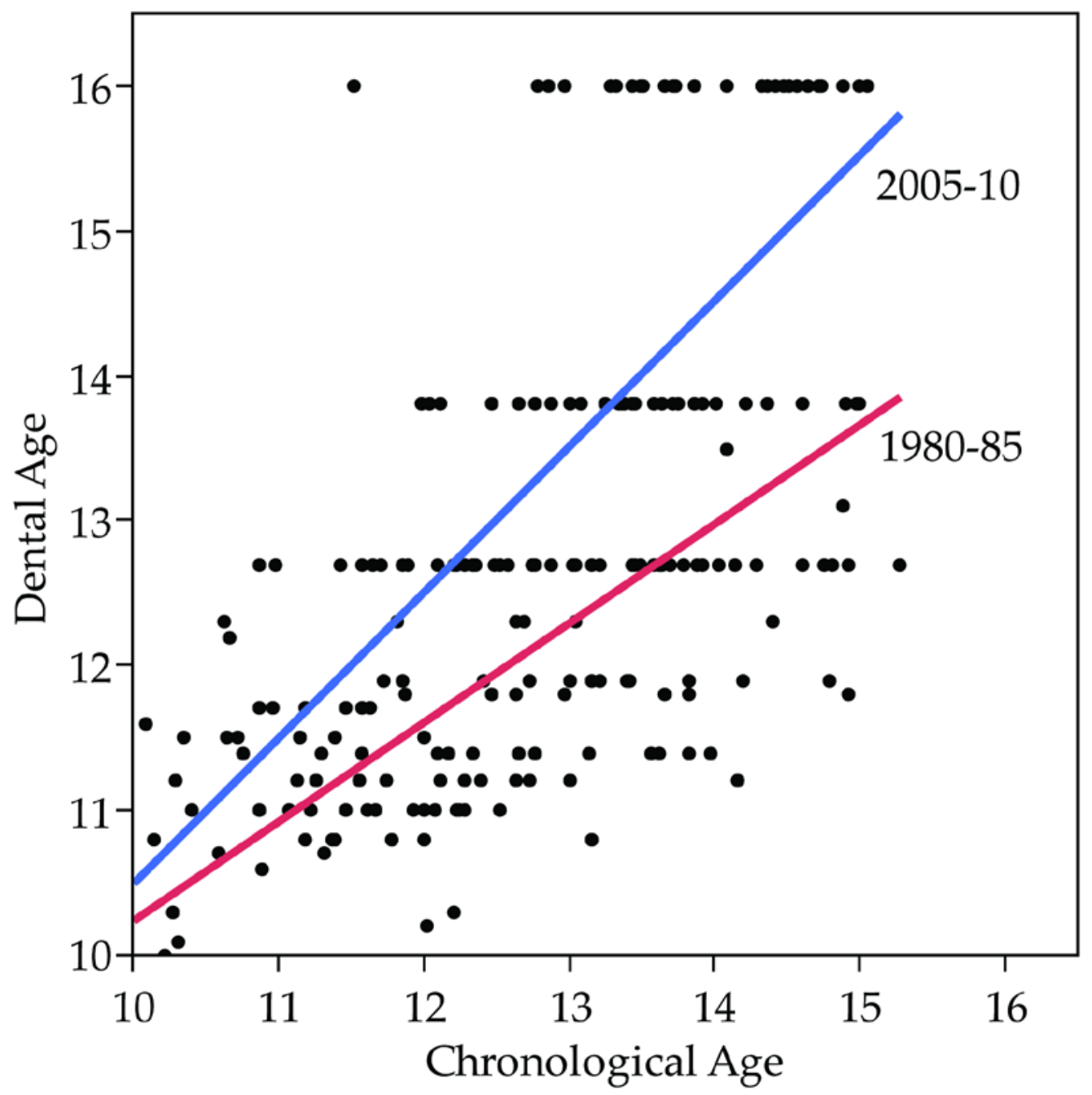

Figure 29. Plot of dental age by chronological age in the two cohorts of girls. Unlike the results for boys, these two cohorts diverge with age, meaning that the tempo of growth is faster in the recent (2005-10) cohort than formerly. 


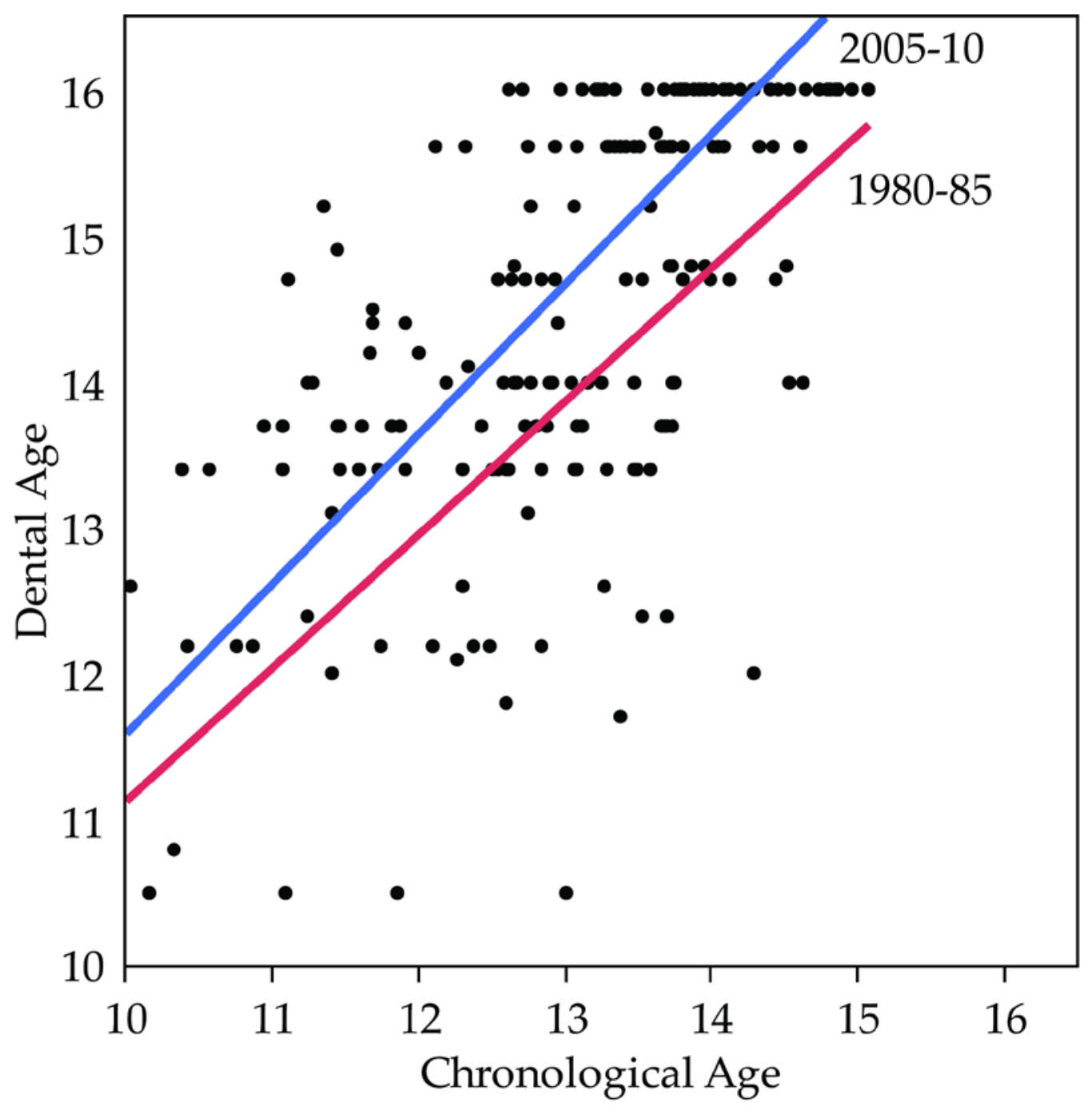

Figure 30. Plot of dental age by chronological age in the two cohorts of boys. Throughout the 10-to-16 age range, the recent (2005-10) cohort parallels the rate seen in the older (1980-85) cohort, but with about a one-year offset because the recent cohort is more mature throughout the age span. 
Boys and girls have both experienced a significant increase in their rates of tooth mineralization (positive secular trends), but the effect has been more dramatic in girls. For boys, the difference between the two cohorts is largely an offset of about a year. For girls, there is an offset-a greater dental age for a given chronological age-but the tempo of development during adolescence also is occurring at a faster pace. The generational difference is about 1 year at 10-11 years of age, but this increases to almost two years by 14-15 years of age. 


\section{CHAPTER 5. DISCUSSION}

A secular trend is a change in the tempo of growth over one or more generations due to changes in the environment (Roche 1979; Garn 1987; Cole 2000). When evolutionary effects such as gene flow (migration) and selection can be dismissed, yet there is a change across generations in the size or timing of a developmental trait, the assumption is that the environment has affected growth - that there has been a secular trend (Roche 1979; Cole 2000).

Secular trends are episodic - they occur when the environment affecting children's growth changes enough to alter growth, and such changes follow no set sequences. In the United States and other industrialized countries, children and, in consequence, adults are becoming larger, and children at each age are taller and heavier than in the past, and these trends have been documented in a number of industrialized nations (e.g., Tanner 1966; Komlos and Lauderdale 2007; Batty et al. 2009). These trends are in concert with observed decreased ages of menarche (Berenberg 1975), increases in tooth sizes (Garn et al. 1968; Lavelle 1973; Warren et al. 2003), increases in arch dimensions (Lindsten 2003), and earlier tooth emergence (Diamanti and Townsend 2003). It is not unanticipated, then, that tooth formation also is proceeding at a faster pace than in the past. The present results fully agree with the preliminary findings of Nadler (1998), who showed that children in his orthodontic practice (Arizona, U.S.) were achieving tooth mineralization stages at early chronological ages (1992-1994) than in the past (1972-1974). Nadler's study suggested a 1.4-year reduction in the average age at achievement of stages across the two decades. Until now, this is the only study that has tested for more rapid tooth development-though faster rates of emergence are evident (e.g., Warren et al. 2003). The present study confirms Nadler's preliminary findings, showing too that girls have experienced a greater change than boys in the same population. Based on our multiple stages and pooling over seven tooth types, the present analysis suggests a secular increase on the order of 0.8 years in boys and 1.1 years in girls over the quarter-century between cohorts. The common theme across the present study is that the older (1980-85) cohort achieved the mineralization stage at an older average chronological age than the recent (2005-10) group. For example-using the Demirjian standards - the average 12-year-old in the 1980-85 cohort possessed a dental age of 12.9 years. A generation later, in contrast, the average 12 year old boy is more mature, with a dental age of 13.7 years. The same degree of dental maturation in a boy in the $1980-85$ cohort now is achieved 0.8 years earlier. 
The present report raises several questions: How long has this secular trend been ongoing? Our choice of two cohorts was defined by the availability of older records (1980-1985) in our archives. It is unlikely that this earlier cohort coincides with the onset of the current secular trend, though it is unclear when this might have begun. Comparably, it is unlikely that the recent (2005-10) cohort in any way coincides with the cessation of increasing tempos of tooth formation. The homogenizing effects of the "modern American culture" suggest that the trend should be widespread across the nation, but this awaits documentation. To date, data on tooth formation and emergence are for the American white majority population. At least for American blacks (Garn et al. 1972, 1973; Harris and McKee 1990), data disclose an inherently faster tempo of growth in blacks than whites, especially for girls (Zhang et al. 2009). Next to nothing is known about Hispanics who are a heterogeneous group. It can only be supposed that these segments of the U.S. population have partaken of the secular trends reported here.

This study also raises the question of causation. Why has this secular trend occurred? Little is known how a child's health translates to his or her tempo of growth. Broadly, under-nutrition (Shaw 1970; Tonge and McCance 1973) seems to act by slowing mitotic rates and, thus, taking longer for the growing animal to reach critical developmental stages. Conversely, proper nutrition up-regulates mitosis (Davis and Fiorotto 2009).

The acceleration in tooth formation may be greater in girls than boys. In 8 of the 10 comparisons, the median changes between cohorts are larger in girls than boys. While this 8:2 split does not exceed chance $\left(\chi^{2}=3.6 ; 0.10>\mathrm{P}>0.05\right)$, the average secular change in boys ( $\sim 0.7$ years) is larger than in girls ( $\sim 0.3$ years).

These sex differences may have corollaries with the recent 'epidemic' of obesity in the United States and other industrialized countries brought about by ample, inexpensive food in combination with reduced physical activity (CDC 1999). Over-nutrition in girls enhances the onset of menarche, probably because of elevated titers of estrogen (Nguyen and El-Serag 2010). The opposite occurs in boys, where elevated weight gain actually slows the onset of puberty (Walvoord 2010), which may translate into larger adult sizes because of a protracted interval of growth. A recent study by Hilgers and colleagues (2009) of 104 children between the ages of 7 and 15 linked higher than normal body mass index (BMI) to accelerated dental development. Their results further suggest that increasing frequencies of children with greater fat deposits probably contribute to the faster trend in tooth formation. This is corroborated by Hilgers' et al. (2007) finding 
that hand-wrist bone age also is accelerated in contemporary children with high BMI. Their work shows that the tempos of dental age and bone age are both accelerated in children with a high BMI even though several studies have shown that there is only a weak statistical association between these two measures of physiological age (e.g., Robinow et al. 1942; Nanda 1960; Björk and Helm 1967; Lancet et al. 1973).

Enhanced nutrition in the U.S. obviously has occurred (CDC 1999), but nutritional improvements can be subtle. For example, it is often overlooked that this past century witnessed the cessation of rickets (vitamin D deficiency), goiter (iodine deficiency), and pellagra (niacin deficiency), among other diseases that were common in the U.S. until the mid-20th century but are uncommon today because of public health initiatives.

Another, potential issue is the growing presence of endocrine-disrupting chemicals (EDCs) in the environment. These are exogenous compounds (such as phytoestrogens and polychlorinated biphenyls) that interfere with the production, action, or metabolism of endogenous hormones (Walvoord 2010). An important consequence seems to be the development of obesity (Newbold 2010), which may lead to earlier pubertal development (Aksglaede et al. 2006). In 2002, Baillie-Hamilton's landmark review first postulated a link between chemical toxins and obesity. She noted that the obesity epidemic coincided with a marked increase of industrial chemicals in the environment and proposed that these chemicals were interfering with weight homeostasis by way of altering hormones, neurotransmitters, or altering the sympathetic nervous system (Baillie-Hamilton 2002). Of particular concern is exposure of the developing fetus to such EDCs while in utero, which may have permanent effects (Newbold 2010). One particular estrogenic compound called diethylstilbestrol (DES) was prescribed to women from the 1940s to the 1970s because it was believed to prevent miscarriages. Instead, DES caused an increase in neoplastic lesions in human offspring, and it has been associated with significant weight gain in mice 6 months after birth (Newbold 2010). Similarly, when genistein, a phytoestrogen common in soy products, is ingested in doses similar to what occurs in western diets, increased fat deposition occurs in males (Newbold et al. 2008). It seems that the current obesity epidemic is not only caused by poor eating and exercise habits, but also seems to be linked to early exposure of environmental chemicals (Newbold et al. 2009).

Causes of these accelerated tempos of growth will remain speculative until prospective studies have quantified the lifestyles of children growing at 
faster tempos. Broadly, diminished childhood morbidity helps children grow at closer to their genetic potentials compared to past populations. Tanner (1962) and others note that, typically, increases in average body dimensions benefit most by enhancing growth of the most-stressed elements of a population.

Orthodontically, the obvious message is that in many instances children can now be treated at earlier chronological ages. The dental consequences of secular trends are that the average child now achieves the level of dental maturation appreciably earlier than a generation ago. If the dentist's interest is in waiting until all 28 permanent teeth have erupted into functional occlusion, then this typically occurs a year or more earlier than a generation ago. If interest is in treating during the mixed dentition, where the opportunities for arch development and orthopedic changes may be greater (e.g., O'Reilly and Yanniello 1988; Hägg and Pancherz 1988), then it is relevant to screen children at earlier chronological ages than in the past. Currently, the American Association of Orthodontists (AAO) suggests that each child be examined by an orthodontist at age 7 . Our findings suggest that this age be lowered to adjust for faster tooth development.

For example, consider a treatment that depends on a given stage of tooth development-such as "the early permanent dentition." Such a procedure might be the development of the lower dental arch during premolar eruption with lip bumper therapy. (The theory is that the lip bumper lessens the pressure of the facial musculature on the lower dentition, thus allowing for the "development" or widening of the dental arch via slightly more buccal eruption of the premolars and flaring of the incisors.) By previous standards, lower premolars emerge between the ages of 10 and 12; however, today they may erupt between ages 911 , thus needing earlier treatment when a lip bumper is required for arch development.

The results of this study stress the notion that medical and dental clinicians need to view "growth standards" as dynamic rather than static. For example, it still is common to use the hand-wrist bone standards of Greulich and Pyle (1959) based on children who grew up in the 1930s and 1940s. The present study suggests that the often-referenced standards of tooth formation (Nolla 1960; Moorrees et al. 1963; Demirjian et al. 1973; Anderson et al. 1976) and of tooth emergence (Hurme 1949; Hägg and Taranger 1985) almost certainly have been biased by subsequent secular trends and would seem to be unrepresentative of the current populations' growth tempos. 
"Dental age" - the extent of crown-root mineralization normally achieved at a given chronologic age-has significantly accelerated across these two cohorts tested here. Standards derived from children in generations gone by are likely to have mineralized and erupted their teeth at older chronological ages. For example, a typical 12-year-old today would have a degree to tooth formation not seen in prior generations until 13-years of age or older. Over-estimating the level of tooth development suggests a contemporary child is a "fast maturer" where in fact he is not vis-à-vis his peers. Older standards also under-estimate a child's growth potential. This might be relevant in the case of a patient with a Class 2 division 1 dental malocclusion in which the orthodontist removes upper premolars to correct the patient's overjet rather than using a growth appliance (e.g., Herbst or MARA) because the clinician has underestimated the patient's anticipated growth.

These suggestions need to be tempered because of the great interindividual variation in growth tempos. While we document highly significant increases in the average rate of growth statistically, it is unlikely that the clinician would be impressed by this change compared to the large variability brought on by age, race, and sex in inter-individual differences. So too, the clinician treats the individual based on that child's specific condition, so group averages play little role in diagnosis or treatment of a given patient, Still, when using group standards for statistical reference (in order to quantify a child's departure from normal) appropriate averages need to be considered.

Finally, the results also have legal and forensic consequences. For instance, several publications suggest that the third molar can be used as a medicolegal marker of whether an individual is an "adult" - where the legal consequences can be quite different than for a minor (e.g., Mincer et al.1993; Liversidge 2009; Panchbhai 2011). Ignoring the considerable variability of the third molar (e.g., Harris 2007), the present findings of a significant secular trend suggests that adolescents now are achieving tooth-mineralization stages not seen until older ages in prior generations. The risk of using older "standards" where growth was slower is to over-estimate a youth's true chronological age. This likewise is true of people without documentation of age and of skeletal remains where age is estimated from the dentition (Brook and Barker 1972; Nuzzolese and Di Vella 2008).

There is no reason to suspect that the secular trend demonstrated in this study has "peaked." The two cohorts studied here (1980-85 and 2005-2010) were simply defined by convenience based on the archived records at our University. 
Continued improvements in children's growth (reduction in illnesses; improved nutrition and over-nutrition) may well cause the trend to continue in this culture. It would be interesting to test prior and subsequent cohorts. It also would be informative to see how pervasive the trend is: Have other segments of the population shared in this trend? What about other areas of the country? 


\section{CHAPTER 6. CONCLUSIONS}

This study compared the tempos of crown-and-root formation in two groups of children separated by a quarter-century (1980-85 and 2005-10). All children were American whites from the same clinic. Both sexes exhibit a significant secular trend, with contemporary children maturing about 1 year faster than in the past. The trend has been somewhat faster for girls. It is necessary to collect prospective data to refine suggestions of what factors are driving the enhanced tempos of growth aside from the obvious but generalized improvements in nutrition and health care. 


\section{LIST OF REFERENCES}

Acheson RM, Dupertius A. The Oxford method of assessing skeletal maturity. Clinical Orthoped 1957;10:19-39.

Agresti A. An introduction to categorical data analysis. New York: John Wiley \& Sons, Inc., 1996. p. 19-27.

Ahmed FE, Vos PW, Holbert D. Modeling survival in colon cancer: a methodological review. Mol Cancer 2007;12:6-15.

Akridge M, Hilgers KK, Silveira AM, Scarfe W, Scheetz JP, Kinane DF.

Childhood obesity and skeletal maturation assessed with Fishman's handwrist analysis. Am J Orthod Dentofacial Orthop 2007;132:185-90.

Aksglaede L, Sørensen K, Petersen J, Skakkebæk, A Juul. Recent decline in age at breast development: the Copenhagen puberty study. Pediatrics 2009;123:932-9.

Al-Emran S. Dental age assessment of 8.5 to 17 Year-old Saudi children using Demirjian's method. J Contemp Dent Pract 2008;9:64-71.

Allison PD. Survival analysis using SAS ${ }^{\circledR}$ : a practical guide. Cary, NC: SAS Institute Inc., 1995.

Anderson DL, Thompson GW. Interrelationships and sex differences of dental and skeletal measurements. J Dent Res 1973;52:431-8.

Anderson DL, Thompson GW, Popovich F. Age of attainment of mineralization stages of the permanent dentition. J Forensic Sci 1976;21:191-200.

Anderson DL, Thompson GW, Popovich F. Interrelationships of dental maturity, skeletal maturity, height and weight from ages 4-14 years. Growth 1975;39:453-62.

Avery JK, ed. Oral development and histology, 2nd ed. New York: Thieme Medical Publishers, Inc., 1994.

Bai KI, Vijayalakshmi B. Sexual maturation of Indian girls in Andhra Pradesh (South India). Hum Biol 1973;45:695-707. 
Baillie-Hamilton PF. Chemical toxins: a hypothesis to explain the global obesity epidemic. J Altern Complement Med 2002;8:185-92.

Bastos JL, Peres MA, Peres KG, Barros AJD. Infant growth, development and tooth emergence patterns: a longitudinal study from birth to 6 years of age. Arch Oral Biol 2007;52:598-606.

Batty GD, Shipley MJ, Gunnell D, Huxley R, Kivimaki M, Woodward M, Lee $\mathrm{CM}$, Smith GD. Height, wealth, and health: an overview with new data from three longitudinal studies. Econ Hum Biol 2009;7:137-52.

Baynouna LM, Revel A, Nagelkerke NJD, Jaber T, Omar A, Ahmed NM, Naziruldeen MK, Sayed MFA, Nour FA, Abdouni S. Secular trend in height in Al Ain-United Arab Emirates. Econ Hum Biol 2009;7:405-6.

Berenberg SR. Puberty, biologic and psychosocial components. Leiden: Stenfert Kroese; 1975.

Björk A, Helm S. Prediction of the age of maximum puberal growth in body height. Angle Orthod. 1967;37:134-43.

Borm GF, Fransen J, Lemmens WAJG. A simple sample size formula for analysis of covariance in randomized clinical trials. J Clin Epidem 2007;60:1234-8.

Boughner JC, Hallgrimsson B. Biological spacetime and the temporal integration of functional modules: a case study of dento-gnathic developmental timing. Devel Dynam 2008;237:1-17.

Bradley RE. The relationship between eruption, calcification, and crowding of certain mandibular teeth. Angle Orthod 1961;31:230-6.

Brook AH. A unifying aetiological explanation for anomalies of human tooth number and size. Arch Oral Biol 1984;29:373-8.

Brook AH, Barker DK. The use of deciduous tooth eruption of the estimation of unknown chronological age. J Trop Pediatr Environ Child Health 1973;19:234-9.

Brundtland GH, Liestöl K, Walloë L. Height and weight of school children and adolescent girls and boys in Oslo 1970. Acta Paediatr Scand 1975;64:56573. 
Cameriere R, Flores-Mir C, Mauricio F, Ferrante L. Effects of nutrition on timing of mineralization in teeth in a Peruvian sample by the Cameriere and Demirjian methods. Ann Hum Biol 2007;34:547-56.

Cameron N. Assessment of growth and maturation during adolescence. Horm Res 1993;39 Suppl 3:9-17.

Carfagna M, Figurelli E, Matarese G, Matarese S. Menarcheal age of schoolgirls in the district of Naples, Italy, in 1969-70. Hum Biol 1972;44:117-25.

Carlson H. Studies on the rate and amount of eruption of certain human teeth. Am J Orthod Oral Surg 1944;30:575-88.

Cattell P. Dentition as a measure of maturity. Harvard Monographs in Education. Harvard University Press, 1928.

Croxton FE, Cowden DJ. 1939. Applied general statistics. New York: PrenticeHall, Inc.

CDC. Achievements in public health, 1900-1999: safer and healthier foods. MMWR 1999;48:905-13.

Cho GJ, Park HT, Shin JH, Hur JY, Kim YT, Kim SH, Lee KW, Kim T. Age at menarche in Korean population: secular trends and influencing factors. Eur J Pediatr 2010;169:89-94.

Cohen J, Cohen P. Applied multiple regression/correlation analysis for the behavioral sciences. New York: John Wiley and Sons, 1975.

Cole TJ. Secular trends in growth. Proc Nutr Soc 2000;59:317-24.

Corliss CE. Patton's human embryology: elements of clinical development. New York: McGraw-Hill Book Company, 1976.

Cox DR, Oakes D. Analysis of survival data. Boca Raton, FL: CRC Press, 1994.

Cronk CE, Roche AF. Race- and sex-specific reference data for triceps and subscapular skinfolds and weight/stature. Am J Clin Nutr 1982;35:347-54.

Dahlberg AA, Menegaz-Bock RM. Emergence of the permanent teeth in Pima Indian children. J Dent Res 1958;37:1123-40. 
Davis TA, Fiorotto ML. Regulation of muscle growth in neonates. Curr Opin Clin Nutr Metab Care 2009;12:78-85.

Defraia E, Baroni G, Marinelli A. Dental arch dimensions in the mixed dentition: a study of Italian children born in the 1950s and the 1990s. Angle Orthod 2006;76:446-51.

Demirjian A. The dentition. In: Human growth, Vol 2. postnatal growth. F Falkner and JM Tanner, eds. New York: Plenum Publishers, 1978:413-44.

Demirjian A, Goldstein H, Tanner JM. A new system of dental age assessment. Hum Biol 1973;45:211-27.

Diamanti J, Townsend GC. New standards for permanent tooth emergence in Australian children. Aust Dent J 2003;48:39-42.

Elandt-Johnson R, Johnson NL. Survival models and data analysis. New York: John-Wiley and Sons, Inc. 1980.

Enwonwu CO. Influence of socio-economic conditions on dental development in Nigerian children. Arch Oral Biol 1973;18:95-107.

Eveleth PB, Tanner JM. Worldwide variation in human growth. New York: Cambridge University Press, 1976.

Eveleth PB, Tanner JM. Worldwide variation in human growth, 2nd ed. New York: Cambridge University Press, 1990.

Falkner F. Deciduous tooth eruption. Arch Dis Child 1957;32:386-91.

Fanning EA. A longitudinal study of tooth formation and root resorption. NZ Dent J 1961;57:202-17.

Fanning EA. Effect of extraction of deciduous molars on the formation and eruption of their successor. Angle Orthod 1962;32:44-53.

Ferguson AD, Scott RB, Bakwin H. Growth and development of Negro infants. VIII. Comparison of the deciduous dentition in Negro and white infants; a preliminary study. J Pediatr 1957;50:327-31.

Fishman LS. Maturational patterns and prediction during adolescence. Angle Orthod 1987;57:178-93. 
Fleiss JL. Statistical methods for rates and proportions, 2nd ed. New York: John Wiley \& Sons, 1981.

Flores-Mir C, Mauricio FR, Orellana MF, Major PW. Association between growth stunting with dental development and skeletal maturation stage. Angle Orthod 2005;75:935-40.

Frank CA. Treatment options for impacted teeth. J Am Dent Assoc 2000;131:62332.

Freedman DS, Khan LK, Serdula MK, Srinivasan SR, Berenson GS. Secular trends in height among children during 2 decades: The Bogalusa Heart Study. Arch Pediatr Adolesc Med 2000;154:155-61.

Friedlaender JS, Bailit HL. Eruption times of the deciduous and permanent teeth of natives of New Guinea: a study of racial variation. Hum Biol 1969;41:516.

Friedman JM. Leptin at $14 \mathrm{y}$ of age: an ongoing story. Am J Clin Nutr 2009;89:973S-979S.

Freund RJ, Littell RC. SAS ${ }^{\circledR}$ systems for regression, 2nd ed. Cary, NC: SAS Institute Inc., 1991.

Fry EI. Assessing skeletal maturity: comparison of the atlas and individual bone techniques. Nature 1968;220:496-7.

Garn SM. Body size and its implications. Rev Child Dev Res 1966;2:529.

Garn SM. The secular trend in size and maturational timing and its implications for nutritional assessment. J Nutri 1987;117:817-23.

Garn SM, Lewis AB, Blizzard RM. Endocrine factors in dental development. J Dent Res 1965b;44A:243-58.

Garn SM, Lewis AB, Bonné B. Third molar polymorphism and the timing of tooth formation. Nature 1961;192:989.

Garn SM, Lewis AB, Kerewsky RS. Genetic, nutritional, and maturational correlates of dental development. J Dent Res 1965a;44:228-43.

Garn SM, Russell AL. The effect of nutritional extremes on dental development. Am J Clin Nutr 1971;24:285-6. 
Garn SM, Lewis AB, Koski PK, Polacheck DL. The sex difference in tooth mineralization. J Dent Res 1958;37:561-6.

Garn SM, Lewis AB, Polacheck DL. Sibling similarities in dental development. J Dent Res 1960;39:170-5.

Garn SM, Lewis AB, Walenga A. Evidence for a secular trend in tooth size over two generations. J Dent Res 1968;47:503.

Garn SM, Sandusky ST, Nagy JM, Trowbridge FL. Negro-Caucasoid differences in permanent tooth emergence at a constant income level. Arch Oral Biol 1973;18:609-15.

Garn SM, Wertheimer F, Sandusky ST, McCann MB. Advanced tooth emergence in Negro individuals. J Dent Res 1972;51:1506.

Gershenfeld NA. The nature of mathematical modeling. Cambridge, UK: Cambridge University Press, 1999.

Gleiser I, Hunt Jr EE. The permanent mandibular first molar: its calcification, eruption and decay. Am J Phys Anthropol 1955;13:253-83.

Gordon-Larsen P, Zemel BS, Johnston FE. Secular changes in statue, weight, fatness, overweight, and obesity in urban African American adolescents from the mid-1950's to the mid-1990's. Am J Hum Biol 1997;9:675-88.

Gorski JP, Marks SC Jr, Cahill DF, Wise GF. Developmental changes in the extracellular matrix of the dental follicle during tooth eruption. Connect Tissue Res 1998;18:175-90.

Greulich WW, Pyle SI. Radiographic atlas of skeletal development of the hand and wrist, 2nd ed. Stanford, CA: Stanford University Press, 1959.

Grøn AM. Prediction of tooth emergence. J Dent Res 1962;41:573-85.

Gustafson, Koch G. Age estimation up to 16 years based on dental development. Odontol Revy 1974;25:297-306.

Haavikko K. The formation and the alveolar and clinical eruption of the permanent teeth: an orthopantomographic study. Proc Finn Dent Soc 1970;66:103-70. 
Hägg U, Pancherz H. Dentofacial orthopaedics in relation to chronological age, growth period and skeletal development. An analysis of 72 male patients with Class II division 1 malocclusion treated with the Herbst appliance. Eur J Orthod 1988;10:169-76.

Hägg U, Taranger J. Dental development dental age and tooth counts. Angle Orthod 1985;55:93-107.

Harris EF. Dental maturation. In: Ulijaszek SJ, Johnston FE, Preece MA, editors. The Cambridge encyclopedia of human growth. Cambridge: Cambridge University Press, 1998:45-8.

Harris EF. Mineralization of the mandibular third molar: a study of American blacks and whites. Am J Phys Anthropol 2007;132:98-109.

Harris EF. Dental development and anomalies in craniosynostosis and facial clefting. In: Mooney MP, Siegel MI, editors. Understanding craniofacial anomalies: The etiopathogenesis of craniosynostosis and facial clefting. New York: John Wiley-Liss, 2002, pp 425-67.

Harris EF, McKee JH. Tooth mineralization standards for blacks and whites from the middle southern United States. J Forensic Sci 1990;35;859-72.

Harris EF, Mincer HH, Anderson KM, Senn DR. Age estimation from oral and dental structures. In: Senn DR, Stimson PG, editors. Forensic dentistry, 2nd edition. Boca Raton, FL: CRC Press, 2010, p. 263-303.

Harris EF, Potter RH, Lin J. Secular trend in tooth size in urban Chinese assessed from two-generation family data. Am J Phys Anthropol 2001;115:312-8.

Hauspie RC, Vercauteren M, Susanne C. Secular changes in growth. Horm Res 1996;45:8-17.

Hauspie RC, Vercauteren M, Susanne C. Secular changes in growth and maturation: an update. Acta Paediatr Suppl 1997;423:20-7.

Hayes RL, Mantel N. Procedures for computing the mean age of eruption of human teeth. J Dent Res 1958;37:938-47.

Hedge RJ, Sood PB. Dental maturity as an indicator of chronological age: radiographic evaluation of dental age in 6-13 years children of Belgaum using Demirjian's methods. J Indian Soc Pedo Prev Dent 2002; 20:132-4. 
Helm S. Secular trend in tooth eruption: a comparative study of Danish school children of 1913 and 1965. Arch Oral Biol 1969;14:1177-91.

Henneberg M, George BJ. Possible secular trend in the incidence of an anatomical variant: median artery of the forearm. Am J Phys Anthropol 1995;96:32934.

Hercshlag-Elkayam O, Even L, Shasha SM. [Clinical manifestations of - Hunger Disease $\|$ among children in the ghettos during the Holocaust]. Harefuah 2003;142:345-9 [in Hebrew].

Hess AF, Lewis JM, Roman B. Radiographic study of mineralization of teeth from birth to adolescence. Dent Cosmos 1932;74:1053-8.

Hilgers KK, Akridge M, Scheetz JP, Kinane DE. Childhood obesity and dental development. Pediatr Dent 2006;1:18-22.

Hoerr N, Pyle SI, Francis CC. Radiographic atlas of development of the foot and ankle: a standard of reference. Springfield: CC Thomas, 1962.

Höffding J, Maeda M, Yamaguchi K, Tsuji H, Kuwabara S, Nohara Y, Sadahiro Y. Emergence of permanent teeth and onset of dental stages in Japanese children. Community Dent Oral Epidemiol 1984;12:55-8.

Hosmer DW, Lemeshow S. Applied logistic regression. New York: John Wiley \& Sons, 1989.

Hotz R, Boulanger B, Weisshaupt H. Mineralization time of permanent teeth in relation to chronological and skeletal age in children. Helv Odont Acta 1959;3:4-9.

Huen KF, Leung SSF, Lau JTF, Cheung AYK, Leung NK, Chiu MC. Secular trend in the sexual maturation of southern Chinese girls. Acta Paediatr 1997;86:1121-24.

Hughes TE, Bockmann MR, Seow K, Gotjamanos T, Gully N, Richards LC, Townsend GC. Strong genetic control of emergence of human primary incisors. J Dent Res 2007;86:1160-5.

Hunter WS, Garn SM. Evidence for a secular trend in face size. Angle Orthod 1969;39:320-3. 
Hurme VO. Ranges of normalcy in the eruption of permanent teeth. J Dent Child 1949;16:11-5.

Hurme VO. Standards of variation in the eruption of the first six permanent teeth. Child Devel 1948;19:213-31.

Hurme VO. Standards of variation in the eruption of the first six permanent teeth. Child Devel 1951;37:800-3.

Infante PF. Sex differences in the chronology of deciduous tooth emergence in white and black children. J Dent Res 1974;53:418-21.

Israel $\mathrm{H}$, Lewis $\mathrm{AB}$. Radiographically determined linear permanent tooth growth from age 6 years. J Dent Res 1971;50:334-42.

Johanson G. Age determination from human teeth. Odont Revy 1971;22:1-126.

Jones LL, Griffiths PL, Norris SA, Pettifor JM, Cameron N. Age at menarche and the evidence for a positive secular trend in urban South Africa. Am J Hum Biol 2009;21:130-2.

Kachman SD. Applications in survival analysis. J Anim Sci 1999;77:147-53.

Kant AK, Graubard BI. Secular trends in patterns of self-reported food consumption of adult Americans: NHANES 1971-1975 to NHANES 19992002. Am J Clin Nutr 2006;84:1215-23.

Komlos J, Lauderdale BE. The mysterious trend in American heights in the 20th century. Ann Hum Biol 2007;34:206-15.

Kozieł S, Danel DP, Zaręba M. Isolation by distance between spouses and its effect on children's growth in height. Am J Phys Anthropol 2011;146:14-19.

Kraus BS, Jordan RE. The human dentition before birth. Philadelphia: Lea and Febiger, 1965.

Krogman WM. Biological timing and the dento-facial complex. ASDC J Dent Child. 1968a;35:175-85.

Krogman WM. Biological timing and the dento-facial complex. ASDC J Dent Child. 1968b;35:328-41. 
Krogman WM. Biological timing and the dento-facial complex. ASDC J Dent Child. 1968c;35:377-81.

Krumholt L, Roed-Petersen B, Pindborg JJ. Eruption times of the permanent teeth in 622 Ugandan children. Arch Oral Biol 1971;16:1281-8.

Kuczmarski RJ. Trends in body composition for infants and children in the U.S. Crit Rev Food Sci Nutr 1993;33:375-87.

Lacey KA, Parkin JM, Steel GH. Relationship between bone age and dental development. Lancet 1973;302:736-7.

Lavelle CL. Secular trends of the face and stature. Angle Orthod 1972;42:221-6.

Lavelle CL. Variation in the secular changes in the teeth and dental arches. Angle Orthod 1973;43:412-21.

Leenstra T, Petersen LT, Kariuki SK, Oloo AJ, Kager PA, ter Kuile FO. Prevalence and severity of malnutrition and age at menarche; cross-sectional studies in adolescent schoolgirls in western Kenya. Eur J Clin Nutr 2005;59:41-8.

Leurs IH, Wattel E, Aartman IH, Etty E, Prahl-Anderson B. Dental age in Dutch children. Eur J Orthod 2005;27:309-14.

Liliequist B, Lundbert M. Skeletal and tooth development: a methodologic investigation. Acta Radiol 1971;11:97-112.

Lin WS, Chen ACN, Su JZX, Xiao JW, Ye GS. Secular change in the growth and development of Han children in China. Ann Hum Biol 1992;19:249-65.

Lindsten R. Secular changes in tooth size and dental arch dimensions in the mixed dentition. Swed Dent J Suppl 2003;157:1-89.

Lindsten R, Ögaard B, Larsson E. Anterior space relations and lower incisor alignment in 9-year-old children born in the 1960s and 1980s. Angle Orthod 2001;71:36-43.

Lindsten R, Ögaard B, Larsson E. Dental arch space and permanent tooth size in the mixed dentition of a skeletal sample from the $14^{\text {th }}$ to the $19^{\text {th }}$ centuries and 3 contemporary samples. Am J Orthod Dentofacial Orthop 2002;122:48-58. 
Lindsten R, Ögaard B, Larsson E. Difference in dental lateral arch length between 9-year-olds born in the 1960s and the 1980s. Am J Orthod Dentofacial Orthop 2000;117:663-8.

Lindsten R, Ögaard B, Larsson E. Transverse dental and dental arch depth dimensions in the mixed dentition in a skeletal sample from the $14^{\text {th }}$ to the $19^{\text {th }}$ century and Norwegian children and Norwegian Sami children of today. Angle Orthod 2002;72:439-48.

Lindsten R, Ögaard B, Larsson E. Transversal dental arch dimensions in 9-yearold children born in the 1960s and the 1980s. Am J Orthod Dentofacial Orthop 2001;120:576-84.

Lindsten R, Ögaard B, Larsson E, Bjerklin K. Transverse dental and dental arch depth dimensions in the mixed dentition in a skeletal sample from the 14th to the 19th century and Norwegian children and Norwegian Sami children of today. Angle Orthod 2002;72:439-48.

Little BB, Buschang PH, Peña Reyes ME, Tan SK, Malina RM. Craniofacial dimensions in children in rural Oaxaca, southern Mexico: secular change, 1968-2000. Am J Phys Anthropol 2006;131:127-36.

Liversidge H. Variation in modern dental development. In: Thompson JL, Krovitz GE, Nelson AJ, eds. Patterns of growth and development in the genus Homo. Cambridge: Cambridge University Press, 2003, p. 73-113.

Liversidge HM. Permanent tooth formation as a method of estimating age. Front Oral Biol 2009;13:153-7.

Liversidge HM, Dean MC, Molleson TI. Increasing human tooth length between birth and 5.4 years. Am J Phys Anthropol 1993;90:307-13.

Ljung BO, Bergsten-Brucefors A, Lindgren G. The secular trend in physical growth in Sweden. Ann Hum Biol 1974;1:245-56.

Logan WHG, Kronfeld R. Development of the human jaws and surrounding structures from birth to age of fifteen years. J Am Dent Assoc 1933;20:379427.

Lysell L, Magnusson B, Thilander B. Relations between the times of eruption of primary and permanent teeth: a longitudinal study. Acta Odontol Scand 1969;27:271-81. 
Malina RM. Physical fitness of children and adolescents in the United States: status and secular change. Med Sport Sci 2007;50:67-90.

Malina RM. Research on secular trends in auxology. Anthropol Anz 1990;48:20927.

Malina RM. Secular trends in growth, maturation and physical performance: A review. Anthropol Rev 2004;67:3-31.

Marshall WA, Tanner JM. Variations in pattern of pubertal changes in girls. Arch Dis Child 1969;44:291-303.

Marshall WA, Tanner JM. Variations in pattern of pubertal changes in boys. Arch Dis Child 1970;45:13-23.

Massler M, Schour I, Poncher HC. Developmental pattern of child as reflected in the calcification pattern of the teeth. Am J Dis Child 1941;62:33-67.

Matiegka J. L'age dentaire comme signe du development total. Rev Anthropologique 1921:31:333-35.

McAllister EJ, Dhurandhar NV, Keith SW, Aronne LJ, Barger J, Baskin M, Benca RM, Biggio J, Boggiano MM, Eisenmann JC, Elobeid M, Fontaine KR, Gluckman P, Hanlon EC, Katzmarzyk P, Pietrobelli A, Redden DT, Ruden DM, Wang C, Waterland RA, Wright SM, Allison DB. Ten putative contributors to the obesity epidemic. Crit Rev Food Sci Nutr 2009;49:868913.

Miller J, Hobson P, Gaskell TJ. 1965. A serial study of the chronology of exfoliation of deciduous teeth and eruption of permanent teeth. Arch Oral Biol 10:805-818.

Mincer HH, Harris EF, Berryman HE. The A.B.F.O. study of third molar development and its use as an estimator of chronological age. J Forensic Sci 1993;38:379-90.

Monteiro CA, D'Aquino Benicio MH, da Cruz Gouveia N. Secular growth trends in Brazil over three decades. Ann Hum Biol 1994; 21:381-90.

Moorrees CFA, Fanning EA, Hunt EE Jr. Age variation of formation stages for ten permanent teeth. J Dent Res 1963a;42:1490-1502. 
Moorrees CFA, Fanning EA, Hunt EE Jr. Formation and resorption of three deciduous teeth in children. Am J Phys Anthropol 1963b;21:99-108.

Murata M. Secular trends in growth and changes in eating patterns of Japanese children. Am J Clin Nutr 2000;72(suppl):1379S-83S.

Murata M, Hibi I. Nutrition and the secular trend of growth. Horm Res 1992;38:89-96.

Nadler G. Earlier dental maturation: fact or fiction? Angle Orthod 1998;68:535-7.

Nanda RS. Eruption of human teeth. Am J Orthod 1960;456:363-78.

Nellhaus G. Head circumference growth in north American negro children. Pediatrics 1970;46:817-20.

Newbold RM. Impact of environmental endocrine disrupting chemicals on development of obesity. Hormones 2010;9:106-17.

Newbold RM, Padilla-Banks E, Jefferson WN. Environmental estrogens and obesity. Mol Cell Endocrinol 2009;304:84-9.

Newbold RM, Padilla-Banks E, Jefferson WN, Heindel JJ. Effects of endocrine disruptors on obesity. Int J Androl 2008;31:201-8.

Neyzi O, Alp H, Orhon A. Sexual maturation in Turkish girls. Ann Hum Biol 1975;2:49-59.

Nguyen DM, El-Serag HB. The epidemiology of obesity. Gastroenterol Clin North Am. 2010;39:1-7.

Nolla CM. Development of the permanent teeth. J Dent Child 1960;27:254-66.

Nuzzolese E, Di Vella G. Forensic dental investigations and age assessment of asylum seekers. Int Dent J 2008;58:122-6.

O'Connell A, Gavin A, Kelly C, Molcho M, Gabhainn NS. The mean age at menarche of Irish girls in 2006. Ir Med J 2009;102:76-9.

Oishi K, Honda S, Takamura N, Kusano Y, Abe Y, Moji K, Takemoto T, Tahara Y, Aoyagi K. Secular trends of sizes at birth in Japanese healthy infants born between 1962 and 1988. J Physiol Anthropol Appl Human Sci 2004;23:15561. 
Omran AR. The epidemiologic transition: A theory of the epidemiology of population change. Milbank Memorial Fund Quarterly 1971;49:509-38.

Omran AR. The epidemiologic transition theory: A preliminary update. J Tropical Pediatrics 1983;29:305-16.

Ondarza A, Jara L, Munoz P, Blanco R. Sequence of eruption of deciduous dentition in a Chilean sample with Down's syndrome. Arch Oral Biol 1997;42:401-6.

Ontell FK, Ivanovic M, Ablin DS, Barlow TW. Bone age in children of diverse ethnicity. AJR Am J Roentgenol 1996;167:1395-8.

O'Reilly MT, Yanniello GJ. Mandibular growth changes and maturation of cervical vertebrae--a longitudinal cephalometric study. Angle Orthod 1988;58:179-84.

Osborn JW, Ten Cate AR. Advanced dental histology, 3rd ed. Bristol: John Wright and Sons, 1976.

Ounstead M, Moar V, Scott A. A longitudinal study of tooth emergence and somatic growth in 697 children from birth to three years. Arch Oral Biol 1987;32:787-91.

Owen GM, Nelsen CE, Garry PJ. Nutritional status of preschool children: hemoglobin, hematocrit and plasma iron values. J Pediatr 1970;76:761-3.

Panchbhai AS. Dental radiographic indicators, a key to age estimation. Dentomaxillofac Radiol 2011;40:199-212.

Papadimitriou A, Konstantinidou M, Christopanou H, Xepapadaki P, Giannouli $\mathrm{O}$, Nicolaidou P. Secular trend in body height of schoolchildren in northeast Attica, Greece. J Pediatr Endocrinol Metab 2009;22:13-7.

Parent AS, Teilmann G, Juul A, Skakkebaek NE, Toppari J, Bourguignon JP. The timing of normal puberty and the age limits of sexual precocity: variations around the world, secular trends, and changes after migration. Endocr Rev 2003;24:668-93.

Parner ET, Heidmann JM, Væth M, Poulsen S. A longitudinal study of time trends in the eruption of permanent teeth in Danish children. Arch Oral Biol 2001;46:425-431. 
Paynter KJ, Grainger RM. The Relation of Nutrition to the Morphology and Size of rat molar teeth. J Can Dent Assoc 1956;22:519-31.

Popkin BM. The nutrition transition and obesity in the developing world. J Nutr 2001;131:871S-3S.

Post RH. Deformed nasal septa and relaxed selection. Eugen Q 1966;13:101-12.

Post RH. Population differences in tear duct size. Implications of relaxed selection. Soc Biol 1969;16:257-69.

Proffit WR, Frazier-Bowers SA. Mechanism and control of tooth eruption: overview and clinical implications. Orthod Craniofac Res 2009;12:59-66.

Pyle SI, Hoerr NL. A radiographic standard for reference for the growing knee. Springfield: CC Thomas, 1969.

Pyle SI, Waterhouse AM, Greulich WW. A radiographic standard of reference for the growing hand and wrist: Prepared for the United States National Health Examination Survey. Chicago: Year Book Medical Publishers, Inc., 1971.

Ranjitkar S, Lin NH, Macdonald R, Taylor JA, Townsend GC. Stature and skeletal maturation of two cohorts of Australian children and young adults over the past two decades. Aust Orthod J 2006;22:47-58.

Rantanen AV. The age of eruption of the third molar teeth. Acta Odont Scand 1967;25:1-86.

Rao SR, Schoenfeld DA. Survival methods. Circulation 2007;115:109-13.

Reid DJ, Dean MC. Variation in modern human enamel formation times. J Hum Evol 2006;50:329-46.

Riesenfeld A. The effect of environmental factors on tooth development: an experimental investigation. Acta Anat (Basel) 1970;77:188-215.

Robinow M. The eruption of deciduous teeth (factors involved in timing). J Trip Pediatr Environ Child Health 1973;18:95-107.

Robinow M, Richards TW, Anderson M. The eruption of deciduous teeth. Growth 1942;6:127-138. 
Roche AF. Secular trends in human growth, maturation, and development. Monogr Soc Res Child Dev 1979;44:1-120.

Roche AF. Secular trends in stature, weight and growth, maturation. Mono Soc Res Child Dev 1979;44:2-27.

Röse C. Uber die mittlere Durchbruchzeit der bleibenden Zahne. Deutsche Monatschrift Zahnheilkunde 1909;27:553-570.

Rousset MM, Boualam N, Delfosse C, Roberts WE. Emergence of permanent teeth: secular trends and variance in a modern sample. J Dent Child (Chic) 2003;70:208-14.

Sabri R. Management of over-retained mandibular deciduous second molars with and without permanent successors. World J Orthod 2008;9:209-20.

Sánchez-Pérez L, Irigoyen ME, Zepeda M. Dental caries, tooth eruption timing and obesity: a longitudinal study in a group of Mexican schoolchildren. Acta Odontol Scand 2010;68:57-64.

Sato S, Parsons P. Eruption of permanent teeth: a color atlas. St. Louis: Ishiyaku EuroAmerica, Inc., 1990.

Saunders E. The teeth as a test of age, considered with reference to the factory children. Addressed to the Members of both Houses of Parliament. London: H. Renshaw, 1837, p. 76.

Schroff FR. Identification by teeth: a possible source of error. Br Dent J 1959;107:178-80.

Selye H. Stress in health and disease. Boston: Butterworth; 1976.

Shaw JH. Influence of marginal and complete protein deficiency for varying periods during reproduction on growth, third-molar eruption and dental caries in rats. J Dent Res 1969;48:310-6.

Shaw JH. Preeruptive effects of nutrition on teeth. J Dent Res 1970;49:1238-1251.

Shaw JH, Griffiths D. Dental abnormalities in rats attributable to protein deficiency during reproduction. J Nutr 1963;80:123-41.

Simondon KB, Simon I, Simondon F. Nutritional status and age at menarche of Senegalese adolescents. Ann Hum Biol 1997;24:521-32. 
Smith BH. Standards of human tooth formation and dental age assessment. In: Kelley MA, Larsen CS, eds. Advances in dental anthropology. New York: Wiley-Liss, 1991, p. 143-68.

Smith BH, Garn SM, Hunter WS. Secular trends in face size. Angle Orthod 1986;56:196-204.

Smith KK. Time's arrow: heterochrony and the evolution of development. Int J Dev Biol 2003;47: 613-21.

Smith SL, Buschang PH. An examination of proportional root lengths of the mandibular canine and premolars near the time of eruption. Am J Orthod Dentofacial Orthop 2010;138:795-803.

Sokal RR, Rohlf FJ. Biometry: the principles and practice of statistics in biological research, 3rd ed. San Francisco: WH Freeman and Company, 1995.

Song Y, Park MJ, Paik HY, Joung H. Secular trends in dietary patterns and obesity-related risk factors in Korean adolescents aged 10-19 years. Int J Obes (Lond) 2010;34:48-56.

Stanger BZ. The biology of organ size determination. Diabetes Obes Metab 2008;10:16-22.

Steedle JR, Proffit WR. The pattern and control of eruptive tooth movements. Am J Orthod 1985;87:56-66.

Steel GH. The relation between dental maturation and physiological maturity. Dent Pract 1965;16:23-34.

Steinbeck K. Obesity and nutrition in adolescents. Adolesc Med State Art Rev 2009;20:900-14.

Stones HH, Lawton FE, Bransby ER, Hartley HO. Time of eruption of permanent teeth and time of shedding of deciduous teeth. Br Dent J 1951;90:1-7.

Stukovsky R, Valsik JA, Bulai-Stirbu M. Family size and menarcheal age in Constanza, Roumania. Hum Biol 1967;39:277.

Suzuki K, Simpson KA, Minnion JS, Shillito JC, Bloom SR. The role of gut hormones and the hypothalamus in appetite regulation. Endocr J 2010;57:359-72. 
Takaishi M. Growth standards for Japanese children-an overview with special reference to secular change in growth. In: Hauspie R, Lindgren G, Falkner F, editors. Essays on auxology presented to James Mourilyan Tanner by former colleagues and fellows. Welwyn Garden City, Herts: Castlemead Publications, 1995, p 302-11.

Takaishi M. Secular changes in growth of Japanese children. J Pediatr Endoc 1994;7:163-73.

Tanguay R, Demirjian A, Thibault HW. Sexual dimorphism in the emergence of the deciduous teeth. J Dent Res 1984;63:65-8.

Tanner JM. Earlier maturation in man. Sci Am 1968;218:21-7.

Tanner JM. Fetus into man, 2nd ed. Cambridge: Harvard University Press, 1990.

Tanner JM. Growth at adolescence, 2nd ed. Oxford: Blackwell Scientific Publications, 1962.

Tanner JM. The regulation of human growth. Child Develop 1963;34:817-47.

Tanner JM. The secular trend towards earlier physical maturation. T Soc Geneesk 1966;44:524.

Tanner JM, Whitehouse RH, Marshall WA, Healy MJ, Goldstein H. Assessment of skeletal maturity and prediction of adult height (TW2 method). London: Academic Press, 1975.

Thompson AM, Baxter-Jones A, Mirwald RL, Bailey DA. Secular trend in the development of fatness during childhood and adolescence. Am J Hum Biol 2002;14:669-79.

Thompson GW, Anderson DL, Popovich F. Sexual dimorphism in dentition mineralization. Growth 1975;39:289-301.

Tonge $\mathrm{CH}$, McCance RA. Normal development of the jaws and teeth in pigs, and the delay and malocclusion produced by calorie deficiencies. J Anat 1973;115:1-22.

Toverud G. The influence of war and post-war conditions on the teeth of Norwegian school children. I. Eruption of permanent teeth and status of deciduous dentition. Milbank Memorial Fund Quarterly 1956;34:354-430. 
Toverud G. The influence of war and post-war conditions on the teeth of Norwegian school children. II. Caries in the permanent teeth of children aged 7-8 and 12-13 years. Milbank Memorial Fund Quarterly 1957;35:12796.

Toverud G. The influence of war and post-war conditions on the teeth of Norwegian school children. III. Discussion of food supply and dental condition in Norway and other European countries. Milbank Memorial Fund Quarterly 1957;35:373-459.

Tukey JW. Exploratory data analysis. Reading, Mass: Addision-Wesley, 1977.

Tunc ES, Koyuturk AE. Dental age assessment using the Demirjian's method on northern Turkish children. Forensic Sci Int 2008;175:23-6.

Uauy R, Kain J. The epidemiological transition: need to incorporate obesity prevention into nutrition programmes. Public Health Nutr 2002;5:223-9.

Uslenghi S, Liversidge HM, Wong FS. A radiographic study of tooth development in hypodontia. Arch Oral Biol 2006;51:129-33.

Van der Linden FPGM. Transition of the human dentition. Center for Human Growth and Development, monograph number 13. Ann Arbor: University of Michigan Press, 1982.

Van der Linden FPGM, Duterloo JS. Development of the human dentition: an atlas. New York: Harper and Row, 1976.

Van Wieringen JC. Secular growth changes. In: Falkner and Tanner, editors. Human Growth. Vol. 3. New York: Plenum Press 1978:445-72.

Van Wieringen JC. Secular growth changes. In: Falkner F, Tanner JM. Human growth, postnatal growth, 2nd ed. New York: Plenum Press, 1986.

Vercauteren M, Susanne C. The secular trend of height and menarche in Belgium: are there any signs of a future stop? Eur J Pediatr 1985;144:306-9.

Waddington $\mathrm{CH}$. Canalisation of development and the inheritance of acquired characters. Nature 1942;150:563-565.

Waddington $\mathrm{CH}$. The strategy of the genes. London: Allen and Unwin, 1957. 
Walvoord EC. The timing of puberty: Is it changing? Does it matter? J Adolesc Health 2010;47:433-9.

Warren JJ, Bishara SE, Yonezu T. Tooth size-arch length relationships in the deciduous dentition: a comparison between contemporary and historical samples. Am J Orthod Dentofacial Orthop 2003;123:614-9.

Waterlow JC. Classification and definition of protein-calorie malnutrition. $\mathrm{Br}$ Med J 1972;3:566-9.

Winer BJ, Brown DR, Michels KM. Statistical principles in experimental design, 3rd ed. New York: McGraw-Hill Book Company, 1991.

Wise GE. Cellular and molecular basis of tooth eruption. Orthod Craniofac Res 2009;12:67-73.

Woolf CM. Principles of biometry. Princeton, NJ: D Van Nostrand Company, Inc., 1968.

Wyshak G, Frisch RE. Evidence for a secular trend in age of menarche. N Engl J Med 1982;306:1033-35.

Young K, Relethford JH, Crawford MH. Postfamine stature and socioeconomic status in Ireland. Am J Hum Biol 2008;20:726-31.

Zhang A, Sayre JW, Vachon L, Liu BJ, Haung HK. Racial differences in growth patterns of children assessed on the basis of bone age. Radiology 2009;250:228-35. 
APPENDIX A. SURVIVAL ANALYSIS BY TOOTH AND GRADE 
Table A-1. Results of survival analysis for stage $G$ of the mandibular canine.

\begin{tabular}{cccccccccc}
\hline Group & $\mathrm{n}$ & Mean & SEM & Median & Q1 & Q3 & Test & df & P \\
\hline 1980-85 Boys & 57 & 12.96 & 0.10 & 12.91 & 12.61 & 13.44 & Log-Rank $=29.06$ & 3 & $<0.0001$ \\
1980-85 Girls & 51 & 12.06 & 0.16 & 12.16 & 11.18 & 12.70 & Wilcoxon $=46.70$ & 3 & $<0.0001$ \\
2005-10 Boys & 28 & 12.05 & 0.17 & 11.91 & 11.35 & 12.66 & & \\
2005-10 Girls & 22 & 11.39 & 0.22 & 11.38 & 10.45 & 11.81 & & \\
\hline
\end{tabular}

Table A-2. Results of survival analysis for stage $H$ of the mandibular canine.

\begin{tabular}{cccccccccc}
\hline Group & $\mathrm{n}$ & Mean & SEM & Median & Q1 & Q3 & Test & df & P \\
\hline 1980-85 Boys & 29 & 13.73 & 0.14 & 13.73 & 13.25 & 14.21 & Log-Rank $=8.23$ & 3 & 0.0416 \\
1980-85 Girls & 71 & 13.34 & 0.13 & 13.40 & 12.52 & 14.14 & Wilcoxon $=11.10$ & 3 & 0.0112 \\
2005-10 Boys & 56 & 13.61 & 0.11 & 13.72 & 13.09 & 14.10 & & \\
2005-10 Girls & 86 & 13.05 & 0.13 & 13.27 & 12.10 & 13.97 & & \\
\hline
\end{tabular}


Table A-3. Results of survival analysis for stage $F$ of the mandibular first premolar.

\begin{tabular}{cccccccccc}
\hline Group & $\mathrm{n}$ & Mean & SEM & Median & Q1 & Q3 & Test & df & P \\
\hline 1980-85 Boys & 11 & 11.74 & 0.28 & 11.49 & 11.04 & 12.23 & Log-Rank $=5.54$ & 3 & 0.1364 \\
1980-85 Girls & 12 & 10.82 & 0.30 & 10.55 & 10.27 & 11.29 & Wilcoxon $=6.97$ & 3 & 0.0727 \\
2005-10 Boys & 12 & 11.16 & 0.26 & 10.87 & 10.60 & 11.80 & & \\
2005-10 Girls & 9 & 10.82 & 0.24 & 10.60 & 10.18 & 11.28 & & \\
\hline
\end{tabular}

Table A-4. Results of survival analysis for stage G of the mandibular first premolar.

\begin{tabular}{cccccccccc}
\hline Group & $\mathrm{n}$ & Mean & SEM & Median & Q1 & Q3 & Test & df & P \\
\hline 1980-85 Boys & 56 & 13.03 & 0.10 & 13.06 & 12.61 & 13.62 & Log-Rank $=21.83$ & 3 & $<0.0001$ \\
1980-85 Girls & 59 & 12.35 & 0.14 & 12.24 & 11.57 & 12.97 & Wilcoxon $=39.58$ & 3 & $<0.0001$ \\
2005-10 Boys & 28 & 11.93 & 0.19 & 11.84 & 11.25 & 12.28 & & \\
2005-10 Girls & 23 & 11.70 & 0.23 & 11.43 & 10.82 & 12.05 & & \\
\hline
\end{tabular}


Table A-5. Results of survival analysis for stage $\mathbf{H}$ of the mandibular first premolar.

\begin{tabular}{cccccccccc}
\hline Group & $\mathrm{n}$ & Mean & SEM & Median & Q1 & Q3 & Test & df & P \\
\hline 1980-85 Boys & 31 & 13.68 & 0.13 & 13.67 & 13.15 & 14.23 & Log-Rank $=5.19$ & 3 & 0.1585 \\
1980-85 Girls & 61 & 13.47 & 0.13 & 13.46 & 12.69 & 14.19 & Wilcoxon $=4.40$ & 3 & 0.2212 \\
2005-10 Boys & 59 & 13.50 & 0.12 & 13.64 & 12.95 & 14.06 & & \\
2005-10 Girls & 76 & 13.22 & 0.12 & 13.31 & 12.40 & 14.02 & & \\
\hline
\end{tabular}

Table A-6. Results of survival analysis for stage $F$ of the mandibular second premolar.

\begin{tabular}{cccccccccc}
\hline Group & $\mathrm{n}$ & Mean & SEM & Median & Q1 & Q3 & Test & df & P \\
\hline 1980-85 Boys & 37 & 12.61 & 0.15 & 12.68 & 11.97 & 13.19 & Log-Rank $=18.76$ & 3 & 0.0003 \\
1980-85 Girls & 38 & 11.57 & 0.15 & 11.65 & 10.83 & 12.21 & Wilcoxon $=24.82$ & 3 & $<0.0001$ \\
2005-10 Boys & 37 & 11.67 & 0.16 & 11.64 & 10.90 & 12.31 & & \\
2005-10 Girls & 29 & 11.47 & 0.21 & 11.34 & 10.66 & 11.80 & & \\
\hline
\end{tabular}


Table A-7. Results of survival analysis for stage G of the mandibular second premolar.

\begin{tabular}{cccccccccc}
\hline Group & $\mathrm{n}$ & Mean & SEM & Median & Q1 & Q3 & Test & df & P \\
\hline 1980-85 Boys & 52 & 13.35 & 0.10 & 13.27 & 12.74 & 13.74 & Log-Rank $=14.03$ & 3 & 0.0029 \\
1980-85 Girls & 67 & 13.13 & 0.12 & 13.02 & 12.44 & 13.80 & Wilcoxon $=16.70$ & 3 & 0.0008 \\
2005-10 Boys & 28 & 12.93 & 0.18 & 13.01 & 12.03 & 13.72 & & \\
2005-10 Girls & 32 & 12.45 & 0.18 & 12.31 & 11.64 & 13.27 & & \\
\hline
\end{tabular}

Table A-8. Results of survival analysis for stage $H$ of the mandibular second premolar. LP2=H

\begin{tabular}{cccccccccc}
\hline Group & $\mathrm{n}$ & Mean & SEM & Median & Q1 & Q3 & Test & df & P \\
\hline 1980-85 Boys & 7 & 14.24 & 0.25 & 13.88 & 13.45 & 14.82 & Log-Rank $=4.32$ & 3 & 0.2286 \\
1980-85 Girls & 24 & 13.64 & 0.23 & 13.61 & 13.07 & 14.72 & Wilcoxon $=3.00$ & 3 & 0.3918 \\
2005-10 Boys & 35 & 13.89 & 0.11 & 13.85 & 13.31 & 14.43 & & \\
2005-10 Girls & 46 & 13.64 & 0.13 & 13.74 & 13.04 & 14.45 & & \\
\hline
\end{tabular}


Table A-9. Results of survival analysis for stage $H$ of the mandibular first molar.

\begin{tabular}{crrrrrrrrr}
\hline Group & $\mathrm{n}$ & Mean & SEM & Median & Q1 & Q3 & Test & df & P \\
\hline 1980-85 Boys & 90 & 13.18 & 0.09 & 13.13 & 12.66 & 13.73 & Log-Rank $=1.37$ & 3 & 0.7129 \\
1980-85 Girls & 129 & 12.80 & 0.11 & 12.73 & 12.00 & 13.62 & Wilcoxon $=6.01$ & 3 & 0.1113 \\
2005-10 Boys & 96 & 12.83 & 0.13 & 13.02 & 11.77 & 13.81 & & \\
2005-10 Girls & 108 & 12.73 & 0.13 & 12.93 & 11.57 & 13.86 & & \\
\hline
\end{tabular}

Table A-10. Results of survival analysis for stage $F$ of the mandibular second molar.

\begin{tabular}{cccccccccc}
\hline Group & $\mathrm{n}$ & Mean & SEM & Median & Q1 & Q3 & Test & df & P \\
\hline 1980-85 Boys & 28 & 12.58 & 0.13 & 12.61 & 11.97 & 13.09 & Log-Rank $=18.49$ & 3 & 0.0003 \\
1980-85 Girls & 28 & 11.54 & 0.17 & 11.66 & 10.83 & 12.15 & Wilcoxon $=29.16$ & 3 & $<0.0001$ \\
2005-10 Boys & 27 & 11.84 & 0.17 & 11.71 & 11.16 & 12.31 & & \\
2005-10 Girls & 20 & 11.25 & 0.21 & 11.38 & 10.33 & 11.61 & & \\
\hline
\end{tabular}


Table A-11. Results of survival analysis for stage $G$ of the mandibular second molar.

\begin{tabular}{cccccccccc}
\hline Group & $\mathrm{n}$ & Mean & SEM & Median & Q1 & Q3 & Test & df & P \\
\hline 1980-85 Boys & 62 & 13.35 & 0.09 & 13.27 & 12.82 & 13.74 & Log-Rank $=7.15$ & 3 & 0.0672 \\
1980-85 Girls & 93 & 13.11 & 0.11 & 13.04 & 12.37 & 13.75 & Wilcoxon $=9.37$ & 3 & 0.0248 \\
2005-10 Boys & 53 & 13.09 & 0.14 & 13.29 & 12.66 & 13.77 & & \\
2005-10 Girls & 59 & 12.76 & 0.14 & 12.89 & 11.94 & 13.57 & & \\
\hline
\end{tabular}

Table A-12. Results of survival analysis for stage $H$ of the mandibular second molar.

\begin{tabular}{lrcccccccc}
\hline Group & $\mathrm{n}$ & Mean & SEM & Median & Q1 & Q3 & Test & df & P \\
\hline 1980-85 Boys & 5 & 14.45 & 0.24 & 14.42 & 13.88 & 14.77 & Log-Rank $=3.61$ & 3 & 0.3062 \\
1980-85 Girls & 8 & 13.90 & 0.33 & 13.80 & 13.14 & 14.78 & Wilcoxon $=3.32$ & 3 & 0.3454 \\
2005-10 Boys & 15 & 14.29 & 0.14 & 14.35 & 13.83 & 14.64 & & \\
2005-10 Girls & 26 & 13.93 & 0.15 & 14.10 & 13.38 & 14.48 & & \\
\hline
\end{tabular}


Table A-13. Results of survival analysis for stage B of the mandibular third molar.

\begin{tabular}{cccccccccc}
\hline Group & $\mathrm{n}$ & Mean & SEM & Median & Q1 & Q3 & Test & df & P \\
\hline 1980-85 Boys & 10 & 12.64 & 0.37 & 12.89 & 11.83 & 13.08 & Log-Rank $=2.45$ & 3 & 0.4842 \\
1980-85 Girls & 12 & 11.97 & 0.40 & 12.04 & 11.22 & 12.47 & Wilcoxon $=4.27$ & 3 & 0.234 \\
2005-10 Boys & 12 & 12.11 & 0.30 & 11.96 & 11.35 & 12.63 & & \\
2005-10 Girls & 9 & 11.71 & 0.41 & 11.52 & 10.74 & 11.73 & & \\
\hline
\end{tabular}

Table A-14. Results of survival analysis for stage $C$ of the mandibular third molar.

\begin{tabular}{cccccccccc}
\hline Group & $\mathrm{n}$ & Mean & SEM & Median & Q1 & Q3 & Test & df & P \\
\hline 1980-85 Boys & 26 & 12.88 & 0.18 & 12.84 & 12.06 & 13.55 & Log-Rank $=10.17$ & 3 & 0.0172 \\
1980-85 Girls & 53 & 12.48 & 0.16 & 12.45 & 11.62 & 13.19 & Wilcoxon $=14.16$ & 3 & 0.0027 \\
2005-10 Boys & 20 & 11.68 & 0.24 & 11.44 & 10.90 & 11.89 & & \\
2005-10 Girls & 22 & 12.13 & 0.28 & 12.09 & 10.93 & 13.29 & & \\
\hline
\end{tabular}


Table A-15. Results of survival analysis for stage D of the mandibular third molar.

\begin{tabular}{cccccccccc}
\hline Group & $\mathrm{n}$ & Mean & SEM & Median & Q1 & Q3 & Test & df & P \\
\hline 1980-85 Boys & 20 & 13.22 & 0.15 & 13.25 & 12.74 & 13.73 & Log-Rank $=0.07$ & 3 & 0.9952 \\
1980-85 Girls & 25 & 13.20 & 0.15 & 13.25 & 12.58 & 13.60 & Wilcoxon $=0.46$ & 3 & 0.9284 \\
2005-10 Boys & 27 & 13.04 & 0.20 & 13.01 & 12.44 & 13.79 & & \\
2005-10 Girls & 45 & 12.98 & 0.16 & 13.21 & 12.11 & 13.74 & & \\
\hline
\end{tabular}

Table A-16. Results of survival analysis for stage $E$ of the mandibular third molar.

\begin{tabular}{cccccccccc}
\hline Group & $\mathrm{n}$ & Mean & SEM & Median & Q1 & Q3 & Test & df & P \\
\hline 1980-85 Boys & 12 & 14.00 & 0.20 & 13.92 & 13.55 & 14.64 & Log-Rank $=2.08$ & 3 & 0.5555 \\
1980-85 Girls & 16 & 13.86 & 0.27 & 13.98 & 12.92 & 14.89 & Wilcoxon $=0.33$ & 3 & 0.9547 \\
2005-10 Boys & 17 & 13.90 & 0.16 & 13.81 & 13.52 & 14.12 & & \\
2005-10 Girls & 16 & 13.74 & 0.28 & 14.27 & 13.11 & 14.56 & & \\
\hline
\end{tabular}


APPENDIX B. PLOTS OF SURVIVAL ANALYSIS 


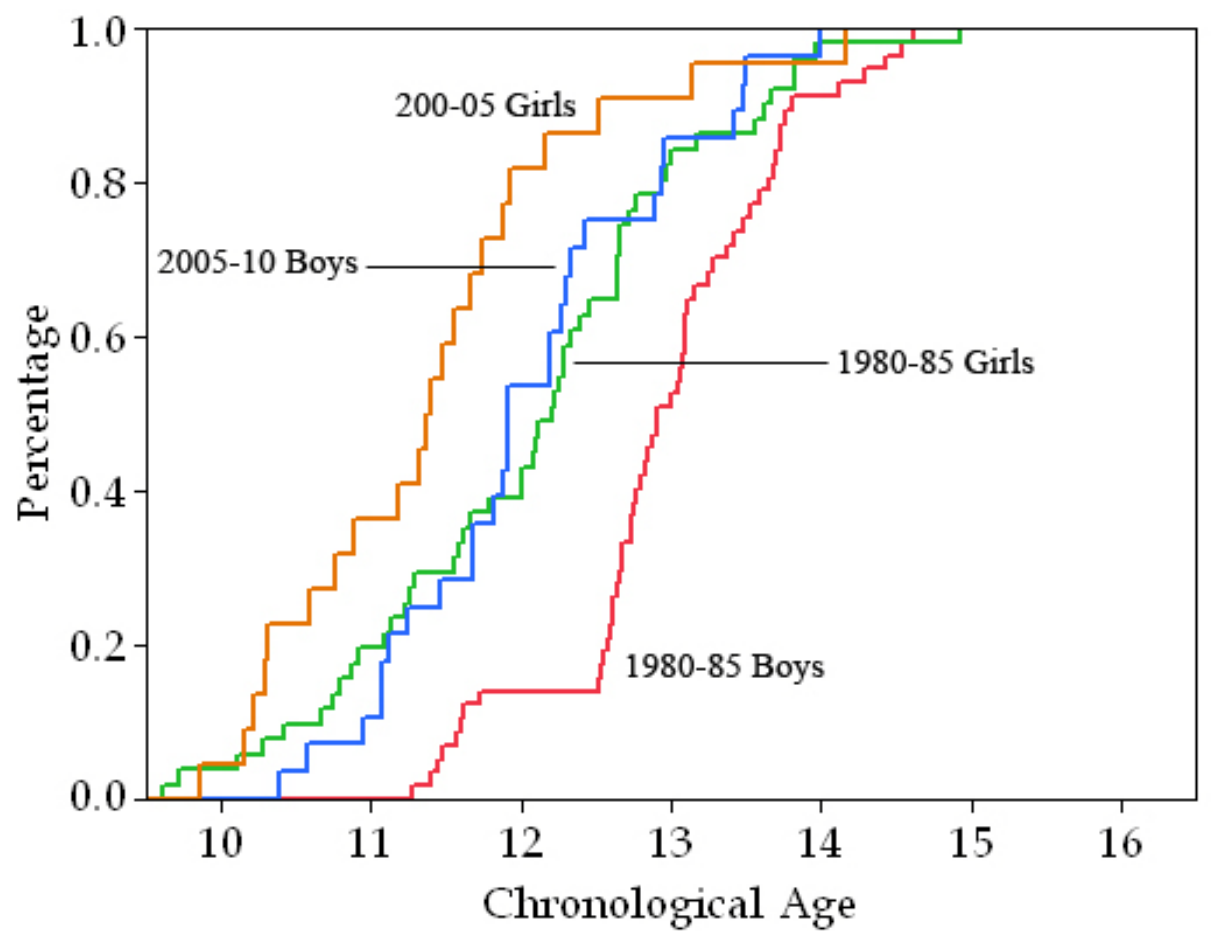

Figure B-1. Results of survival analysis applied to stage G of the mandibular canine. 


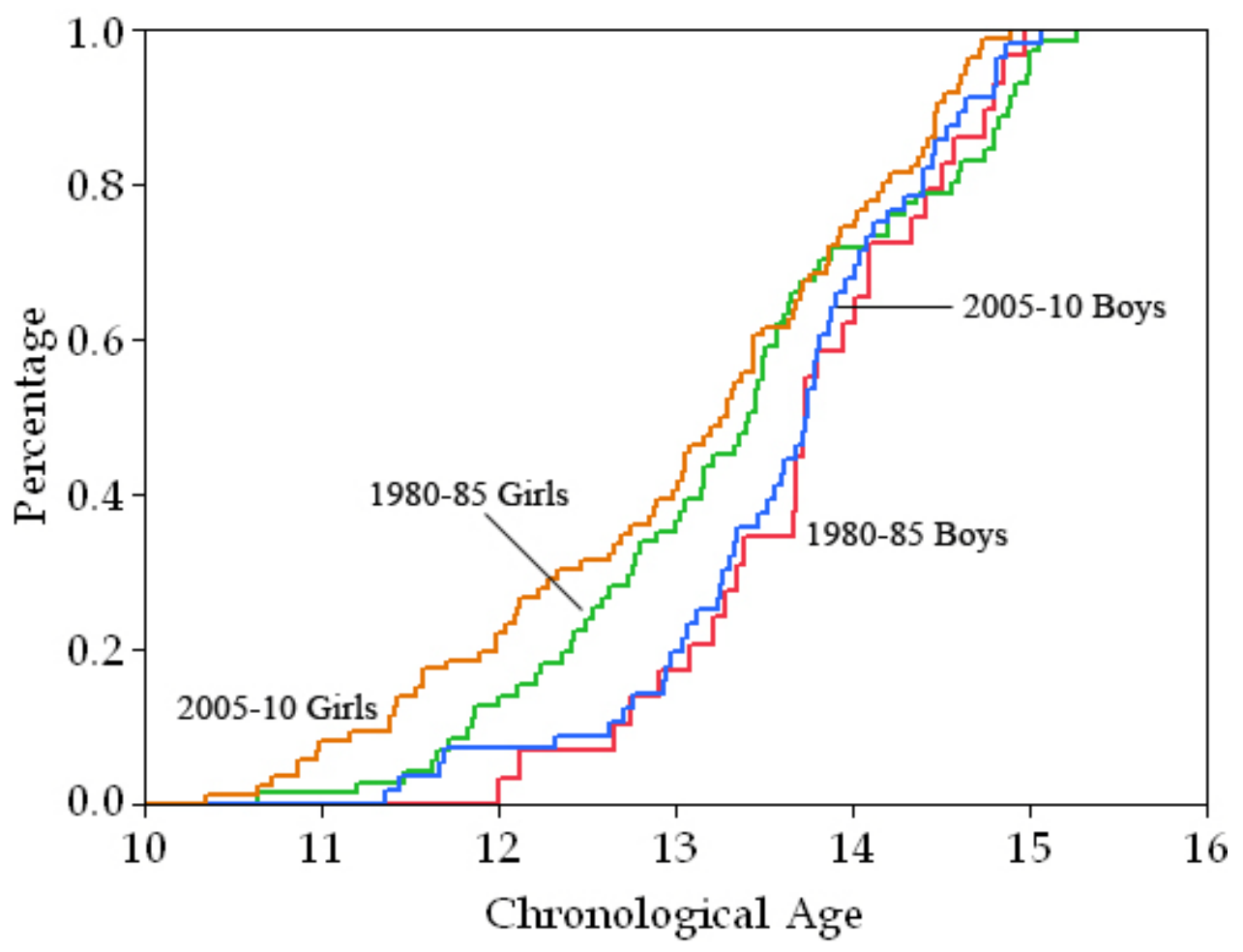

Figure B-2. Results of survival analysis applied to stage $H$ of the mandibular canine. 


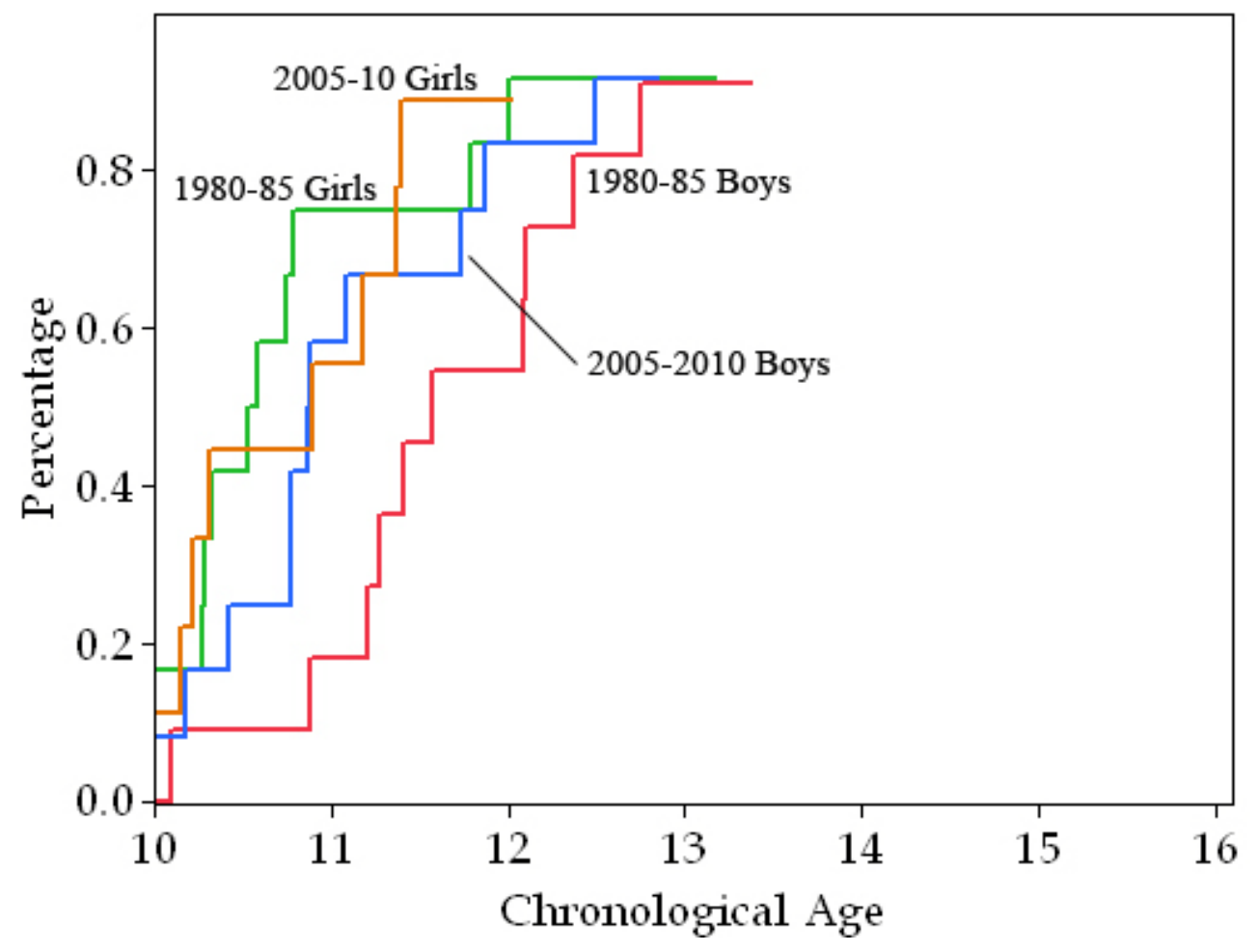

Figure B-3. Results of survival analysis applied to stage F of the mandibular first premolar. 


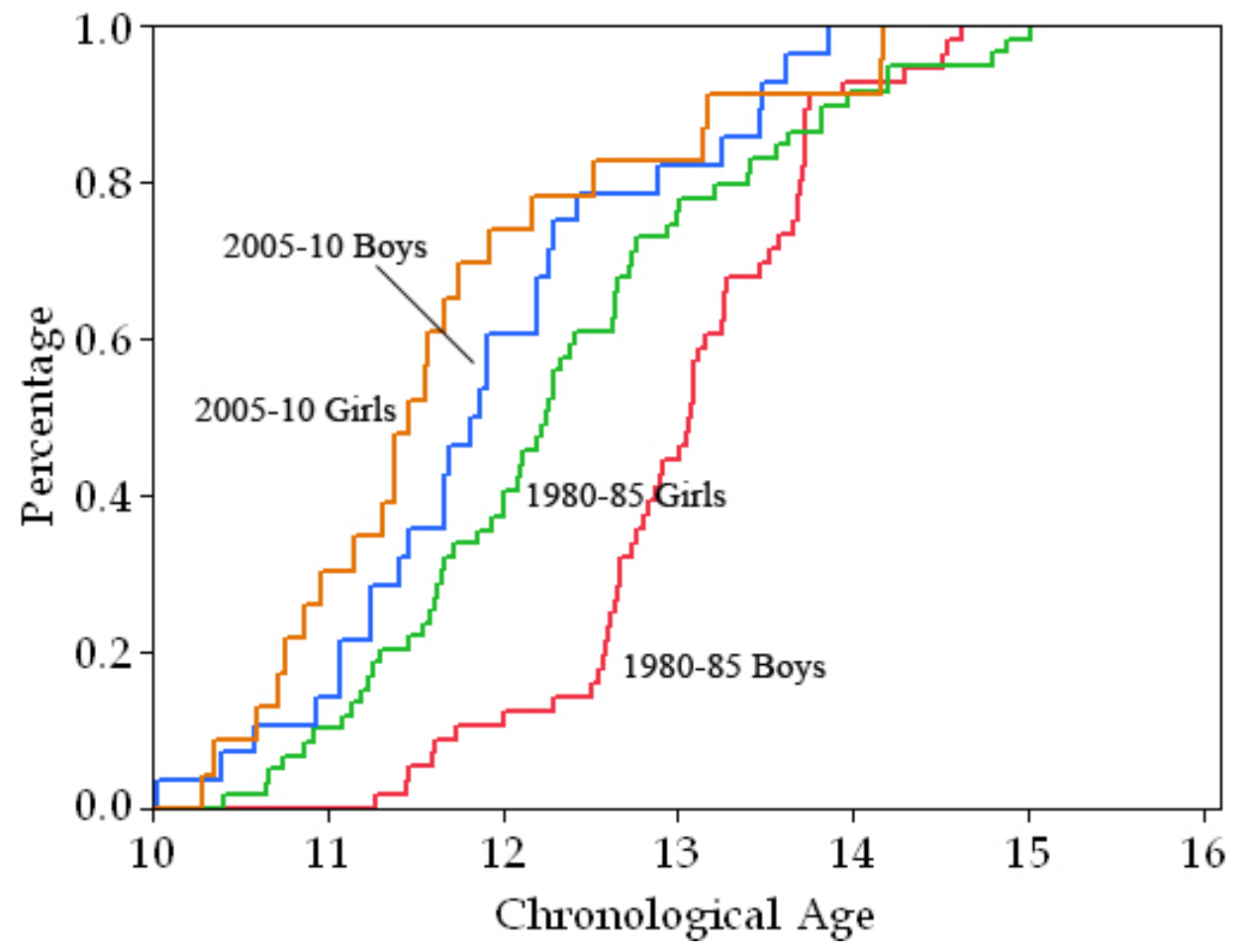

Figure B-4. Results of survival analysis applied to stage $G$ of the mandibular first premolar. 


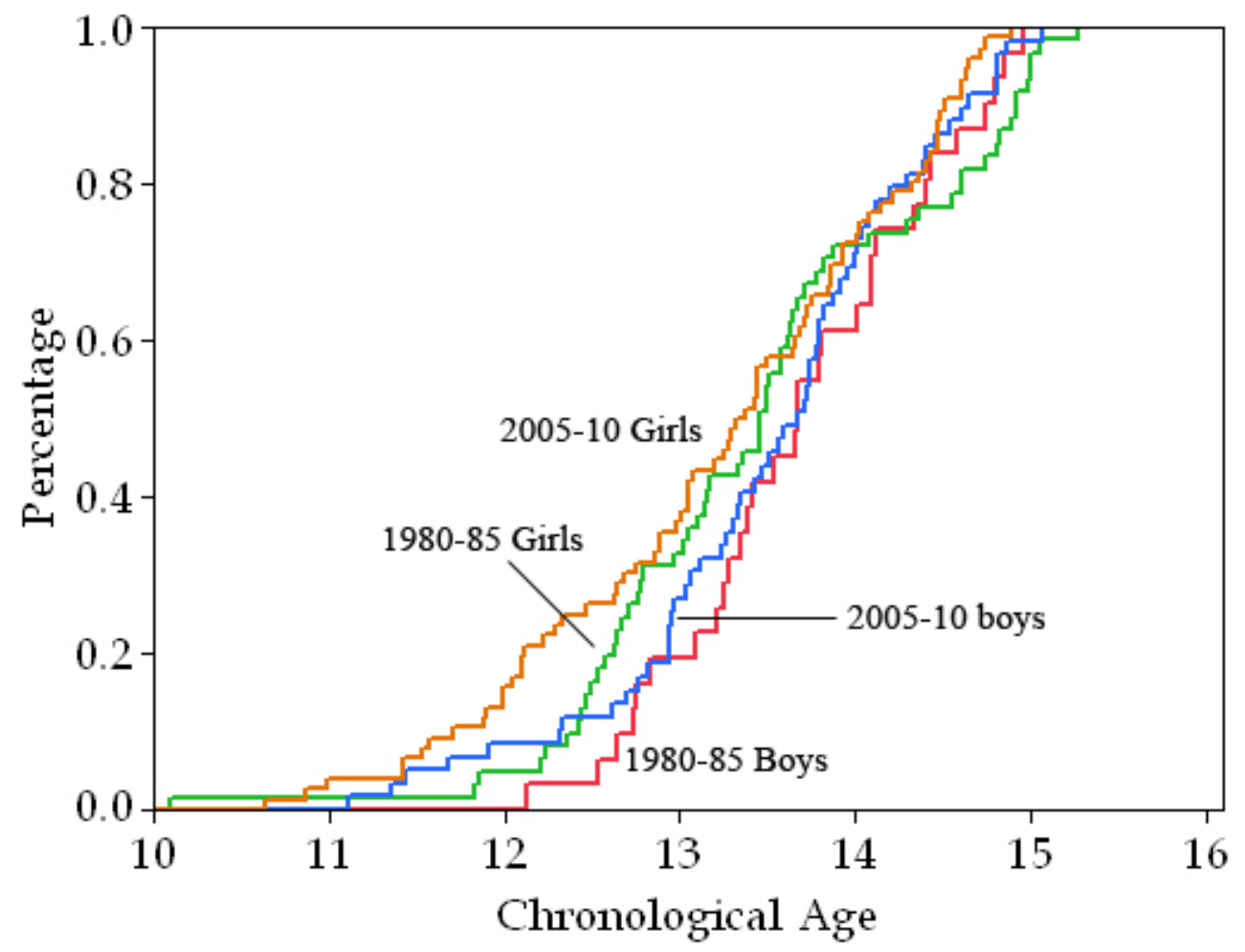

Figure B-5. Results of survival analysis applied to stage $H$ of the mandibular first premolar. 


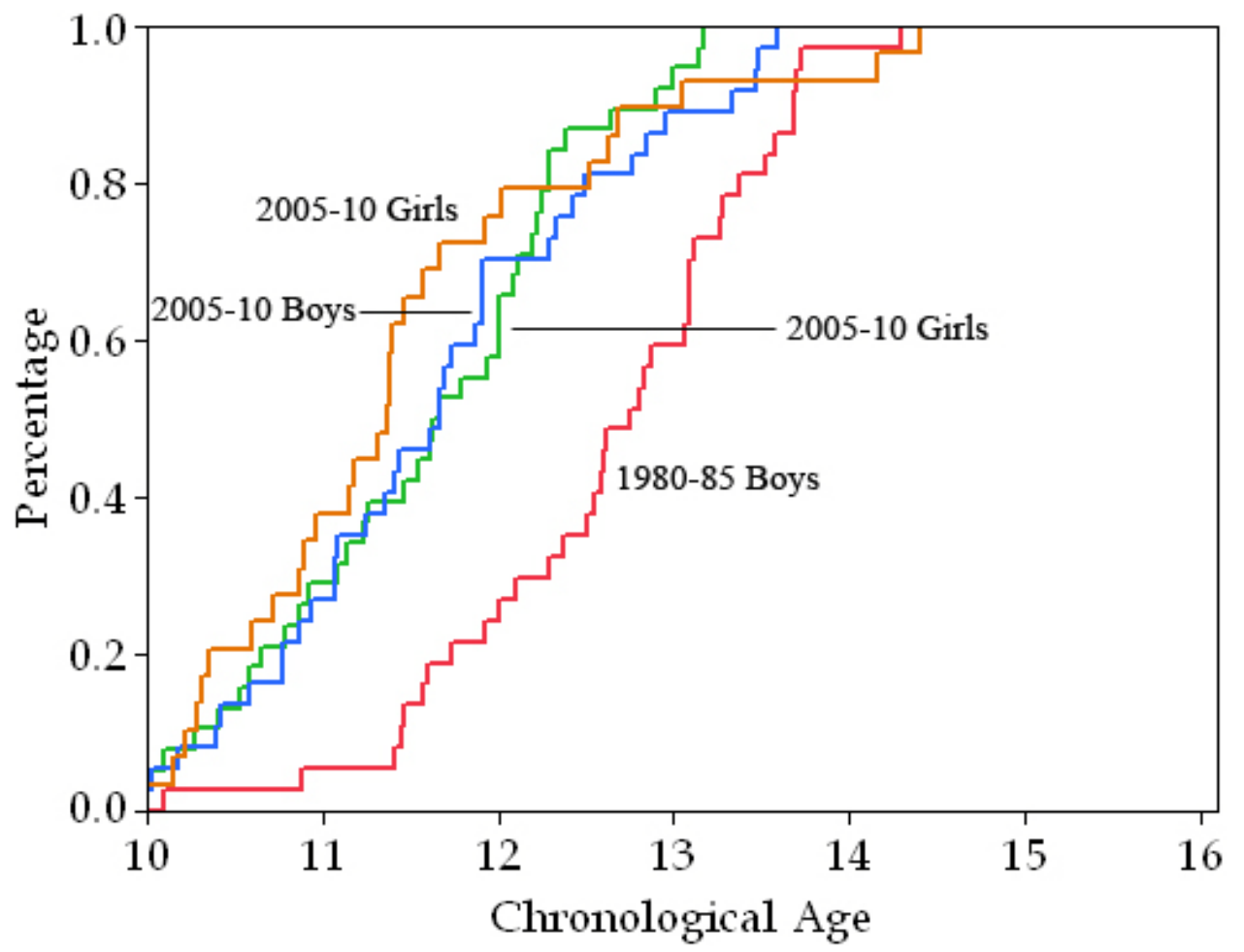

Figure B-6. Results of survival analysis applied to stage F of the mandibular second premolar. 


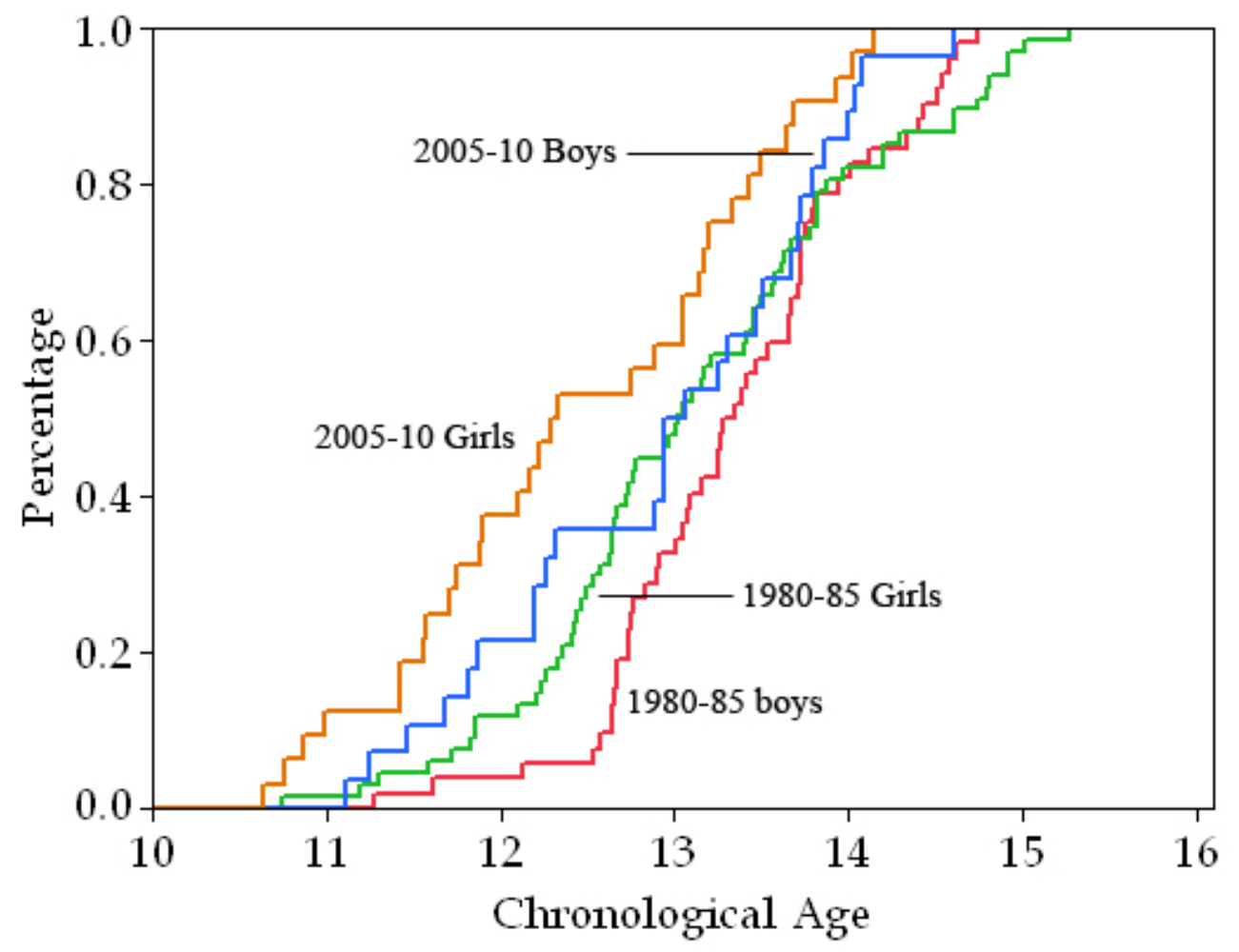

Figure B-7. Results of survival analysis applied to stage $G$ of the mandibular second premolar. 


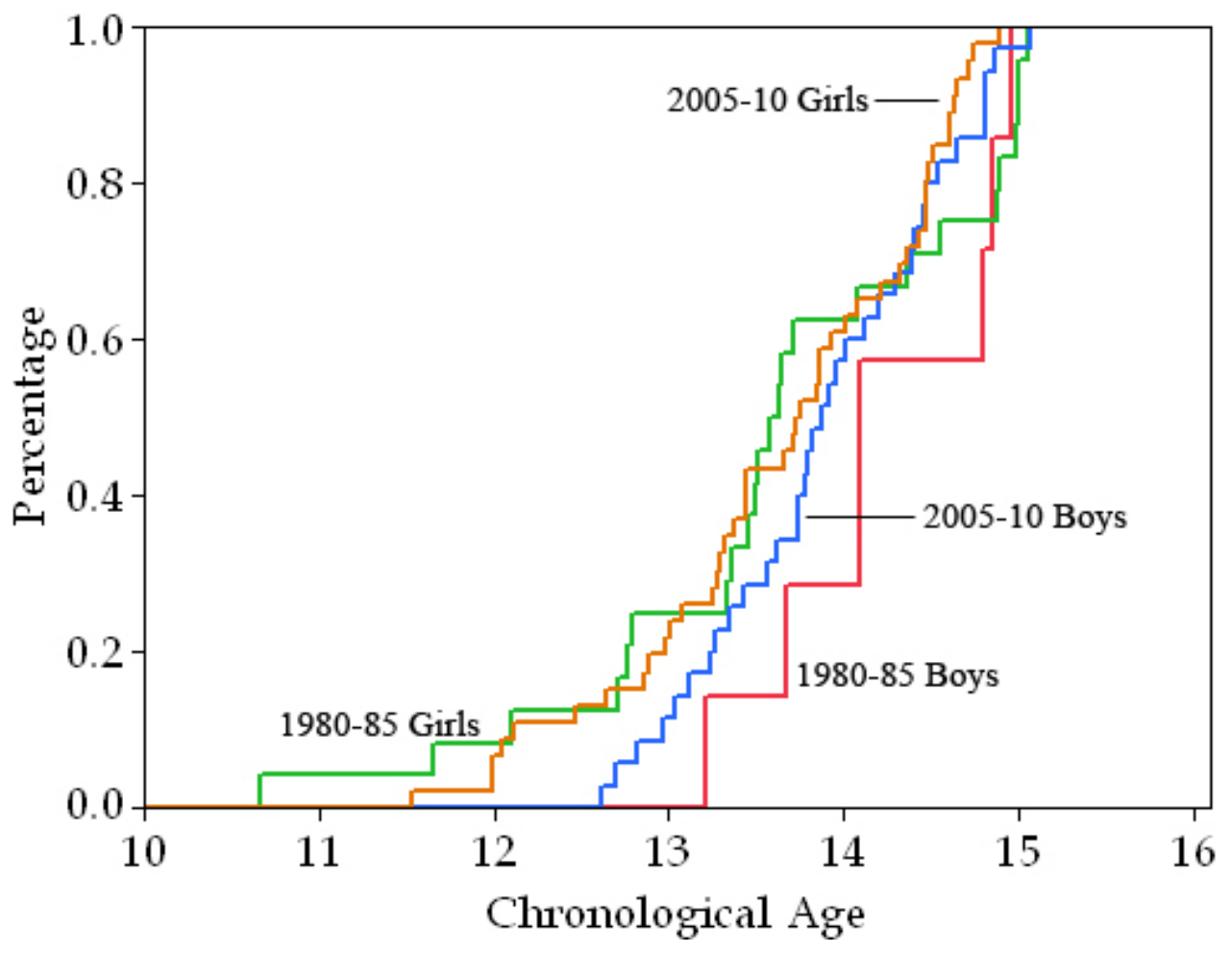

Figure B-8. Results of survival analysis applied to stage $H$ of the mandibular second premolar. 


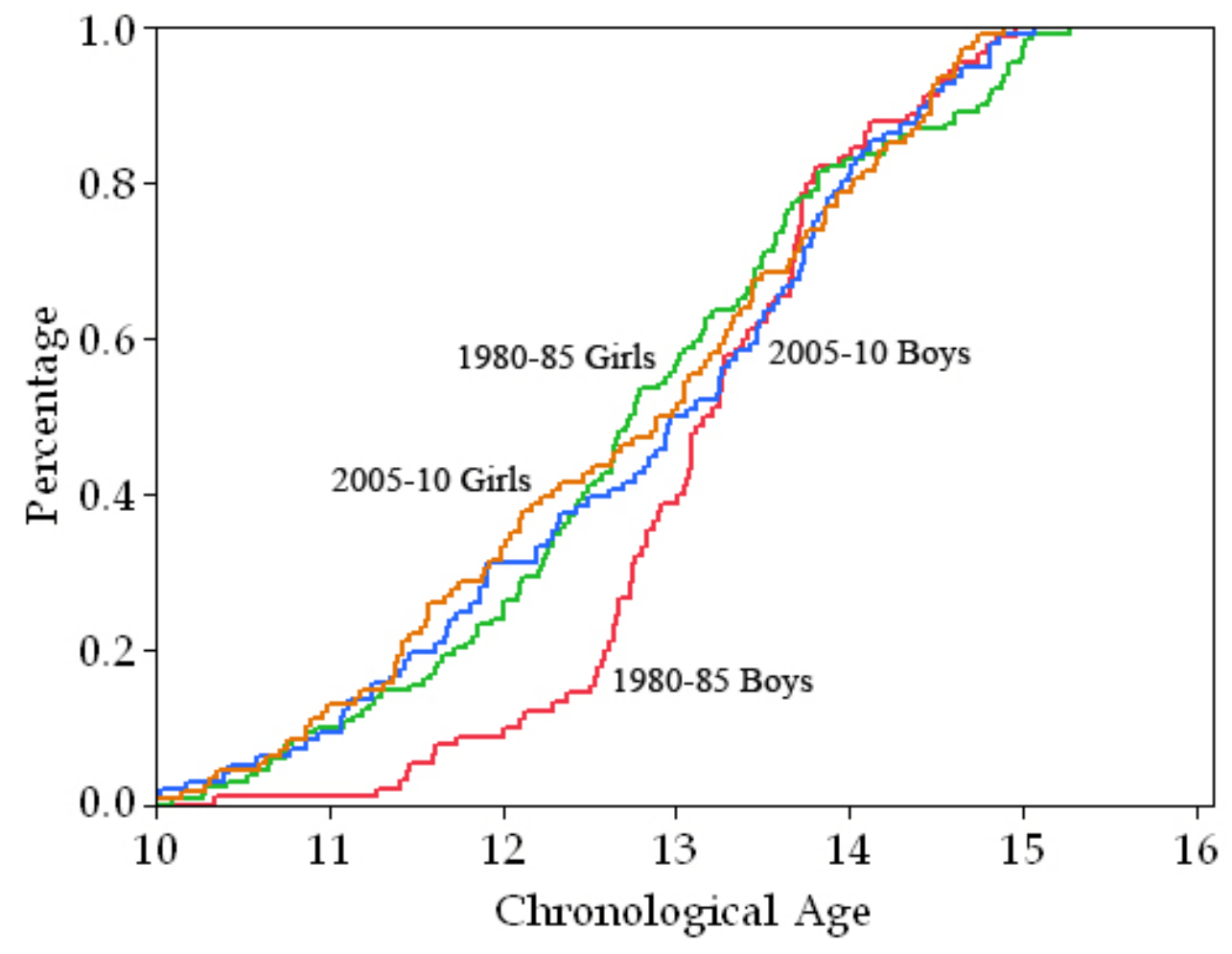

Figure B-9. Results of survival analysis applied to stage $H$ of the mandibular first molar. 


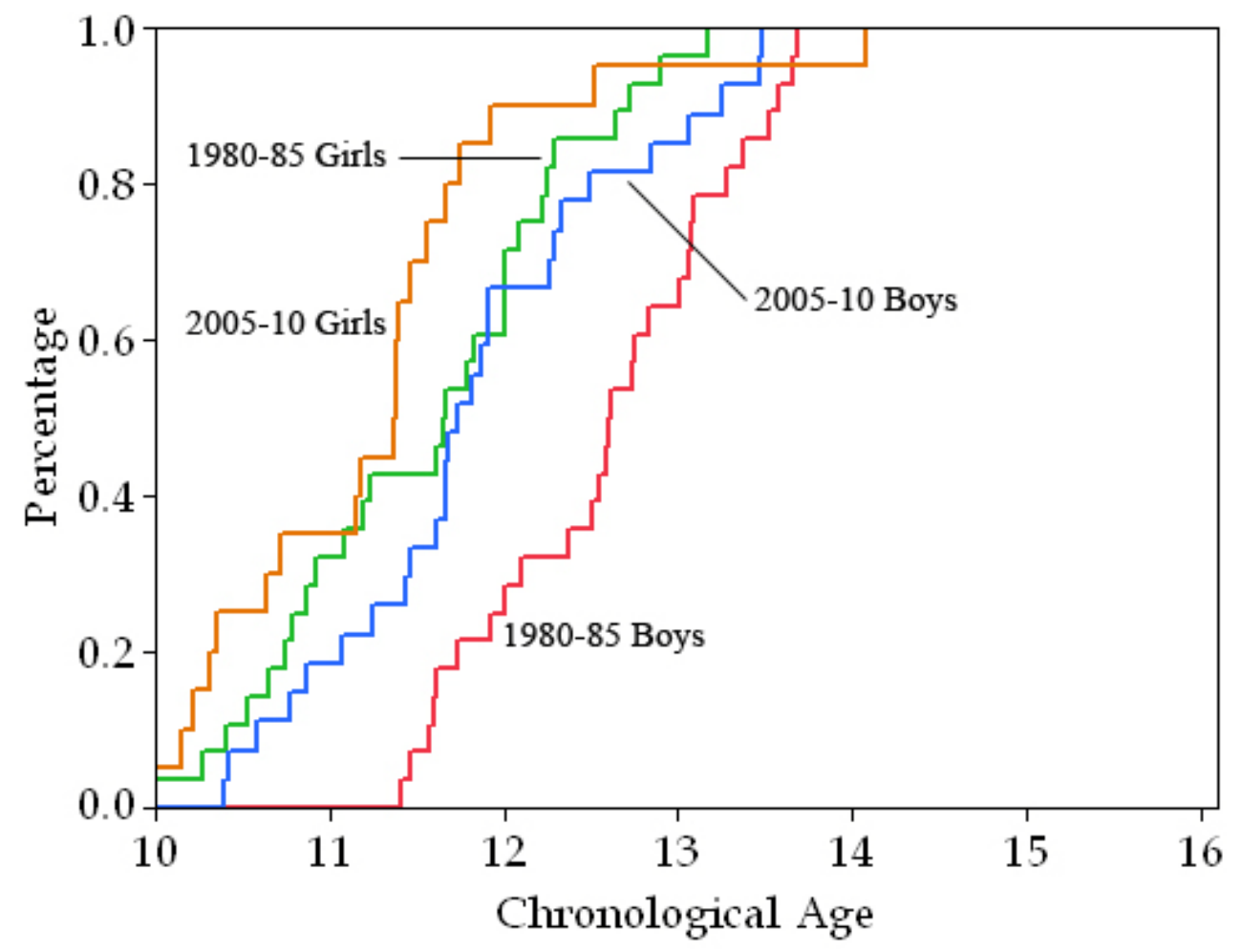

Figure B-10. Results of survival analysis applied to stage F of the mandibular second molar. 


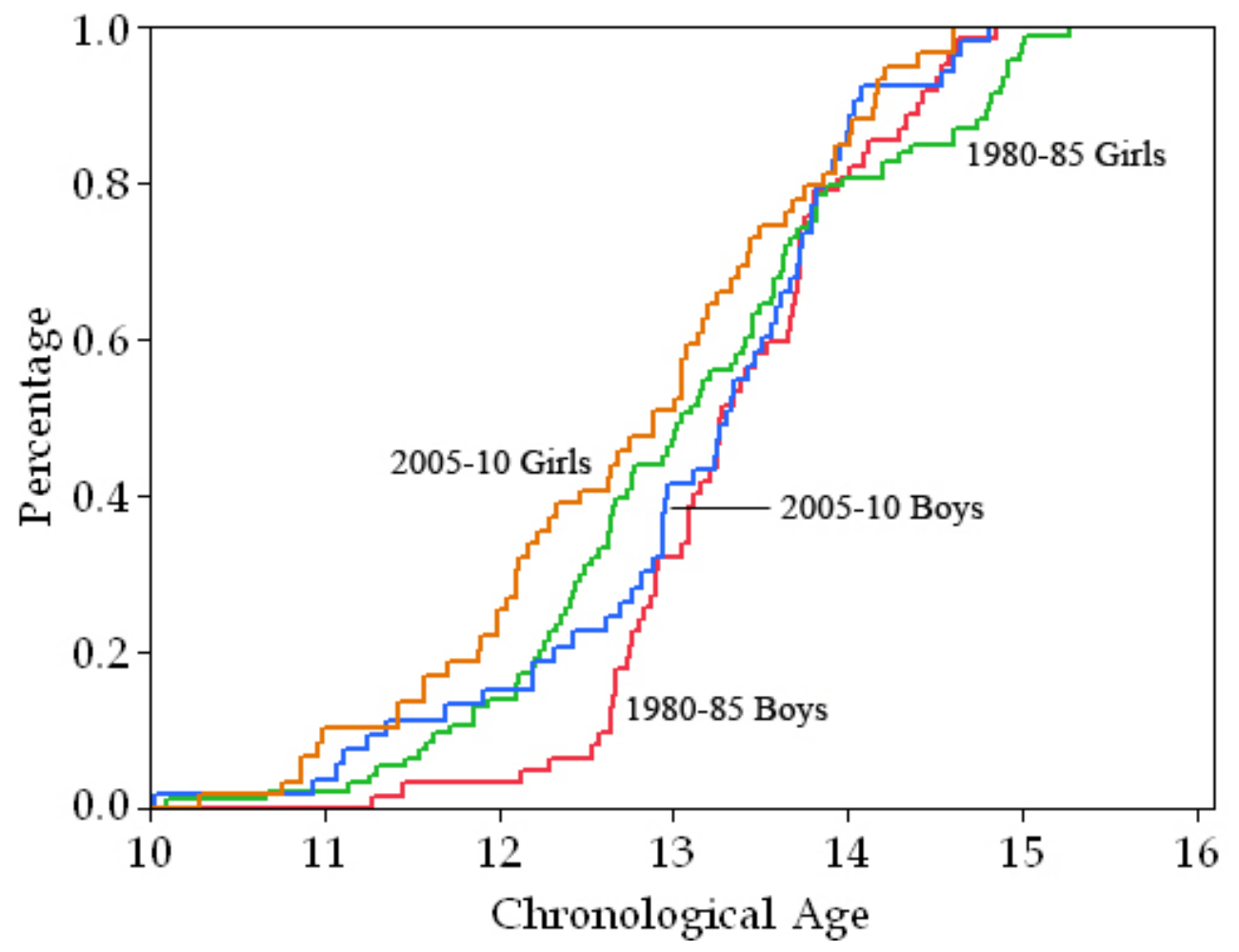

Figure B-11. Results of survival analysis applied to stage $G$ of the mandibular second molar. 


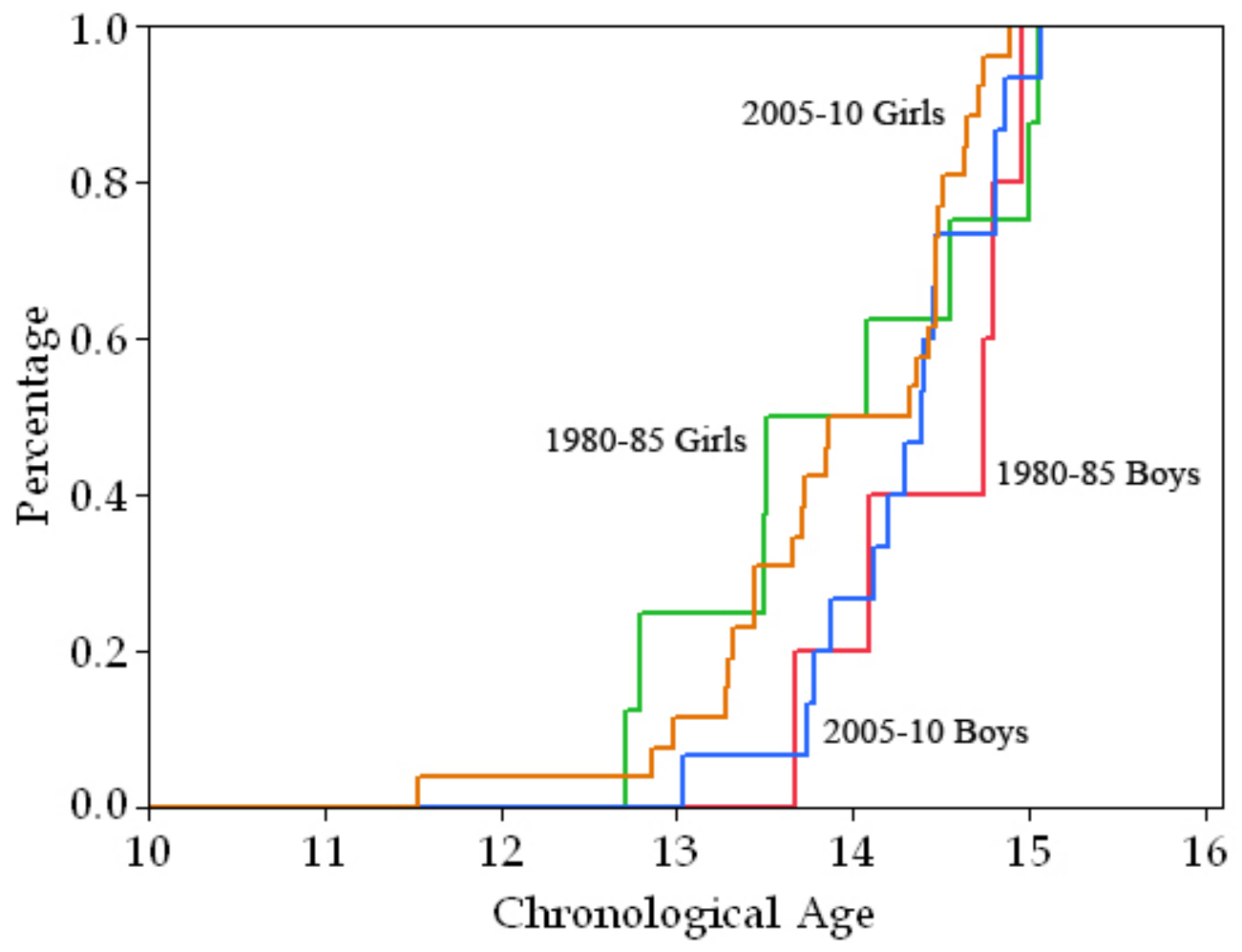

Figure B-12. Results of survival analysis applied to stage $\mathrm{H}$ of the mandibular second molar. 


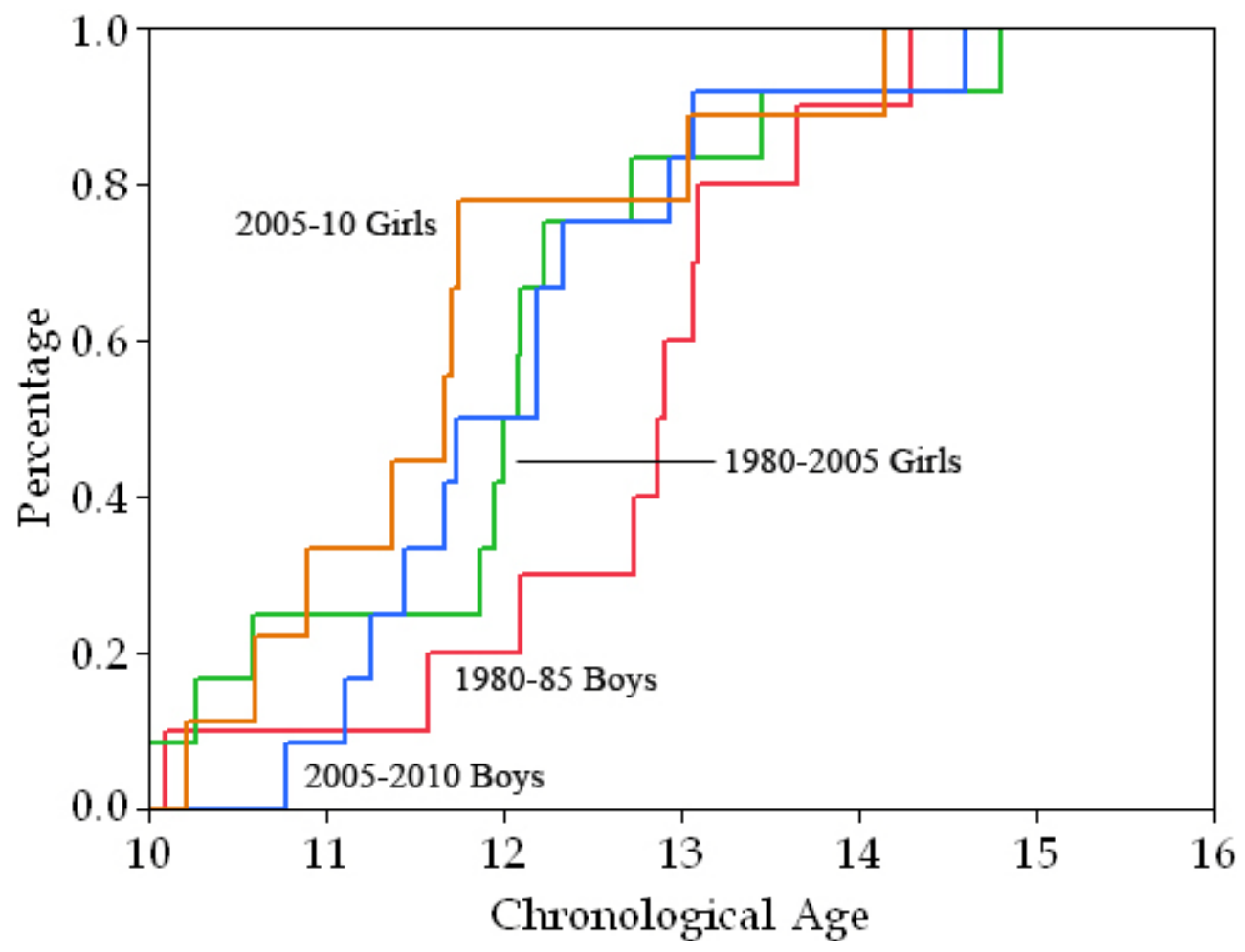

Figure B-13. Results of survival analysis applied to stage B of the mandibular third molar. 


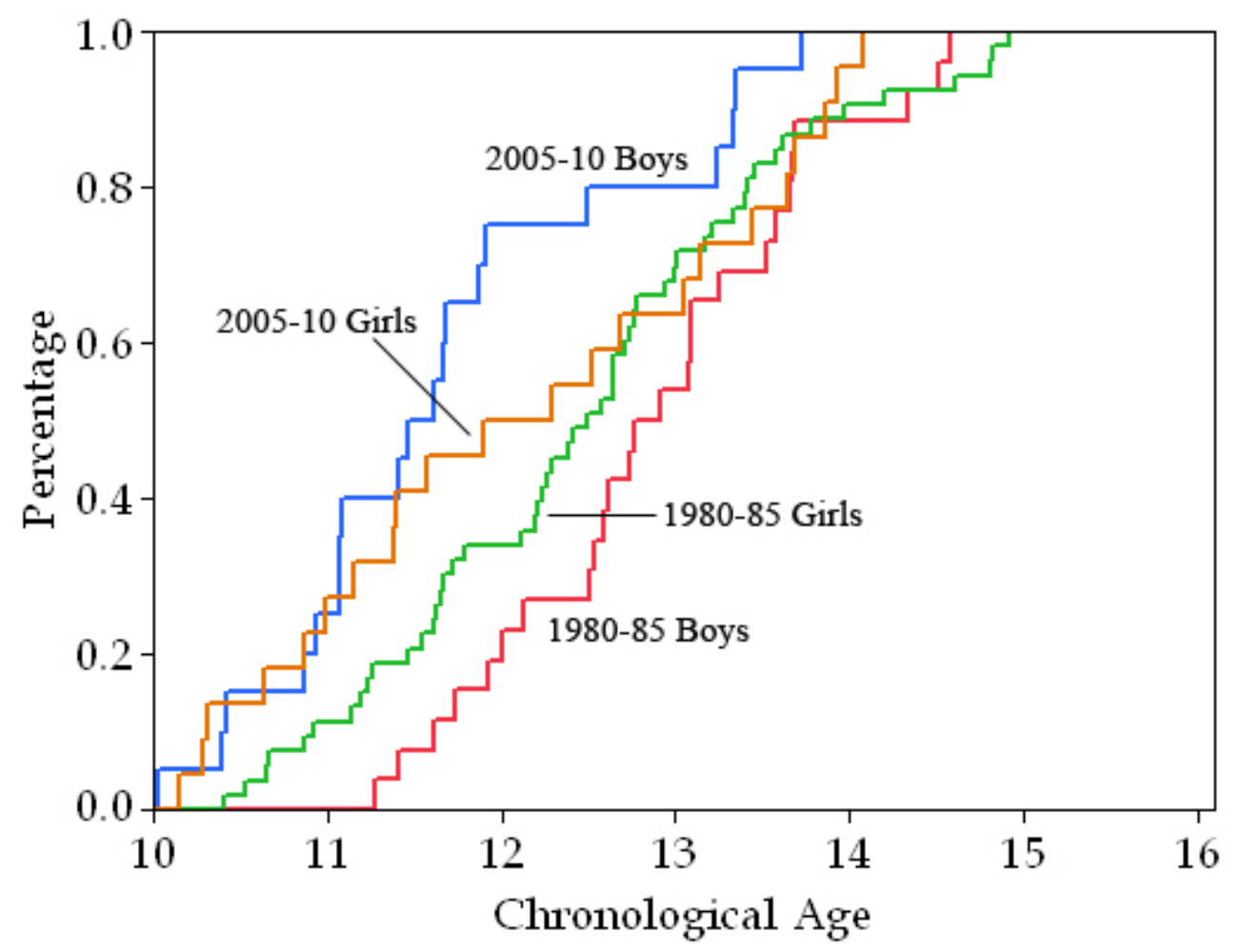

Figure B-14. Results of survival analysis applied to stage $C$ of the mandibular third molar. 


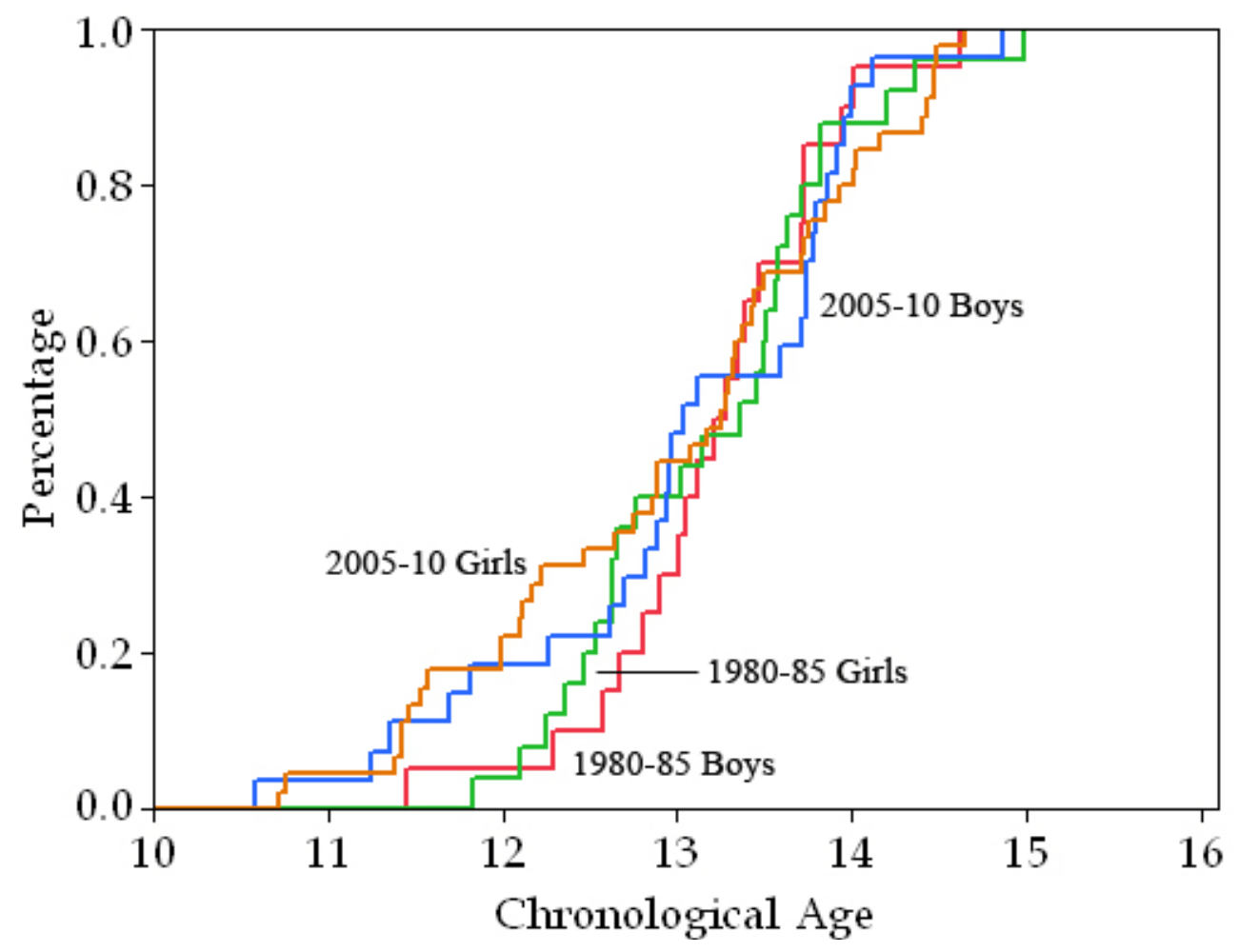

Figure B-15. Results of survival analysis applied to stage $D$ of the mandibular third molar. 


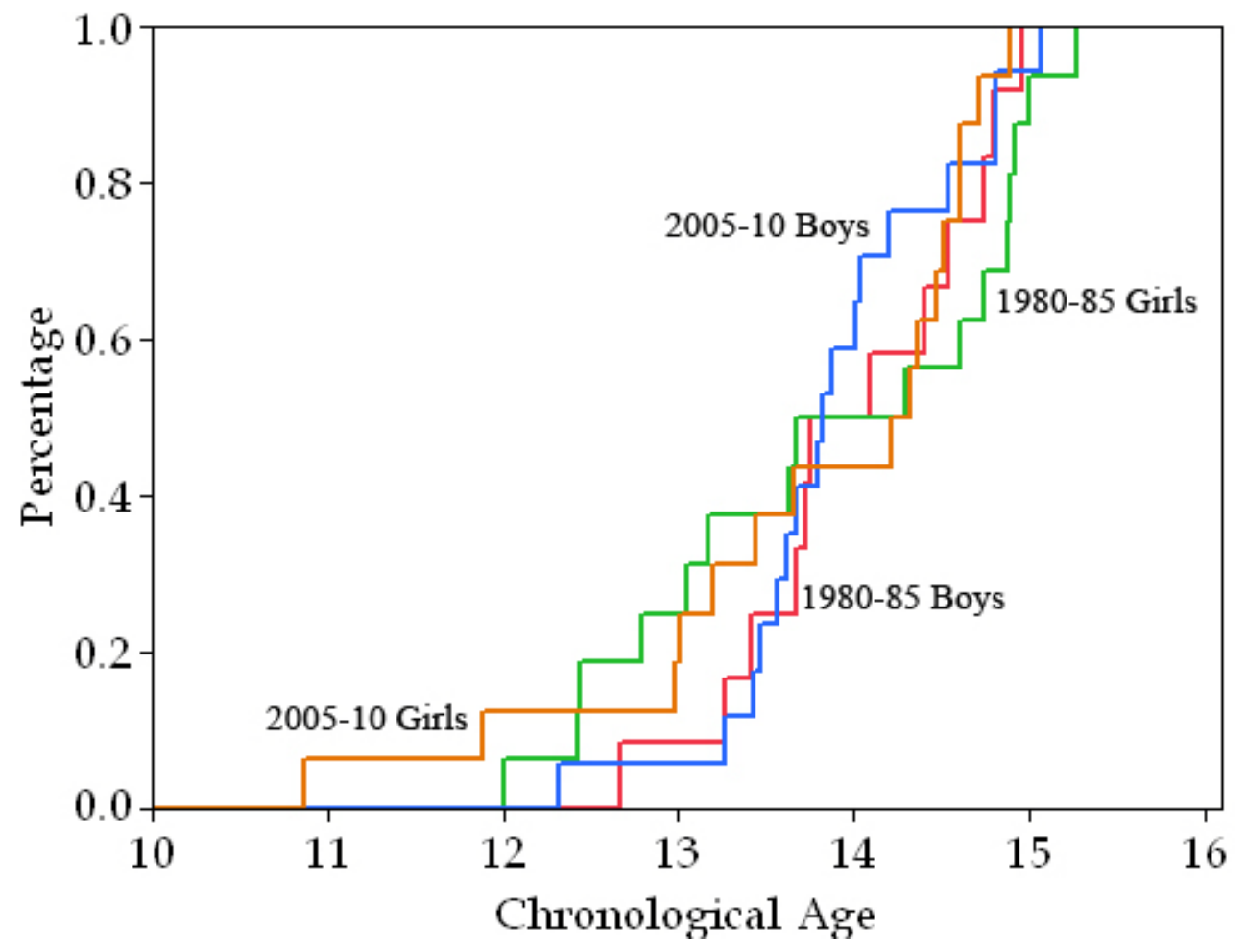

Figure B-16. Results of survival analysis applied to stage E of the mandibular third molar. 


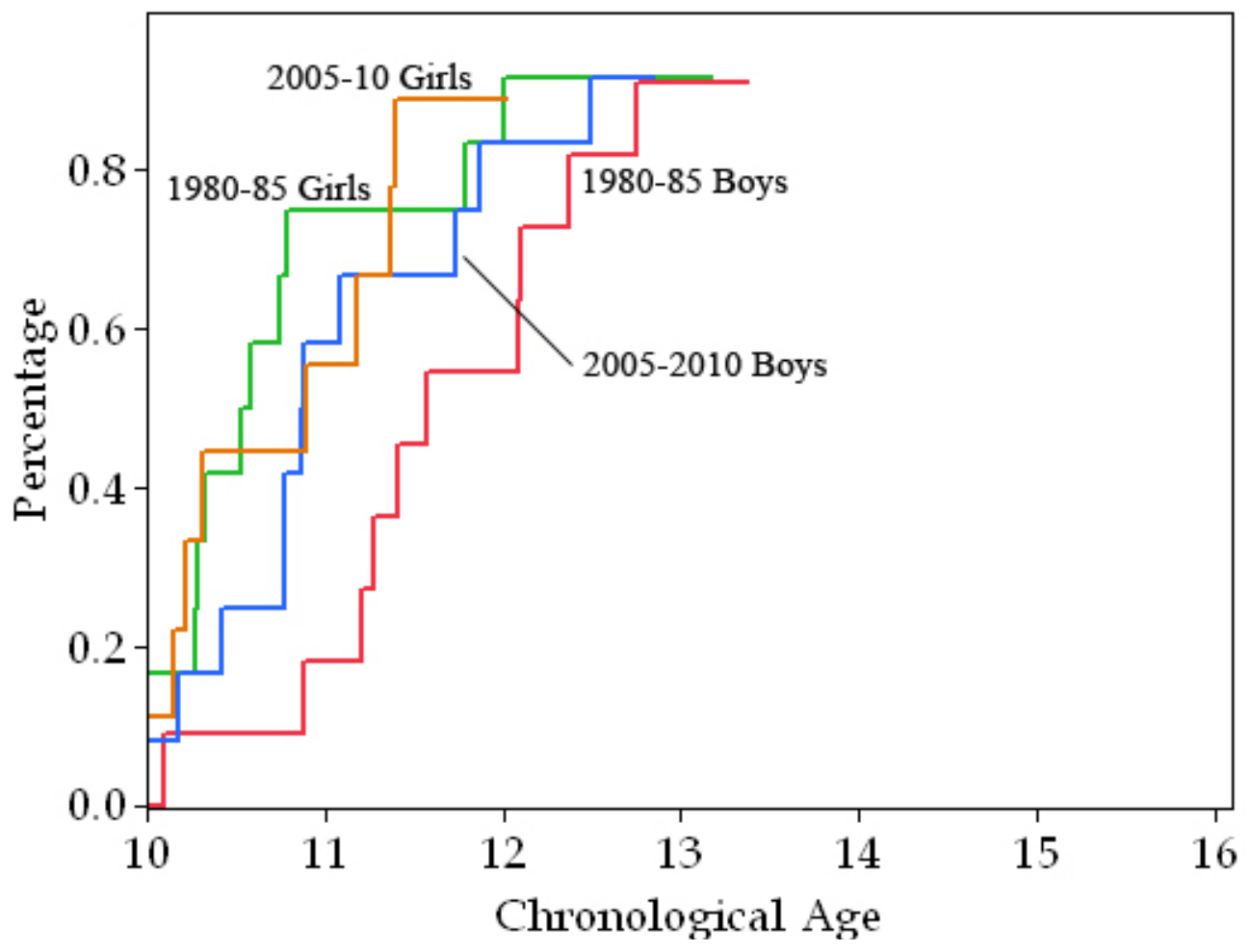

Figure B-17. Results of survival analysis applied to stage $F$ of the mandibular third molar. 


\section{VITA}

Kevan Michael O'Neill, born in 1983, is the son of parents James and Christine $\mathrm{O}^{\prime}$ Neill. He grew up in the small town of Lima, Ohio and followed in his father's footsteps to the University of Notre Dame where he majored in theology and pre-professional studies. In 2009, he graduated from the Columbia College of Dental Medicine in the City of New York and continued his education as a Resident in Orthodontics at the University of Tennessee, where he will receive his Master of Dental Science and Certificate in Orthodontics upon graduation in 2012. He will continue his education at New York University as a fellow in Craniofacial Orthodontics. One day he hopes to open an orthodontic practice with his identical twin brother, Brendan. His interests beyond making beautiful smiles are golfing, traveling, spending relaxing weekends at the lake, art house movies, and unique food (thanks to his lovely sister, Shannon). 